\title{
INTRODUCCIÓN AL CÁLCULO DE REDES DE SANEAMIENTO CON SWMM
}
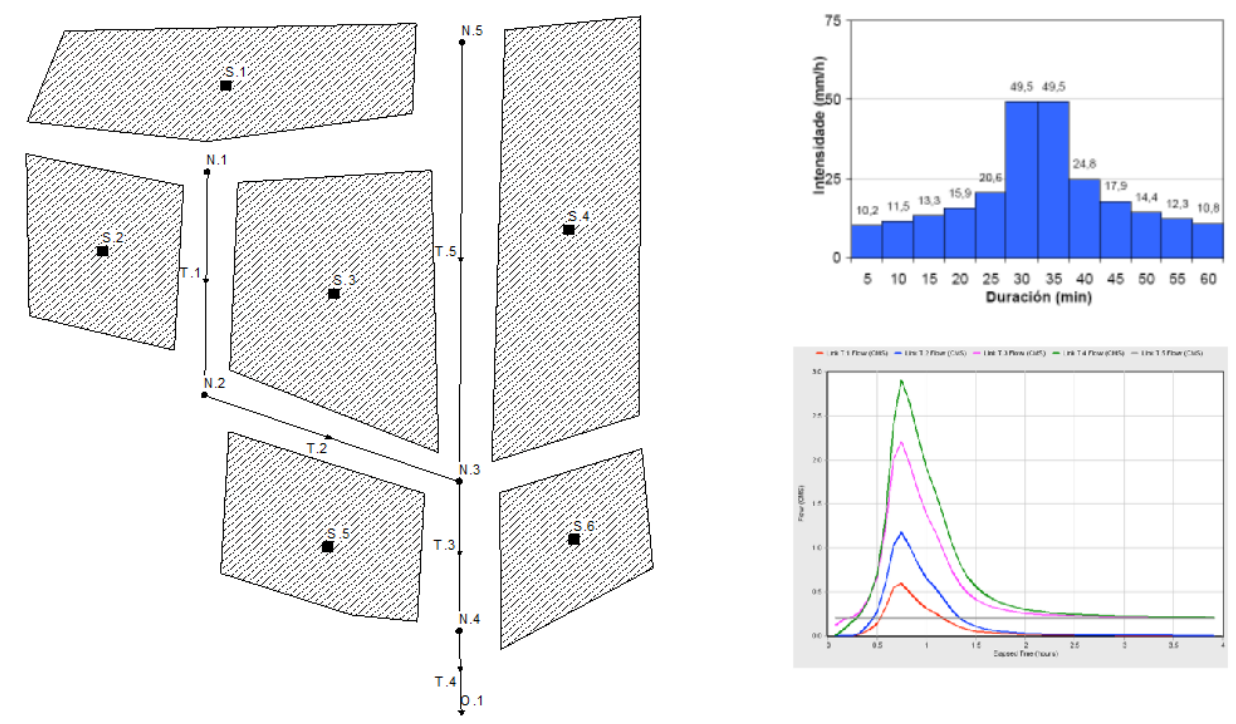

Jose Anta Álvarez

Acacia Naves García-Rendueles Juan Naves García-Rendueles 



\section{Introducción al cálculo de redes de saneamiento con SWMM}

Jose Anta Álvarez

Acacia Naves García-Rendueles

Juan Naves García-Rendueles 


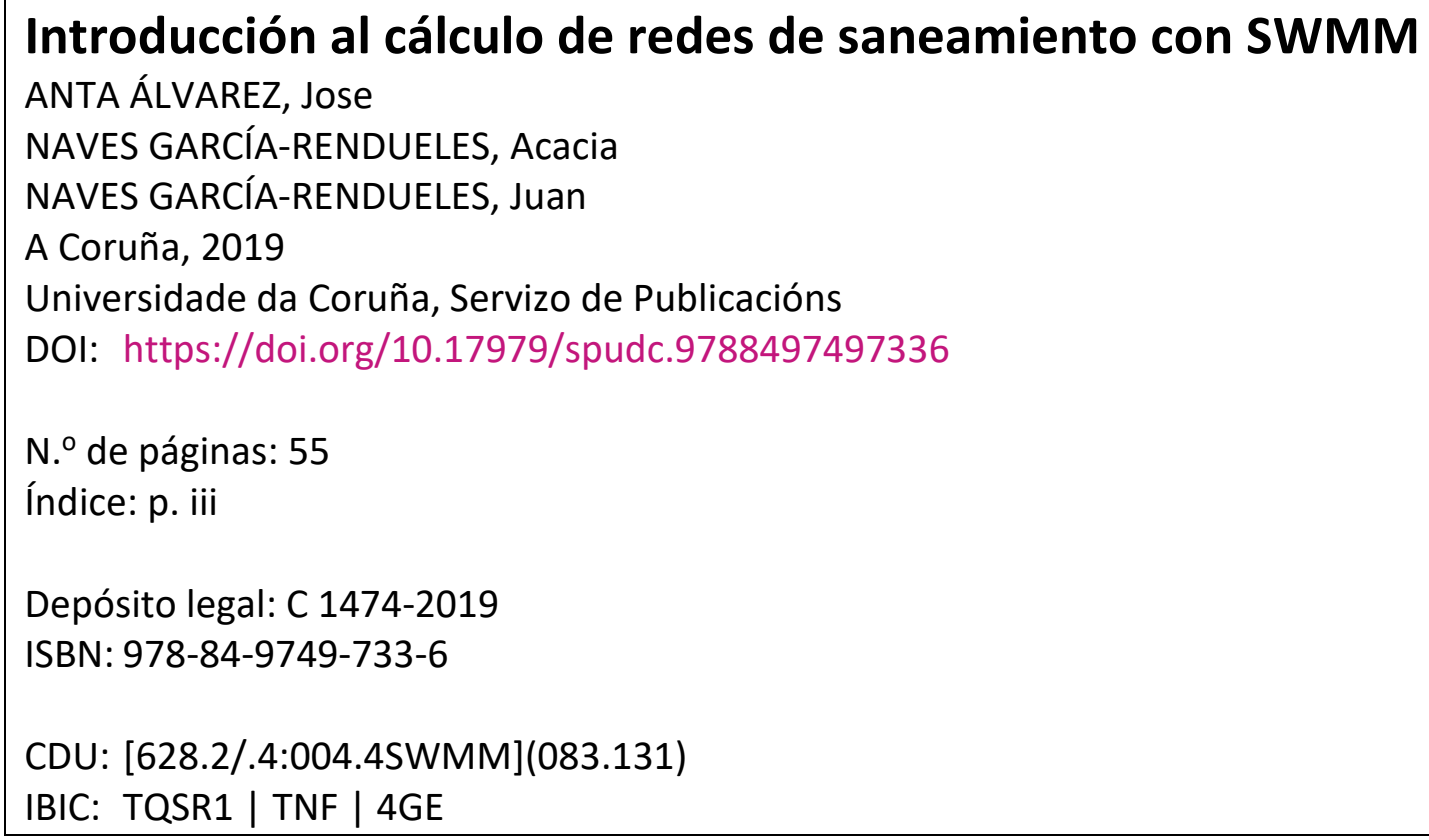

\section{EDICIÓN}

Universidade da Coruña, Servizo de Publicacións <http://www.udc.gal/publicacions>

(C) de la edición, Universidade da Coruña

(C) de los textos, gráficos y figuras, los autores

Esta obra se complementa con los recursos necesarios para el desarrollo de los modelos, y que se describen en el apartado 6 de este manual $(\S 6, p .52)$. Pueden encontrarse en un archivo comprimido con la URL persistente http://hdl.handle.net/2183/23619 (repositorio institucional de la UDC). Para el uso de estos datos, se recomienda copiar la carpeta "Manual SWMM" del archivo comprimido al directorio raíz del disco duro (C:\Manual SWMM).

\section{(c) (1) (9)(2)}

Esta obra se edita bajo una licencia Creative Commons

CC BY-NC-SA (Atribución-NoComercial-Compartirlgual) 4.0 Internacional 



\section{ÍNDICE}

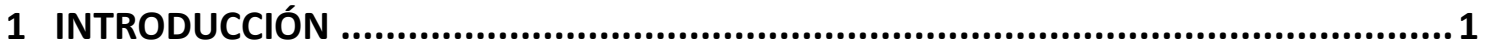

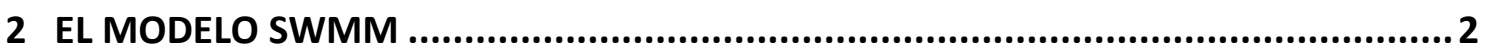

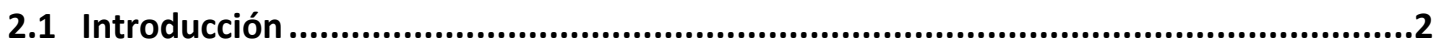

2.2 Modelo conceptual de la red de saneamiento y drenaje en SWMM ........................4

2.3 Principales elementos de la red de saneamiento y drenaje en SWMM .....................6

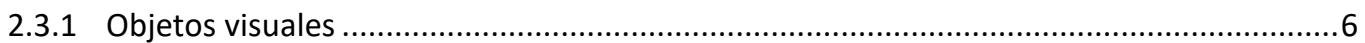

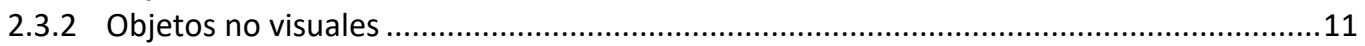

3 CÁlCULO DEL SISTEMA DE DRENAJE DE LA PLATAFORMA CIENTÍFICA DE ENSAYOS DE HIDROLOGÍA URBANA ........................................................................... 12

3.1 Descripción de la Plataforma Científica de Ensayos de Escorrentía Urbana ...............12

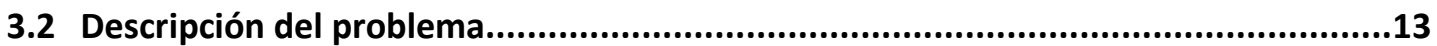

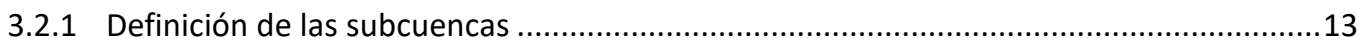

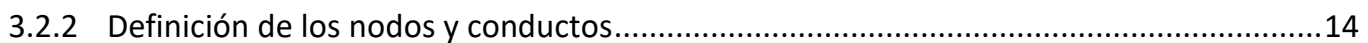

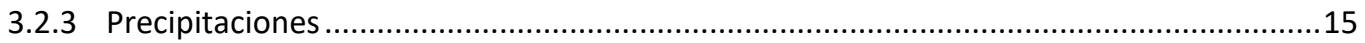

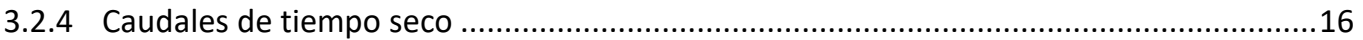

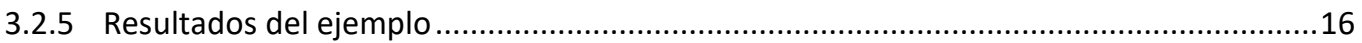

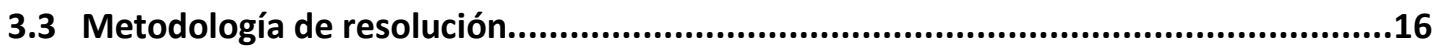

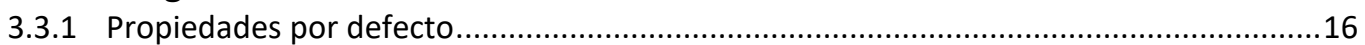

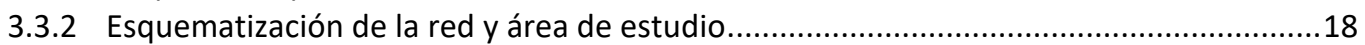

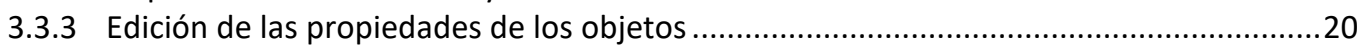

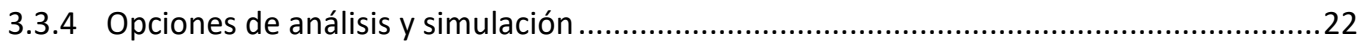

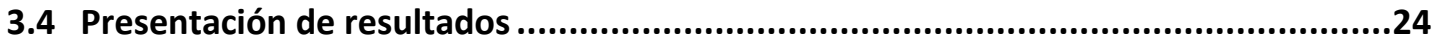

4 CÁlCULO DE UNA RED SIMPLIFICADA DE SANEAMIENTO UNITARIO .................. 27

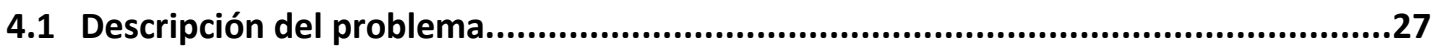

4.2 Metodología de resolución del ejercicio ...............................................................30

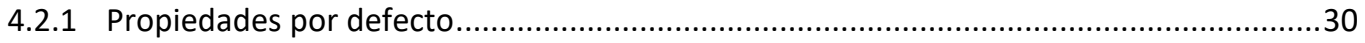

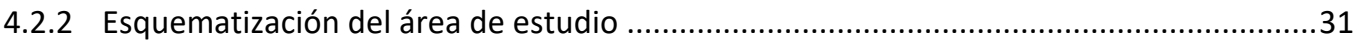

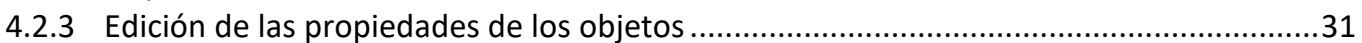

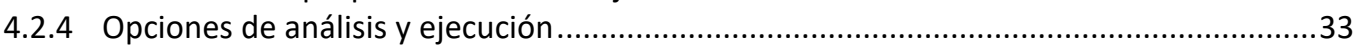

4.3 Visualización de resultados y resolución del ejemplo ............................................34

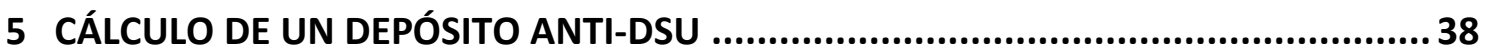

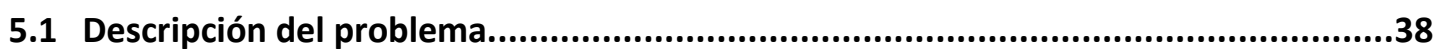

5.2 Cálculo del depósito anti-DSU para la lluvia de diseño ..........................................38

5.3 Cálculo del depósito anti-DSU para el año medio ..................................................45

6 DATOS PARA LA REALIZACIÓN DE LOS MODELOS................................................5 52

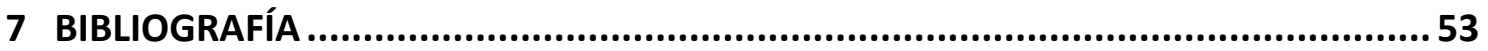





\section{INTRODUCCIÓN}

El software Storm Water Management Model (SWMM) es un programa desarrollado por la Agencia de Protección Ambiental de los Estados Unidos (US-EPA) utilizado a nivel mundial para el diseño y análisis de las redes de saneamiento. El software resuelve el proceso de transformación de lluvia en caudal de escorrentía en la superficie de las cuencas urbanas, y el tránsito del flujo a través de las redes de tuberías y a través de otras estructuras típicas del saneamiento y drenaje urbano como estaciones de bombeo o tanques de tormenta. El software también incluye un módulo para la modelización de técnicas de drenaje urbano sostenible (técnicas SUDS). SWMM es un programa de uso libre y se puede descargar de forma gratuita en la web de la Agencia de Protección Medioambiental de los Estados Unidos (US-EPA): <www.epa.gov/water-research /storm-water-management-model-swmm>.

El objetivo de este manual es utilizar el programa SWMM como una herramienta docente para mejorar el aprendizaje de los procesos hidrológicos propios de los sistemas de saneamiento y drenaje urbano e introducir el diseño de los mismos. Para ello se propone una serie de problemas de modelización en los que se aborda, con un orden creciente de complejidad, el proceso de diseño de una red simplificada de drenaje con la incorporación de los flujos de aguas residuales en tiempo seco y las estructuras para el control de los vertidos en los sistemas unitarios.

La resolución de los ejercicios se complementa con una visita al Laboratorio de Hidráulica del Centro de Innovación Tecnolóxica en Edificación e Enxeñaría Civil de la UDC (CITEEC: www.citeec.es), donde se dispone de un modelo físico de un barrio con un simulador de lluvia y una red completa de drenaje, que se realiza dentro de las actividades docentes de las asignaturas Obras Hidráulicas e Hidrología - del Máster de Ingeniería de Caminos- y Sistemas de Abastecimiento y Saneamiento - del Máster Internacional en Ingeniería del Agua-, ambos impartidos en la Universidade da Coruña. Esta visita pretende facilitar la comprensión de los fenómenos hidrológicos e hidráulicos. El primer problema propuesto en este manual, que se aconseja resolver tras la visita, consiste en la modelización de la instalación del laboratorio para mejorar la conceptuación de los procesos que se simulan con el software SWMM.

A lo largo del texto se va explicando de manera progresiva el funcionamiento del programa SWMM para que el alumnado pueda resolver los problemas propuestos. El objetivo del manual no es proporcionar las bases teóricas del proceso de diseño de las redes de saneamiento, ni tampoco proporcionar una descripción detallada de todas las opciones del programa. Únicamente se explicarán las nociones necesarias para la realización de los ejercicios propuestos. Por lo tanto, este manual es un complemento a las bases teóricas impartidas en las clases.

Para cada uno de los ejercicios propuestos se proporciona una carpeta con el modelo base de SWMM, en el que se incluye un esquema conceptual del problema y los datos de partida en formato de texto. Además, también se incluye el problema resuelto para que el alumnado pueda comprobar los resultados o modificar algunas opciones del modelo y analizar su comportamiento. 


\section{EL MODELO SWMM}

\subsection{Introducción}

El software Storm Water Management Model (SWMM) es un programa desarrollado por la US-EPA para la modelización completa de los sistemas de saneamiento y drenaje urbano. El modelo SWMM permite modelizar tanto la hidráulica coma la contaminación generada y movilizada en los sistemas de saneamiento y drenaje urbano, aunque su punto fuerte radica en la modelización de los procesos hidrológicos e hidráulicos de la red. El bloque de análisis de la contaminación no está tan desarrollado y los resultados obtenidos presentan cierta incertidumbre, por lo que su uso para estos fines no está tan aceptado.

La primera versión del modelo se desarrolló en el año 1969 en los Estados Unidos. Su popularización comenzó en los años 80 con el desarrollo de su versión 4.4. La versión 4 de SWMM se ejecutaba en un entorno MS-DOS en formato de línea de comando. El programa empleaba ficheros de entrada para los distintos elementos del sistema y para describir las precipitaciones.

La versión actual de SWMM, la 5.1.xxx, proporciona un entorno visual que permite introducir los datos para el área de drenaje, simular el comportamiento hidráulico de la red, estimar la calidad de agua, visualizar todos los resultados con gran variedad de gráficos y generar archivos de salida para su visualización y posterior tratamiento con otras herramientas como hojas de cálculo. Además de la visualización de los resultados como hidrogramas, mapas temáticos de la red y tablas, el software dispone de una herramienta estadística muy potente que nos permitirá, por ejemplo, caracterizar el régimen pluviométrico o el número de desbordamientos o vertidos que se producen desde el sistema de saneamiento y drenaje. Además, esta versión de SWMM ha incorporado la modelización de elementos de drenaje sostenible, como técnicas SUDS.

La versión 5.1.xxx está en inglés. También existe una versión del programa en castellano desarrollada por el Departamento de Ingeniería Hidráulica y Medio Ambiente de la Universidad Politécnica de Valencia (UPV). No se recomienda utilizar estar versión porque no ha sido actualizada desde el año 2010.

La aplicación tradicional de SWMM es la de diseño de redes de saneamiento y drenaje mediante la simulación detallada de un único evento de lluvia, la lluvia de diseño. La Iluvia de diseño está asociada a un cierto nivel de riesgo definido por el periodo de retorno del cálculo. Esta visión inicial del diseño de sistemas, basado fundamentalmente en criterios antiinundación, ha sido superada en los últimos años. En la actualidad, el diseño de una estructura de drenaje urbano requiere considerar dos aspectos: el diseño antiinundaciones y el diseño basado en el control de la contaminación. SWMM se utiliza también actualmente para evaluar el comportamiento global de los sistemas con otros objetivos vinculados a la reducción de los impactos producidos por los desbordamientos de los sistemas de saneamiento (DSS). Para la evaluación de los impactos producidos sobre las masas acuáticas durante los episodios de lluvia, se emplearán series históricas de precipitaciones que reproduzcan el comportamiento medio del sistema. 
No es objeto de este manual describir las bases teóricas para el diseño de sistemas de drenaje, ya que estas se incluyen en los contenidos teóricos de las asignaturas de los Máster de Ingeniería de Caminos e Ingeniería del Agua de la UDC. Estas bases teóricas pueden consultarse en numerosos manuales y reglamentos técnicos, como las Instrucciones para Obras Hidráulicas en Galicia, ITOHG (Augas de Galicia, 2010), que se emplearán como referencia en algunos apartados de este texto.

En definitiva, con SWMM podremos realizar las siguientes tareas:

- Diseñar y dimensionar los componentes de un sistema de drenaje para el control de inundaciones.

- Diseñar distintos elementos de retención o infiltración para el control de inundaciones, control hidrológico o el control de la contaminación.

- Diseñar estrategias para la minimización de los vertidos desde las redes de saneamiento unitarias, conocidos como desbordamientos de sistemas unitarios (DSU) en la legislación española o combined sewer overflows (CSO) en la literatura internacional.

- Evaluar el impacto de las infiltraciones en los sistemas de drenaje unitarios o separativos.

- Diseñar y evaluar la eficacia de medidas para el control de la escorrentía, como la aplicación de técnicas SUDS.

Cuando se realiza una búsqueda bibliográfica del modelo SWMM en la red se encuentran numerosas referencias, manuales, trabajos científicos, cursos y foros especializados sobre la aplicación de SWMM. Quizás el mejor punto de partida sea la propia página web de la US-EPA del modelo, en la que se pueden encontrar los siguientes bloques de información:

1. La última versión del software.

2. Códigos fuente y errores detectados. Este apartado es útil si queremos desarrollar alguna funcionalidad nueva para el programa.

3. Manuales y Guías. Se compone de los siguientes textos:

- Manual de usuario. Disponible a través de la ayuda del programa.

- Manual de aplicaciones. Este manual cuenta con una serie de aplicaciones con ejemplos resueltos.

- Manuales de referencia. Incluye los manuales de referencia hidrológico, hidráulico y de calidad de agua. En esta sección se describen los algoritmos empleados y cómo se han implementado.

- Una guía para la simulación de infraestructuras verdes y la aplicación de Sistemas de Información Geográfica con el programa.

4. Otros documentos. Se compone de un enlace a una comunidad de usuarios que está desarrollando mejoras del modelo en paralelo a las versiones oficiales de la US-EPA.

A continuación, realizamos una pequeña descripción del modelo conceptual utilizado por SWMM para definir los sistemas de saneamiento y drenaje, revisamos los principales elementos de los modelos y ofrecemos una breve reseña de los métodos de cálculo de los principales procesos. Estos apartados están enfocados a cubrir las 
necesidades docentes de las materias impartidas en la ETS de Ingenieros de Caminos, Canales y Puertos de A Coruña, por lo que algunos elementos como la modelización de la contaminación, la infiltración o la modelización de técnicas SUDS no se tratarán en el texto.

\subsection{Modelo conceptual de la red de saneamiento y drenaje en SWMM}

El programa SWMM considera el sistema de drenaje como un conjunto de elementos interrelacionados denominados objetos que se sitúan en una serie de capas. Los objetos pueden ser elementos visuales (que representan un elemento concreto, como por ejemplo un pozo de registro) o elementos no visuales (que representan propiedades generales de todo el sistema y que no se visualizan en el entorno de trabajo). Cada capa representa un proceso hidrológico, hidráulico o de contaminación. La estructura de capas es accesible desde el panel de navegación Proyecto de la interfaz de SWMM (Figura 1).

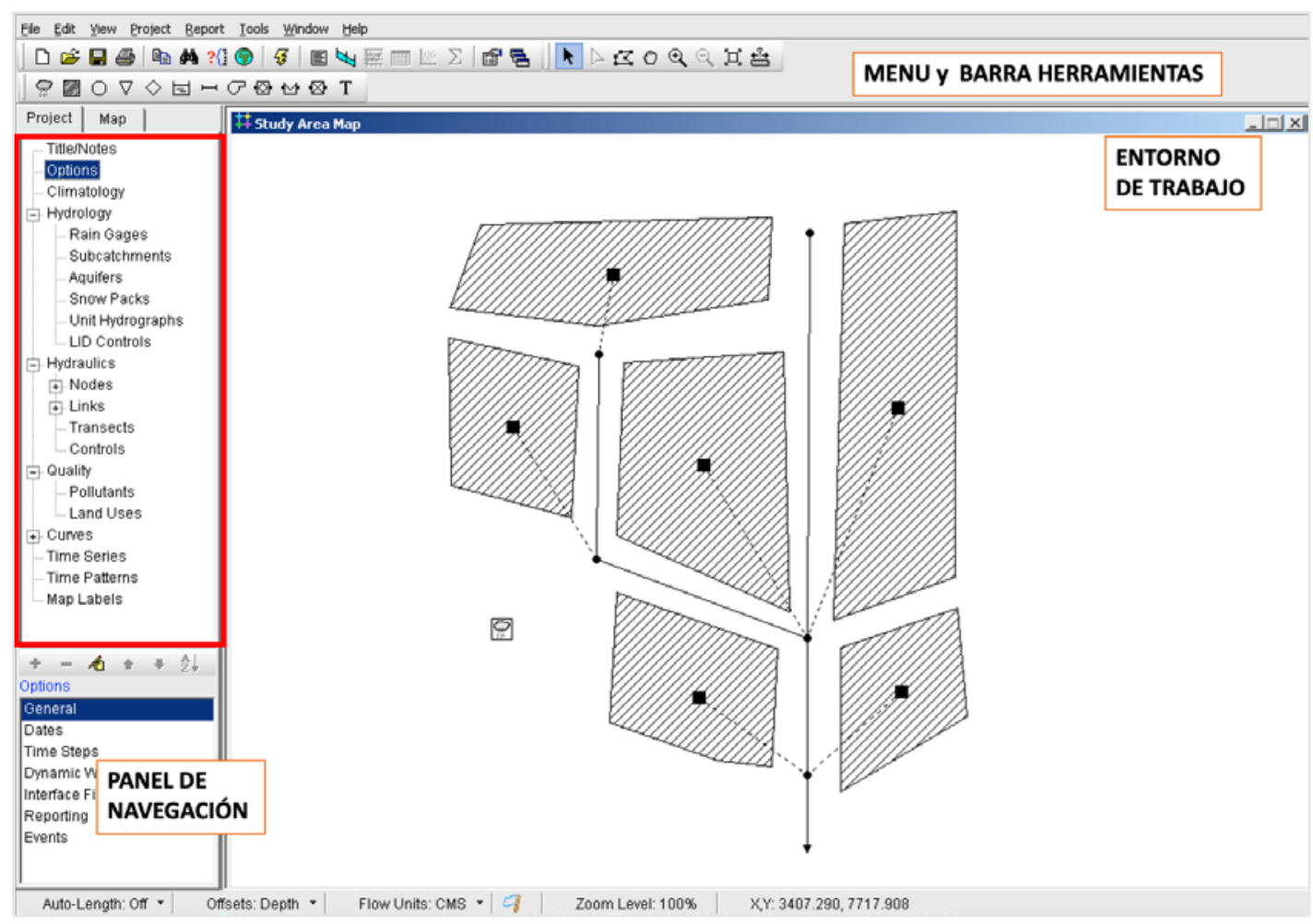

Figura 1. Esquema de capas y objetos del programa SWMM v5.

Las capas principales son las siguientes:

- La capa climatology incluye los datos relativos a los procesos de modelización de la transformación nival en escorrentía (velocidad del viento, derretimiento de nieve, temperatura del aire, etc.) y las pérdidas de precipitación por evapotranspiración. Para simulaciones de lluvias de diseño (diseño antiinundaciones) no es necesario incorporar ningún parámetro en esta capa. Sin embargo, cuando se realicen simulaciones continuas es conveniente introducir el valor de la evaporación (ya sea un valor constante diario o con un patrón de variación mensual). Al introducir la evaporación se permite el secado de las superficies impermeables tras las 
precipitaciones, y de este modo se contabiliza la detracción superficial en la determinación de la lluvia neta.

- En la capa hydrology se introducirán dos elementos fundamentales en cualquier modelización de un sistema de drenaje urbano: los pluviómetros (raingages) y las subcuencas (subcatchments).

Los pluviómetros representan la entrada de precipitaciones en el modelo: la lluvia total. La lluvia neta es la parte de la lluvia total que se transformará en escorrentía superficial en los elementos subcuenca. La Iluvia neta que considera SWMM es la Iluvia total menos la evaporación, la detracción superficial y la infiltración. La detracción superficial incluye las pérdidas por interceptación en la vegetación y en otras superficies como las fachadas de los edificios y el almacenamiento superficial en las depresiones del terreno (por ejemplo, en los charcos de las calles). La infiltración se considerará solo en las zonas permeables de las cuencas. La correcta definición de las subcuencas es quizás el aspecto más importante en un modelo de SWMM, ya que determina la generación de los caudales en tiempo de lluvia.

En la capa hydrology se pueden definir otros elementos no visuales que no se utilizan en la mayoría de las aplicaciones habituales de SWMM como los acuíferos, los paquetes de nieve, o los hidrogramas unitarios vinculados a los procesos de infiltración-exfiltración de agua desde la red de conducciones o desde el terreno. También se incluyen en esta capa los elementos que representan a los sistemas de drenaje sostenible que son las técnicas SUDS (LID controls).

- En la capa hydraulics se definen los elementos de la red de saneamiento y drenaje (canales, tuberías, bombas y elementos de regulación) que transportan el agua hacia puntos de vertido, por ejemplo, un río o la entrada de una EDAR y, en su caso, unidades de almacenamiento y tratamiento, como tanques de tormenta. Los flujos pueden provenir de la escorrentía superficial, la interacción con el acuífero, los caudales de agua residual en tiempo seco o hidrogramas de entrada definidos por el usuario para nodos concretos, por ejemplo, si se conoce el caudal de descarga de una cuenca situada aguas arriba o el caudal vertido por una industria concreta.

La capa hydraulics incluye cuatro tipos de elementos: elementos puntuales, elementos lineales, secciones definidas por el usuario y reglas de control. Los elementos más comunes en los modelos de los sistemas de drenaje son los elementos puntuales y lineales. Los elementos puntuales más habituales son los pozos de registro (junctions), los puntos de vertido de las redes (outfalls) y las unidades de almacenamiento y regulación de caudales (storage units), que son los empleados para modelizar por ejemplo los depósitos anti-DSU. Los elementos lineales pueden ser tuberías (conduits), bombas (pumps) y órganos de alivio y desagüe definidos con las ecuaciones de orificio, vertedero o a través de una curva de gasto (orifice, weir y outlets, respectivamente). Cuando se desea introducir una sección transversal para un conducto (tubería o canal) que no esté incluida en el catálogo de secciones tipo de SWMM, se puede emplear la opción transect para definirla. Por último, la opción controls permite introducir lógicas de operación en 
las estructuras de los sistemas de saneamiento y drenaje, por ejemplo, activar el arranque de una bomba en un depósito cuando se supera cierto valor de nivel del agua. Estos elementos, transects y controls, no se describirán en este manual, aunque se puede encontrar más información en el Manual de Usuario de SWMM (Rossman et al., 2015).

- En la capa quality se introducen los parámetros vinculados a los procesos de acumulación y arrastre de contaminación en la superficie de las cuencas, a través de la definición de los contaminantes tipo (pollutants) y los diferentes usos del suelo (land uses).

El programa incluye otra serie de capas complementarias en las que se puede introducir un título para la simulación o las opciones de simulación, que se describen en los ejercicios prácticos. Otros elementos complementarios necesarios en muchas simulaciones con SWMM son: las curvas (curves) o relaciones entre dos variables, como el calado y el área de una estructura de regulación; las series temporales (time series), empleadas por ejemplo para definir las precipitaciones; los patrones temporales (time patterns) y las etiquetas de los mapas (map labels).

No es necesario que aparezcan todos los elementos descritos anteriormente en un modelo de SWMM determinado. Por ejemplo, se puede analizar el funcionamiento de una red separativa de aguas fecales en tiempo seco sin introducir datos de lluvia.

\subsection{Principales elementos de la red de saneamiento y drenaje en SWMM}

SWMM 5 representa los elementos del sistema de drenaje y los procesos hidrológicoshidráulicos y de contaminación que ocurren en dicho sistema mediante objetos. El programa considera dos tipos de objetos: (i) visuales y (ii) no visuales. Los objetos visuales representan procesos físicos del sistema, por ejemplo: la precipitación, la escorrentía o el flujo en conductos. Los objetos no visuales describen algunos elementos o procesos adicionales que no se encuentran en el área de trabajo. A continuación, se presentan los objetos visuales y no visuales más habituales que se emplean para resolver los problemas propuestos en este manual. El Manual de Usuario de SWMM (Rossman, 2015) o la propia ayuda en línea del programa contienen una descripción más detallada de estos objetos.

\subsubsection{Objetos visuales}

La Figura 2 muestra un modelo de una red de saneamiento convencional que contiene sus elementos más comunes. El pluviómetro (raingage) y las subcuencas (subcatchments) son los objetos principales utilizados para la simulación de la transformación lluvia-escorrentía. El tránsito de los caudales de escorrentía por la red de drenaje se realiza a través de la red de pozos (junction) y tuberías (links). En el esquema, aparece también un depósito de almacenamiento (storage unit) y dos puntos de vertido (outfall). A la salida del depósito existen dos elementos de regulación. Uno de ellos (outlet) permite limitar el caudal de salida hacia la EDAR. El otro es un aliviadero (weir) desde el que se producen DSU. 


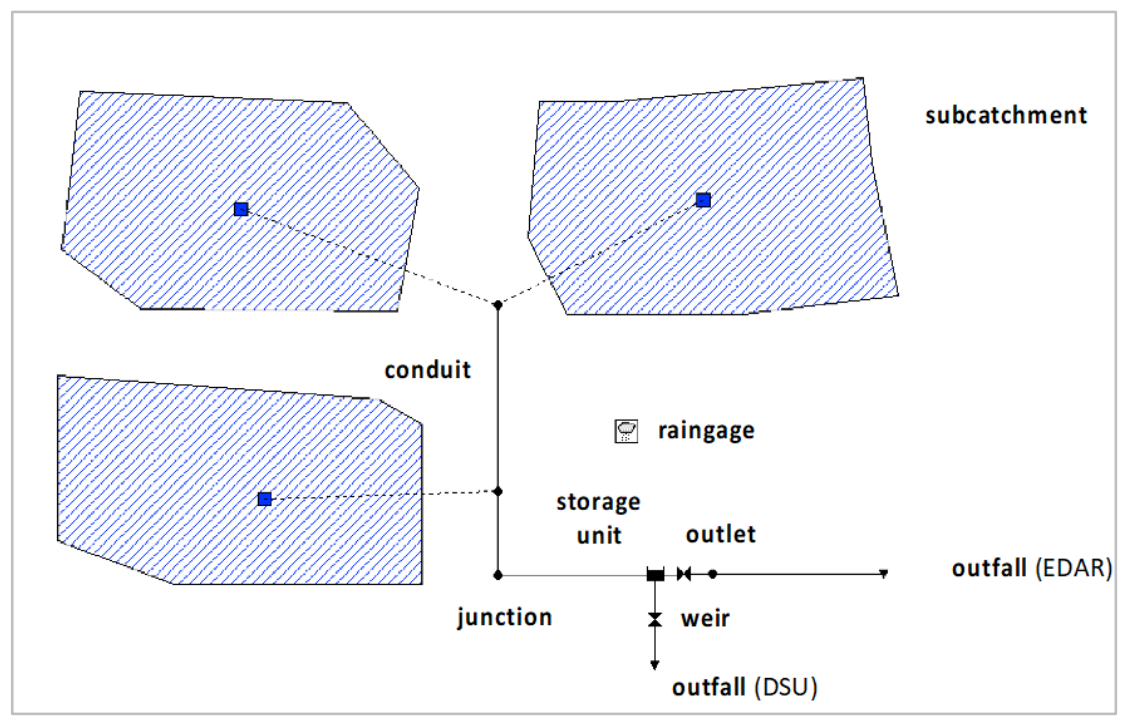

Figura 2. Disposición de objetos visuales que conforman una red de saneamiento convencional.

Los pluviómetros (raingages) contienen los datos de entrada de las precipitaciones que ocurren sobre una o varias de las subcuencas definidas en el área de estudio. Los datos de lluvia pueden ser definidos por el usuario mediante una serie temporal de datos, hietograma de diseño, o provenir de un archivo externo al programa. Para la definición de los hietogramas de diseño de la red se puede emplear la ITOGH SAN 1/1-Cálculo de caudales en saneamiento (Augas de Galicia, 2010). Para series largas de precipitación se recomienda emplear un archivo externo (véase el capítulo 5).

Las subcuencas (subcatchments) son unidades hidrológicas de terreno cuya topografía y elementos del sistema de drenaje conducen la escorrentía directamente hacia un punto de descarga. Son ejemplo de una subcuenca la superficie de una calle o un tejado. La discretización del dominio en subcuencas es uno de los elementos más importantes de la modelización con SWMM. El usuario es el encargado de definir las áreas de modo que tengan unas características hidrológicas homogéneas (por ejemplo, la rugosidad superficial o la forma) e identificar el punto de salida (outlet) de cada una de ellas. Los puntos de salida de cada subcuenca suelen ser nodos del sistema (Nodes), que representan los pozos de registro de la red.

Cada cuenca se puede dividir en dos zonas de características hidrológicas diferentes: el área impermeable y el área permeable. La escorrentía superficial sólo puede infiltrarse en las zonas permeables. El programa incorpora varios modelos de infiltración para las zonas permeables. Desde un punto de vista práctico, se suele emplear la ecuación de Horton para evaluar la infiltración hacia el terreno cuando el grado de impermeabilidad de la cuenca es elevado (por ejemplo, superior al 40\%). Cuando las cuencas son muy permeables, se recomienda emplear el método del Número de Curva (SCS CN).

Por otra parte, las áreas impermeables pueden dividirse a su vez en dos subáreas: una que contempla el almacenamiento como detracción inicial -por ejemplo, como charcos- y otra que no lo contempla. Se recomienda fijar como cero el porcentaje de área sin detracción inicial. 
Por último, el flujo de escorrentía desde un área de la cuenca puede fluir hacia otra área - por ejemplo, la escorrentía de una zona verde puede fluir hacia una carretera- o, por el contrario, se pueden conectar las zonas permeables e impermeable directamente al nodo de salida. Esta segunda opción es la más habitual. Los detalles de cómo SWMM incorpora la modelización de la transformación lluvia-escorrentía se pueden consultar en el Manual de Referencia Hidrológico (Rossman y Huber, 2016).

El modelo de la Figura 2 incluye los objetos de la red de drenaje. Existen varios tipos de objetos de tipo puntual o nodos. Los más habituales son elementos de unión (junctions), los puntos de vertido de la red (outfalls) y los tanques o unidades de almacenamiento (storage units).

Los elementos tipo junction tienen la función de unir elementos de tipo lineal (links). Lo más habitual es que los elementos de tipo junction representen pozos de registro, pero también se pueden emplear para modelizar un imbornal, la unión de cunetas, etc. Para definir un nodo debemos indicar al menos la cota del fondo y de la superficie del elemento. En algunos casos nos puede interesar acerrojar un elemento tipo nodo. Este proceso consiste en utilizar una tapa de registro especial que se fija a la altura de la superficie y no permite que el agua salga por el pozo durante un episodio de lluvia. Esta opción se consigue indicando un nivel máximo de agua (surchage depth) que debe ser superior a la cota geométrica de la calle (max depth). Cuando el nivel del agua no alcanza la cota máxima de las tuberías, el flujo es en lámina libre. Cuando el nivel supera este umbral, el flujo en las conducciones de entrada y salida del nodo se convierte en flujo a presión.

En los elementos junction también se pueden introducir series temporales o patrones de variación (diario, semanal o mensual) para los caudales de tiempo seco que se generan en la superficie de la cuenca y se incorporan a la red en el nodo. Los caudales en cada nodo o grupo de nodos deben determinarse a partir de la densidad de población, superficie y dotación de caudales de saneamiento. El procedimiento de cálculo de los caudales de tiempo seco se encuentra en la ITOGH SAN 1/1-Cálculo de caudales en saneamiento (Augas de Galicia, 2010).

Los storage units son nodos que representan elementos con capacidad de almacenamiento. Físicamente pueden representar desde sistemas de almacenamiento pequeños, como cámaras de la red, hasta depósitos anti-DSU de grandes dimensiones. Las propiedades volumétricas de un sistema de almacenamiento se representan como una tabla en la que se relacionan una serie de alturas en el elemento con la superficie en planta del elemento a dichas alturas. Este tipo de tabla es un elemento tipo curve: curva de almacenamiento o storage curve. Otra opción disponible es emplear una ecuación de llenado que relaciona el área con el calado aunque, para reducir los errores a la hora de introducir la geometría del depósito, se recomienda emplear las curvas de almacenamiento. Para definir un depósito es necesario indicar la cota del fondo y la curva de almacenamiento.

Los elementos tipo outfalls representan en SWMM los nodos terminales de la red, como puntos de alivio. A un outfall solo se le puede conectar un único elemento tipo link como una tubería. En estos nodos es necesario definir la cota del fondo del elemento y las 
condiciones de contorno del punto de vertido. Se pueden emplear condiciones de vertido en calado crítico, condiciones de calado normal, un nivel fijo de lámina de agua, una tabla de mareas o una serie temporal que defina la elevación de la lámina de agua con el paso del tiempo. El vertido en calado crítico es el más habitual si no existen condiciones impuestas desde aguas abajo.

Con respecto a los elementos tipo link, tenemos en primer lugar los conduits (conductos), que representan tuberías o canales superficiales como cunetas por las que circula el agua entre dos nodos. Es conveniente, aunque no necesario, dibujar las conducciones desde el nodo situado aguas arriba hacia el nodo situado aguas abajo.

Los conduits se definen a partir de su longitud, la identificación de sus nodos inicial y final, su sección transversal, y una serie de coeficientes para evaluar la pérdida de carga que se produce en los mismos. La pendiente de las conducciones se establece en SWMM a partir de las cotas de entrada y salida de los nodos a los que se conecta la tubería. Es posible definir pozos de resalto, indicando un valor para el parámetro inlet o outlet offset, que representa la distancia entre la cota del pozo y la del arranque de la conducción (ver Figura 3).

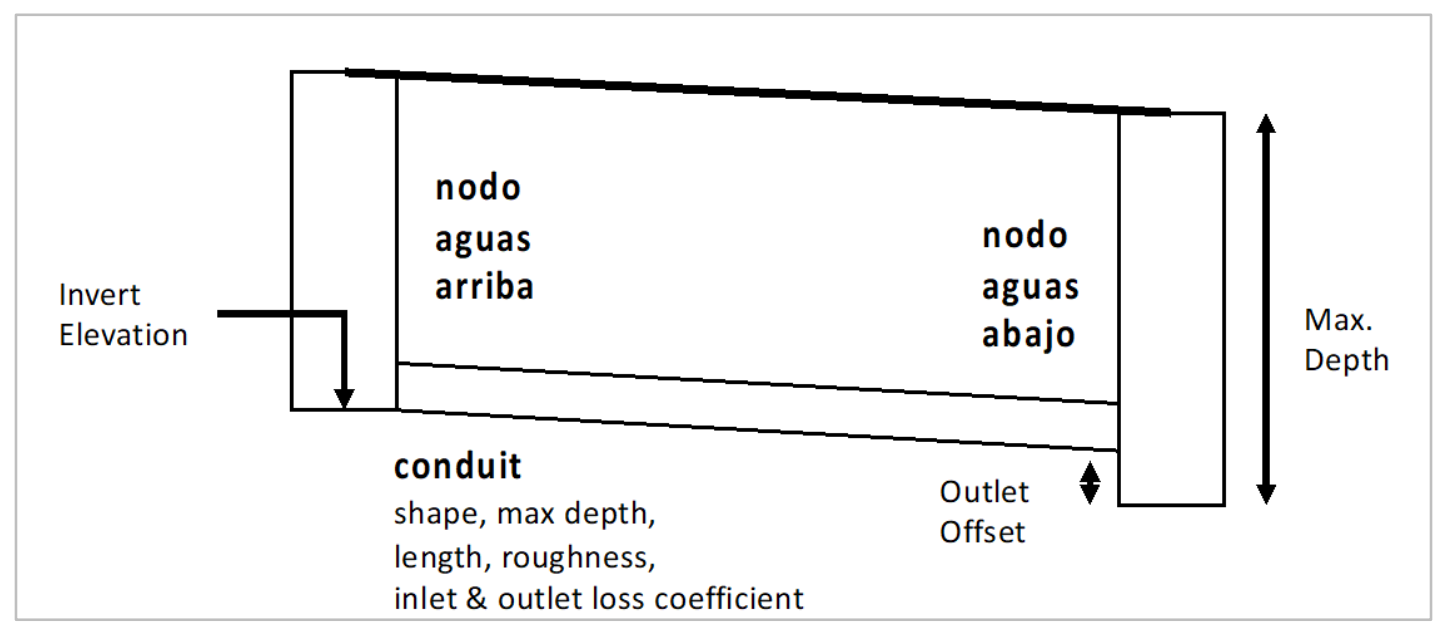

Figura 3. Representación de los elementos conduit in SWMM.

En relación a la sección transversal de los conductos, SWMM permite escoger entre 21 formas predeterminadas por el programa. La forma más habitual será la sección circular, que es la que viene incluida por defecto. Esta forma se caracteriza por el diámetro de la conducción (max depth). Si se desea incluir varias tuberías idénticas en paralelo, se puede usar la opción barrel incluida en la pestaña shape.

SWMM permite incluir pérdidas de carga puntuales o lineales en los conductos. Las pérdidas de carga lineales se calculan con la ecuación de Darcy-Weisbach introduciendo como dato la rugosidad del conducto, definida con el coeficiente de Manning. Las pérdidas de carga puntuales a la entrada y salida de los nodos se definen en las propiedades de la tubería. La pérdida de carga en los pozos depende de muchos factores como la forma del fondo del pozo, si tiene o no resalto, la alineación en planta de las conducciones de entrada y salida del pozo o el grado de anegamiento del mismo. En SWMM se deben fijar valores constantes en la simulación. Se recomiendan los valores de 1 y 0.5 para la entrada y salida de la tubería, respectivamente. Estos valores están 
del lado de la seguridad en la mayoría de las simulaciones y asumen pérdidas de carga por contracción y expansión súbita de las líneas de corriente.

SWMM permite aplicar tres tipos de aproximaciones para la simulación del flujo en tuberías: régimen permanente, onda cinemática y onda dinámica. Con la potencia de cálculo de los equipos actuales solo se puede recomendar la opción de onda dinámica, que resuelve las ecuaciones completas de Saint-Vennant en lámina libre. Cuando las tuberías entran en carga, se emplea la aproximación del slot de Priessman o una formulación específica desarrollada para el módulo EXTRAN de la versión 4 de SWMM para modelizar este tipo de flujos. En el Manual de Referencia Hidráulico (Rossman, 2017) se describen con detalles estos aspectos.

Las bombas (pumps) son elementos tipo link que permiten elevar el agua desde zonas de menor cota a zonas con mayor cota. Las bombas se definen mediante una curva que se puede escoger entre varios tipos: la curva característica de la bomba de tipo caudalaltura de bombeo o una curva que relacione el caudal bombeado con el volumen almacenado o la cota disponible en el nodo inicial de la bomba. La puesta en marcha y parada de las bombas puede ser controlada dinámicamente empleando reglas de control.

La regulación de caudales en los elementos tipo nodo como cámaras de carga o depósitos se puede modelizar en SWMM con los elementos flow regulator. Estos elementos son de tipo link entre dos nodos. Existen tres tipos de elementos de regulación que se describen con más detalle en el Manual de Referencia Hidráulico (Rossman, 2017) y en la propia ayuda del programa.

- Orificios (orificies), que son elementos de desagüe situados en los paramentos de los muros de depósitos o cámaras de regulación, y que pueden funcionar hidráulicamente como un orificio libre, anegado (si están completamente sumergidos) o como orificios parcialmente sumergidos. Los orificios quedan definidos por la cota del eje del mismo, el área y los coeficientes de desagüe. En estos elementos pueden incorporarse reglas de control para modificar el área del orificio, lo que permite simular el comportamiento de compuertas automáticas.

- Aliviaderos (weirs), que son elementos de alivio situados, por ejemplo, en el punto de DSU de un depósito de tormenta. Existen 4 tipos de aliviaderos en SWMM: frontal, lateral, en $\mathrm{V}$ y trapezoidal. A nivel práctico, un aliviadero sin deflectores o tamices para el control de flotantes o sólidos gruesos en un tanque de tormenta se debe modelizar como un aliviadero de tipo frontal (transverse) con un coeficiente de vertido similar al de los vertederos de pared delgada que, sin considerar correcciones por sumergencia o anegamiento, es igual 1.7. Para definir un aliviadero es necesario, además del coeficiente de desagüe, la cota a la que sitúa el labio de vertido, el ancho y la cota máxima del aliviadero. Así, cuando un aliviadero está confinado y el agua alcanza la clave de la galería, SWMM modifica la ecuación de vertedero por la de un orificio automáticamente. 
- El elemento tipo outlet permite modelizar órganos de desagüe o alivio que no se representen mediante las ecuaciones de desagüe o vertedero. Se pueden definir empleando una curva de gasto tipo nivel-caudal. Ejemplos habituales de este tipo de flow regulators son las válvulas vórtex que regulan el caudal de salida de un tanque o los aliviaderos con tamices para el control de flotantes, que tienen su propia curva de gasto, la cual debe ser proporcionada por el fabricante.

Existe otro tipo de objeto visual que son las etiquetas de texto que podemos añadir opcionalmente en el entorno de trabajo de SWMM. Se denominan map labels y se emplean para poder identificar objetos singulares o regiones del mapa.

\subsubsection{Objetos no visuales}

Los objetos no visuales son una serie de elementos que permiten parametrizar una serie de procesos globales de la simulación. Los elementos que se utilizan de manera habitual son: el objeto climatology, empleado para definir la evaporación; el objeto transects, que permite definir secciones transversales irregulares o no incluidas en el catálogo de conductos; o las control rules, que consisten en reglas que gobiernan la operación de los reguladores de flujo o bombas durante el transcurso de la simulación. En el apéndice C.3 del manual de usuario (Rossman, 2015) se describe con detalle el formato que deben tener estas reglas.

Otros objetos no visuales empleados en la mayoría de las simulaciones son las curvas (curves). Estos objetos definen relaciones entre dos variables de forma tabular. Existen seis tipos de curvas, aunque las más comunes son las siguientes:

- Storage curve, que describe la curva de llenado de una unidad de almacenamiento (storage unit) a partir de la relación entre altura de la lámina de agua o calado y superficie del elemento.

- Pump curve, que relaciona las variables caudal, altura y volumen en función del tipo de bomba empleada en la simulación.

- Rating curve, que describe la curva de gasto calado-caudal para un elemento outlet.

Por último, los elementos time series permiten introducir o importar una serie de datos, por ejemplo de precipitaciones o de caudales. Los elementos time patterns, por su parte, permiten introducir los patrones de variación para los caudales de tiempo seco que se entran en un pozo de registro. 


\section{CÁlCULO DEL SISTEMA DE DRENAJE DE LA PLATAFORMA CIENTÍFICA DE ENSAYOS DE HIDROLOGÍA URBANA}

\subsection{Descripción de la Plataforma Científica de Ensayos de Escorrentía Urbana}

El primer ejemplo de este manual consiste en realizar la simulación del sistema de drenaje de la Plataforma Científica de Ensayos de Escorrentía Urbana ubicada en el laboratorio de hidráulica del CITEEC. Este modelo físico consiste en un cruce de calles en un área urbana sobre el que se pueden generar lluvias de diferentes intensidades (30 $\mathrm{mm} / \mathrm{h}, 50 \mathrm{~mm} / \mathrm{h}$ y $80 \mathrm{~mm} / \mathrm{h}$ ). La escorrentía generada en tejados, aceras y vías se drena a una red de colectores situada en la parte inferior del modelo. En la Figura 4 se presentan una serie de fotografías de la plataforma, mientras que en la Figura 5 se presenta una planta acotada de la superficie del viario, indicando las pendientes de las calles y la distribución de los pozos de registro y conducciones.
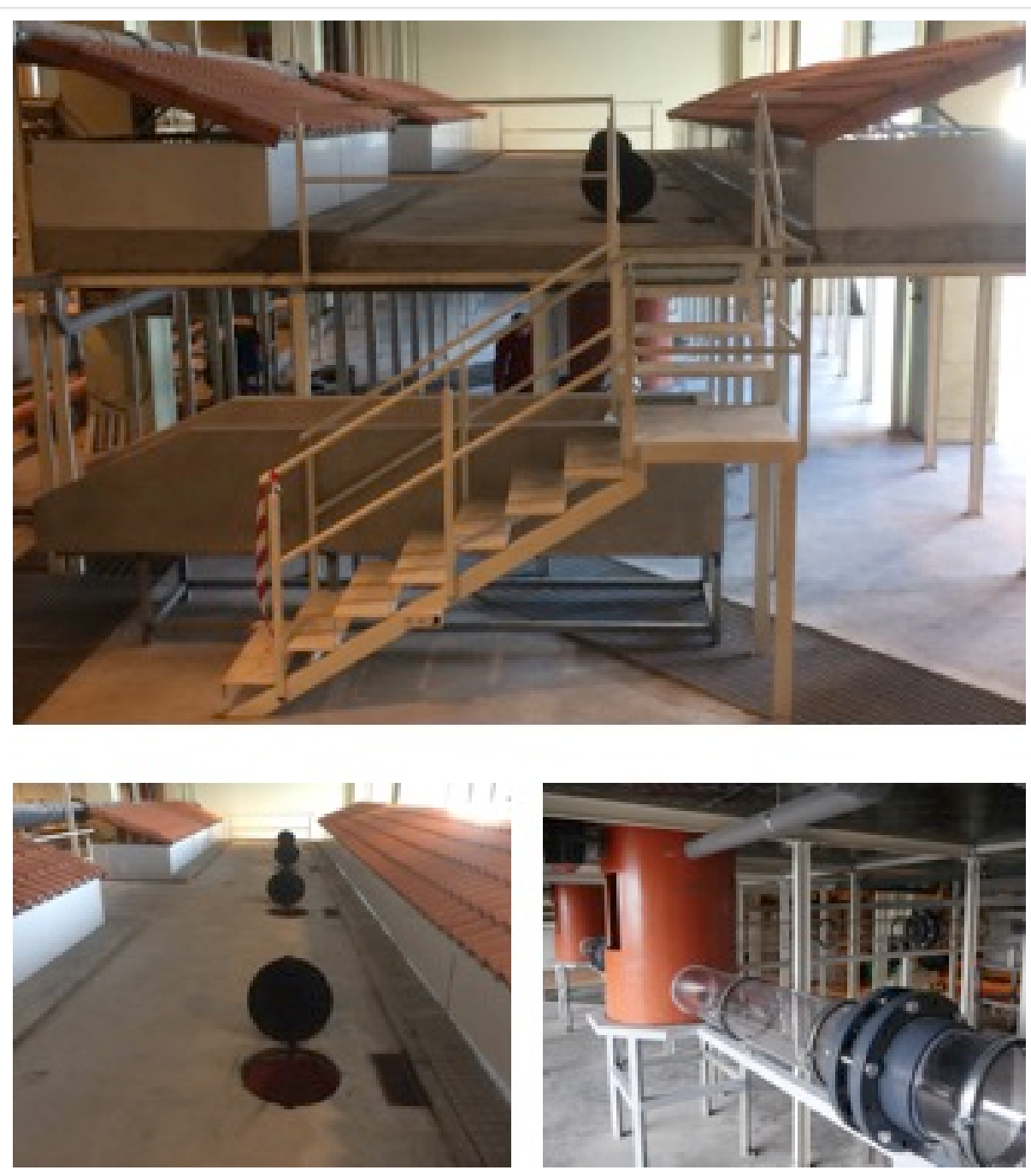

Figura 4. Vista general de la PCEHU (arriba) y superficie y red drenaje del modelo físico (abajo). 


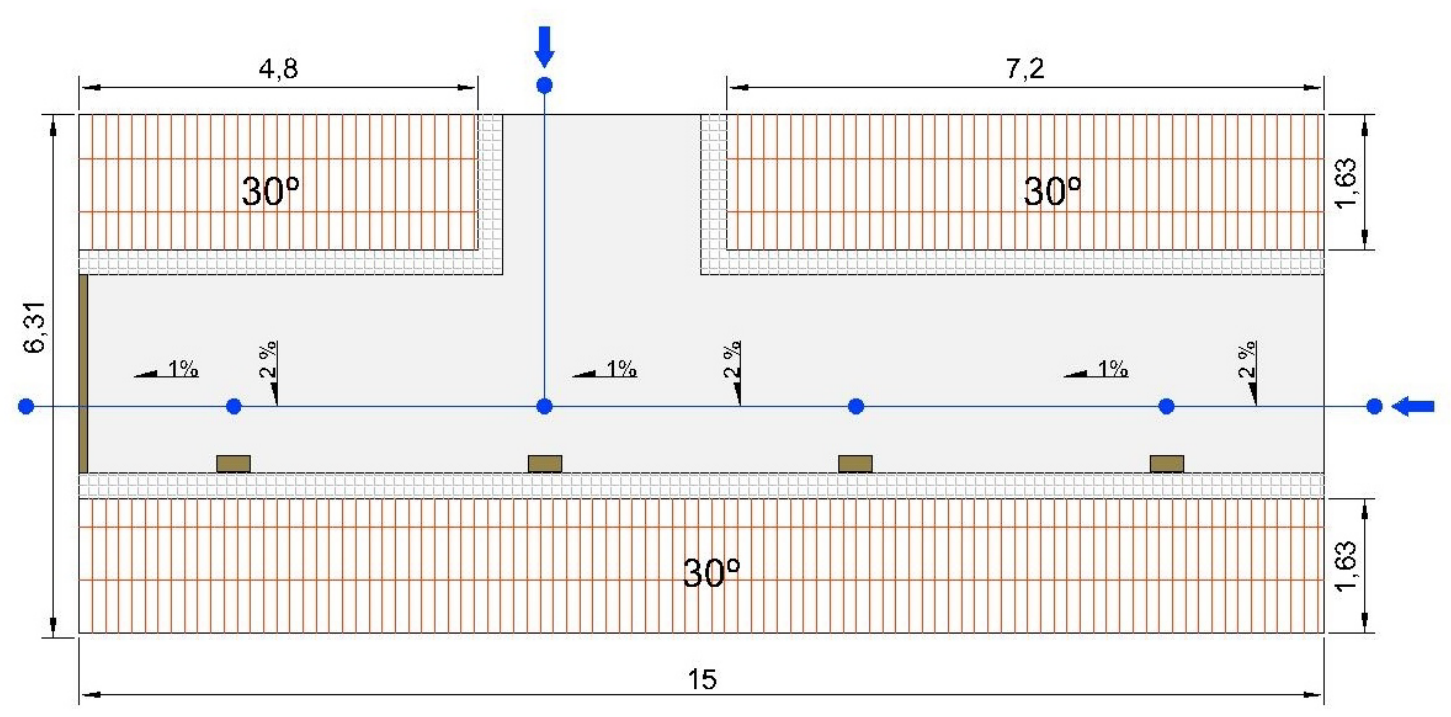

Figura 5. Esquema en planta de la superficie de la PCEHU.

\subsection{Descripción del problema}

Para la construcción de un modelo con el programa SWMM necesitaremos información sobre la superficie de la cuenca, definir la discretización en una serie de subcuencas e información sobre las propiedades de los distintos nodos (pozos de registro, imbornales, elementos de regulación, etc.). Además de las subcuencas y la topología de la red, es necesario incluir en el modelo los datos de las precipitaciones de diseño y caudales de tiempo seco.

\subsubsection{Definición de las subcuencas}

En el modelo tenemos 4 sumideros que drenan la escorrentía superficial de la calle a los pozos de la red de drenaje. Para determinar los límites de cada una de las subcuentas tenemos que tener en cuenta las pendientes de la superficie de la calle ( $2 \%$ transversal y $1 \%$ longitudinal). Además, existen cuatro canalones que recogen el agua interceptada por los tejados y la incorporan a distintos pozos. El modelo conceptual de la red, esquematizado en la Figura 6, cuenta con un total de 9 subcuencas: 5 tipo calle y 4 tipo tejado.

Las características geométricas de las subcuencas y su conectividad con los nodos del modelo se presentan en la Tabla 1. Otros datos necesarios para la definición completa de las subcuencas son la rugosidad de la superficie, que se fijará con un coeficiente de Manning $n=0.016$, y la detracción superficial, que se establece en $1 \mathrm{~mm}$ para todas las superficies impermeables. Al ser una cuenca completamente impermeable no es necesario definir los parámetros de las áreas no permeables ni la infiltración. 

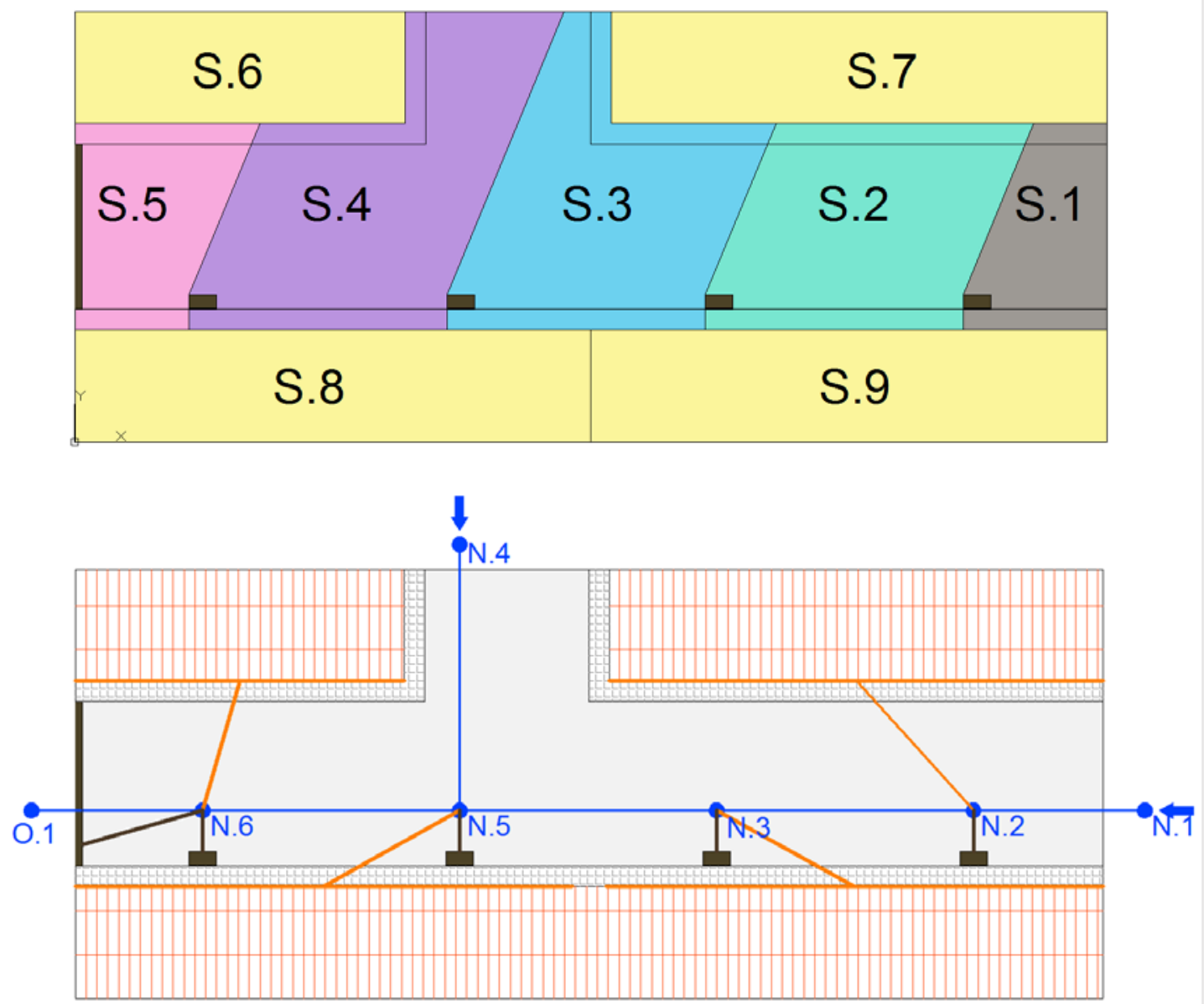

Figura 6. Esquema de cuencas para el modelo de la PCEHU (arriba) y definición de los nodos de la red (abajo).

Tabla 1. Definición de las subcuencas del modelo de drenaje de la PCEHU.

\begin{tabular}{|c|c|c|c|c|c|}
\hline Subcuenca & $\begin{array}{c}\text { Nodo de } \\
\text { salida }\end{array}$ & Área (ha) & Ancho (m) & $\begin{array}{c}\text { Pendiente } \\
\text { (\%) }\end{array}$ & $\begin{array}{c}\text { Impermeab. } \\
\text { (\%) }\end{array}$ \\
\hline S.1 & N.2 & 0.00050 & 1.5 & 2.24 & 100 \\
\hline S.2 & N.3 & 0.00113 & 2.5 & 2.24 & 100 \\
\hline S.3 & N.5 & 0.00129 & 2.4 & 2.24 & 100 \\
\hline S.4 & N.6 & 0.00145 & 2.2 & 2.24 & 100 \\
\hline S.5 & N.6 & 0.00063 & 2.6 & 2.24 & 100 \\
\hline S.6 & N.6 & 0.00078 & 4.8 & 0.01 & 100 \\
\hline S.7 & N.2 & 0.00117 & 7.2 & 0.01 & 100 \\
\hline S.8 & N.5 & 0.00122 & 7.5 & 0.01 & 100 \\
\hline S.9 & N.3 & 0.00122 & 7.5 & 0.01 & 100 \\
\hline
\end{tabular}

\subsubsection{Definición de los nodos y conductos}

El modelo incluye 6 nodos o pozos, de los cuales 4 reciben agua del drenaje de la superficie, y un punto de vertido aguas abajo, que consideramos como un vertido libre en calado crítico (ver Figura 6). 
La red de tuberías está formada por tuberías de policarbonato de $250 \mathrm{~mm}$ de diámetro y un coeficiente de Manning $n=0.009$. La pendiente de todas las tuberías es de $0.5 \%$. Esta pendiente se define a partir de las cotas del fondo de los nodos del eje drenante principal (nodos 0.1 a N.1). La conducción T.4, perpendicular al eje principal, se conecta al pozo N.5 a una altura de $30 \mathrm{~cm}$ medida sobre el fondo del pozo.

En el modelo también se considerarán pérdidas de carga a la entrada y a la salida de cada uno de los pozos. Las pérdidas de carga se definirán en la entrada y salida de cada una de las conducciones como 0.2 y 0.5 respectivamente.

En la Tabla 2 y en la Tabla 3 se presentan los datos relativos a los pozos de registro y tuberías del modelo.

Tabla 2. Definición de los pozos del modelo de drenaje de la PCEHU.

\begin{tabular}{|c|c|c|}
\hline Pozo & Elevación fondo $(\mathbf{m})$ & $\begin{array}{c}\text { Profundidad } \\
\text { máxima }(\mathbf{m})\end{array}$ \\
\hline N.1 & 1.081 & 1.256 \\
\hline N.2 & 1.069 & 1.244 \\
\hline N.3 & 1.050 & 1.225 \\
\hline N.4 & 1.351 & 0.926 \\
\hline N.5 & 1.031 & 1.206 \\
\hline N.6 & 1.013 & 1.188 \\
\hline O.1 & 1.000 & - \\
\hline
\end{tabular}

Tabla 3. Definición de las tuberías del modelo de drenaje de la PCEHU.

\begin{tabular}{|c|c|c|c|c|}
\hline Conducción & Nodo de entrada & Nodo de salida & Longitud (m) & $\mathbf{D}(\mathbf{m})$ \\
\hline T.1 & N.1 & N.2 & 2.50 & 0.25 \\
\hline T.2 & N.2 & N.3 & 3.75 & 0.25 \\
\hline T.3 & N.3 & N.5 & 3.75 & 0.25 \\
\hline T.4 & N.4 & N.5 & 3.90 & 0.25 \\
\hline T.5 & N.5 & N.6 & 3.75 & 0.25 \\
\hline T.6 & N.6 & O.1 & 2.50 & 0.25 \\
\hline
\end{tabular}

\subsubsection{Precipitaciones}

En este ejemplo se considerará un hietograma de 30 minutos de duración formado por 6 bloques de precipitación con las intensidades que se pueden generar en la Plataforma de Ensayos. Este hietograma se presenta en la Figura 7. 


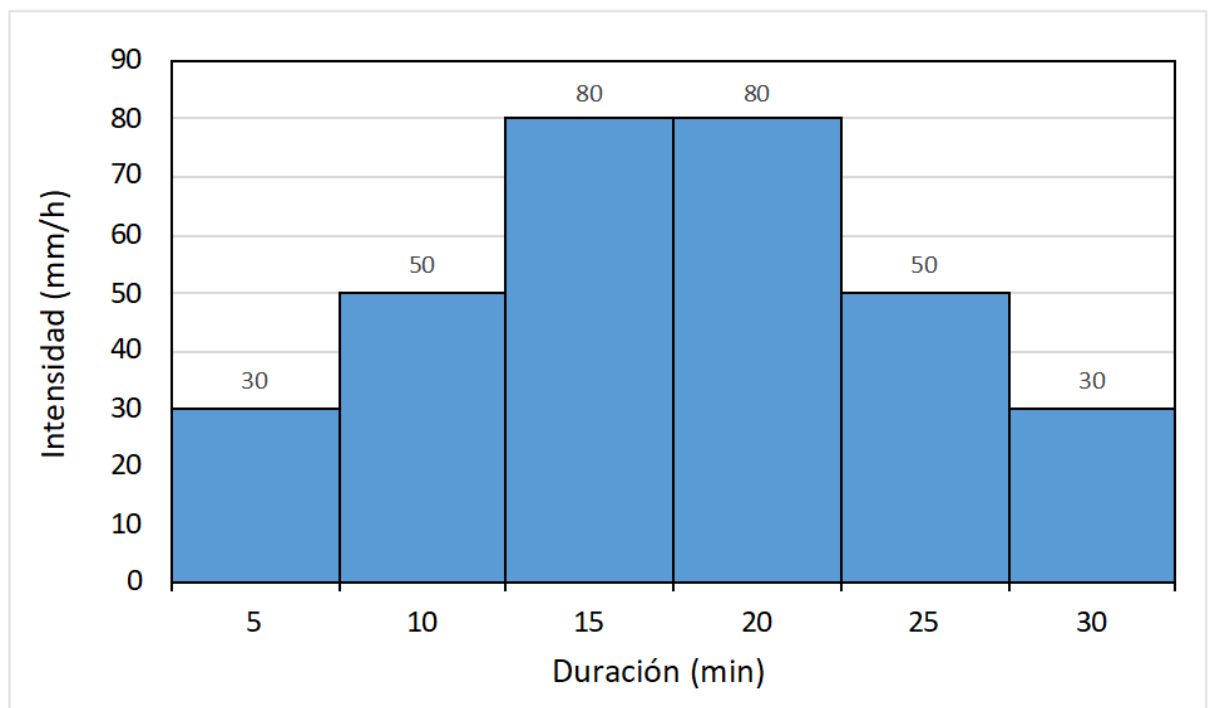

Figura 7. Hietograma de cálculo del modelo de drenaje de la PCEHU.

\subsubsection{Caudales de tiempo seco}

A modo de ejemplo se introducirán caudales de tiempo seco constantes de valor 1 y 2 L/s en los pozos N.1 y N.4, respectivamente.

\subsubsection{Resultados del ejemplo}

Para la resolución del ejercicio, una vez realizada la modelización del sistema con el SWMM se deberán visualizar los siguientes resultados:

- Perfil longitudinal entre los nodos N.1 y 0.1.

- Hidrograma de todas las conducciones.

- Mapa de velocidades en las tuberías para el momento pésimo de la tubería T.6.

- Curva de gasto en el punto de vertido O.1.

\subsection{Metodología de resolución}

Para realizar una modelización con SWMM los pasos a seguir serán los siguientes:

- Determinación de las propiedades por defecto de la simulación.

- Esquematización de la red y el área de estudio.

- Edición de las propiedades.

- Opciones de análisis y simulación.

- Presentación de los resultados.

\subsubsection{Propiedades por defecto}

En primer lugar, se han de especificar los valores por defecto de los identificadores y las propiedades comunes de los objetos visuales en Project $\gg>$ Defaults. 
En la Figura 8 se indican las opciones por defecto que se deben incluir en el modelo. En la pestaña "ID Labels" introduciremos los prefijos que queremos utilizar para la numeración de los distintos elementos de la red (por ejemplo T. para las tuberías).

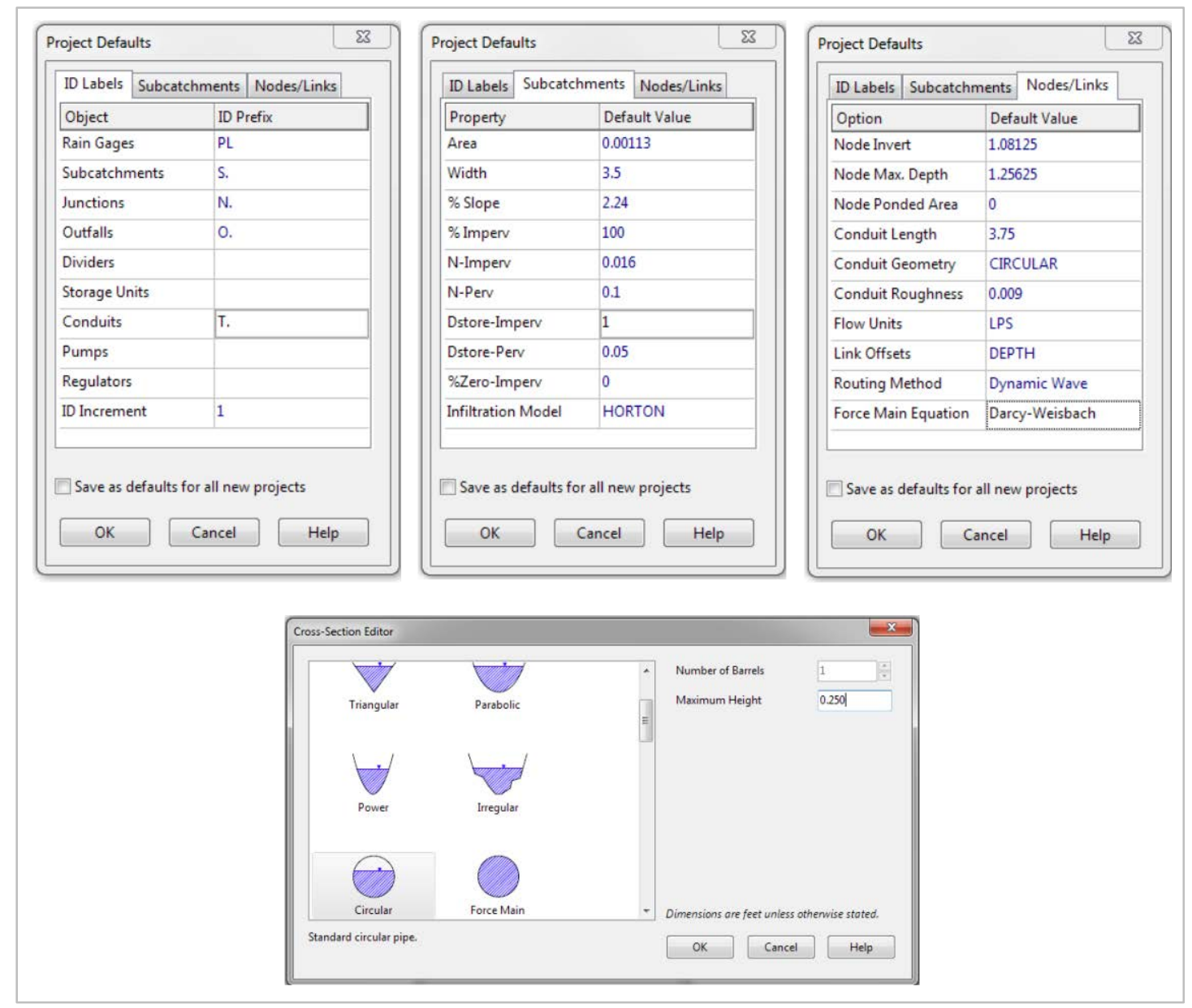

Figura 8. Opciones por defecto de la simulación del modelo de drenaje de la PCEHU.

En la segunda pestaña "Subcatchments", se indican las opciones por defecto para las distintas subcuencas. Algunas opciones como el área no tienen mucho sentido, ya que cada subcuenca tendrá diferente área. Otras opciones como la pendiente, el porcentaje de impermeabilidad, la detracción o el coeficiente de Manning permitirán ahorrar tiempo en la introducción de los datos del modelo.

La última pestaña "Nodes/Links" contiene los datos de pozos y tuberías. Los parámetros específicos de cada elemento como cotas o longitudes no serán muy útiles, pero otros como el diámetro o el coeficiente de Manning permitirán un ahorro significativo de tiempo. Además de los parámetros específicos de elemento, en esta pestaña se introducen las unidades del flujo (Flow units), la manera de referencias las cotas en el modelo (Link offsets), el método de cálculo (Routing Method) y la manera de calcular las pérdidas continuas en las conducciones (Force Main Equation).

Con respecto a las unidades de caudal (flow units), en este caso vamos a utilizar LPS $(\mathrm{L} / \mathrm{s})$, ya que resulta más cómodo al tratarse de una cuenca muy pequeña. En cuencas reales, donde se manejan caudales mucho mayores, lo habitual es trabajar en CMS 
$\left(\mathrm{m}^{3} / \mathrm{s}\right)$. Al escoger las unidades de caudal, definimos el resto de unidades del modelo. Así, si escogemos una unidad del $\mathrm{SI}$, el resto de objetos del modelo se definirán en SI (por ejemplo, las cotas en $\mathrm{m}$ ).

La opción Link Offsets le indica al modelo cómo queremos definir las cotas dentro de los elementos tipo nodo. Podemos utilizar unidades relativas a la cota de fondo de cada elemento -indicándolo en esta opción Depth - o unidades absolutas del sistema de referencia general del modelo - con la opción Elevation-. Por ejemplo, si tenemos un pozo de registro que está a la cota $+10.0 \mathrm{~m}$ y la tapa de registro está en la cota $+12.5 \mathrm{~m}$, para definir la cota del pozo debemos indicar como Node Maximum Depth 2.5 en coordenadas relativas (Link Offsets >> Depth) o 12.5 en coordenadas absolutas (Link Offsets $\gg$ Elevation).

Para las dos últimas opciones de la pestaña "Nodes/Links", Routing Method y Force Main Equation, se recomienda escoger siempre las opciones Dynamic Wave y Darcy-Weisbach respectivamente.

Por último, si queremos que estas opciones por defecto se mantengan para futuros modelos, debemos marcar la opción Save as default for all new projects.

\subsubsection{Esquematización de la red y área de estudio}

Se esquematizará la red a partir de las imágenes (.jpg) que se entregan en este ejemplo (ver Capítulo 6). Para ello, se activará antes la opción Auto-Length en la barra de herramientas inferior. Esta herramienta permite que los objetos dibujados, subcuencas y tuberías, adquieran las áreas y longitudes directamente del esquema que carguemos en el entorno de trabajo. En el caso de desactivar la opción Auto-Length las dimensiones del esquema serán meramente orientativas y habrá que introducir a mano todas las áreas y distancias del modelo.

Una vez activado la opción Auto-Length, se cargará el archivo del esquema de la calle que se corresponde con la imagen Barrio_red.jpg desde View > Backdrop > Load (Image File).

A continuación, es necesario dar a esta imagen dimensiones para poder utilizarla como plantilla de dibujo y que se establezcan automáticamente las áreas y longitudes. Para dotar de dimensiones a la imagen de fondo, se indicarán las coordenadas inferior izquierda y superior derecha de la imagen en el menú View $>>$ Backdrop $>>$ Resize (Figura 9). Las coordenadas de las esquinas de la imagen en este caso son $(0,0)$ y $(19,10)$. Al seleccionar Scale Map to Backdrop Image, lo que se consigue es ajustar las dimensiones en la ventana del área de estudio a las de la imagen cargada.

Antes de empezar a dibujar se recomienda revisar de nuevo que la opción Auto-Length está activada. 


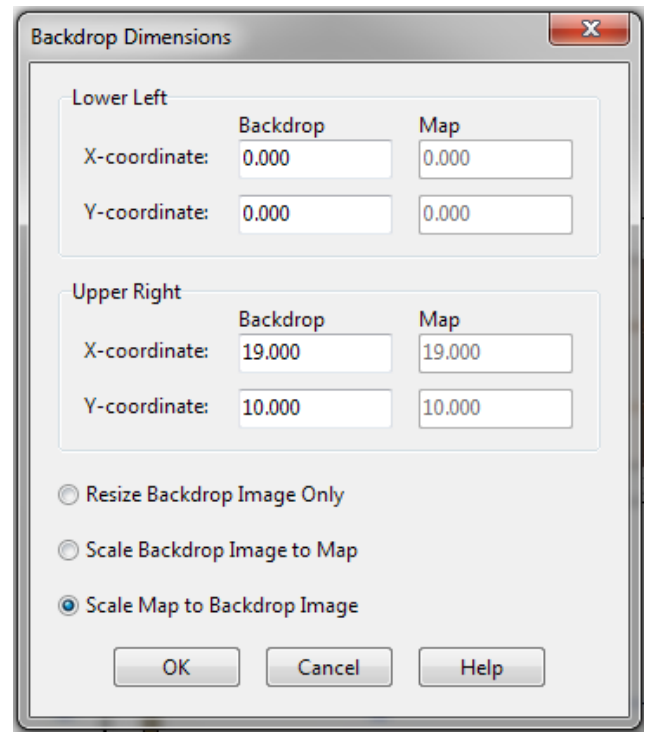

Figura 9. Definición de las dimensiones de la imagen de fondo del modelo de drenaje de la PCEHU.

Sobre la imagen del esquema del modelo físico, se dibuja la red de drenaje comenzando por los nodos, puntos de vertido y conducciones. Cada tipo de objeto se selecciona en la Objects toolbar, que es la barra de herramientas situada en la parte superior de la barra de trabajo, y se coloca sobre el esquema. Se recomienda seguir el orden de los objetos indicado en la Figura 10. Después se representarán los conductos, que se deben dibujar desde el nodo de aguas arriba hacia el nodo de aguas abajo para evitar confusiones a la hora de introducir los datos del modelo.

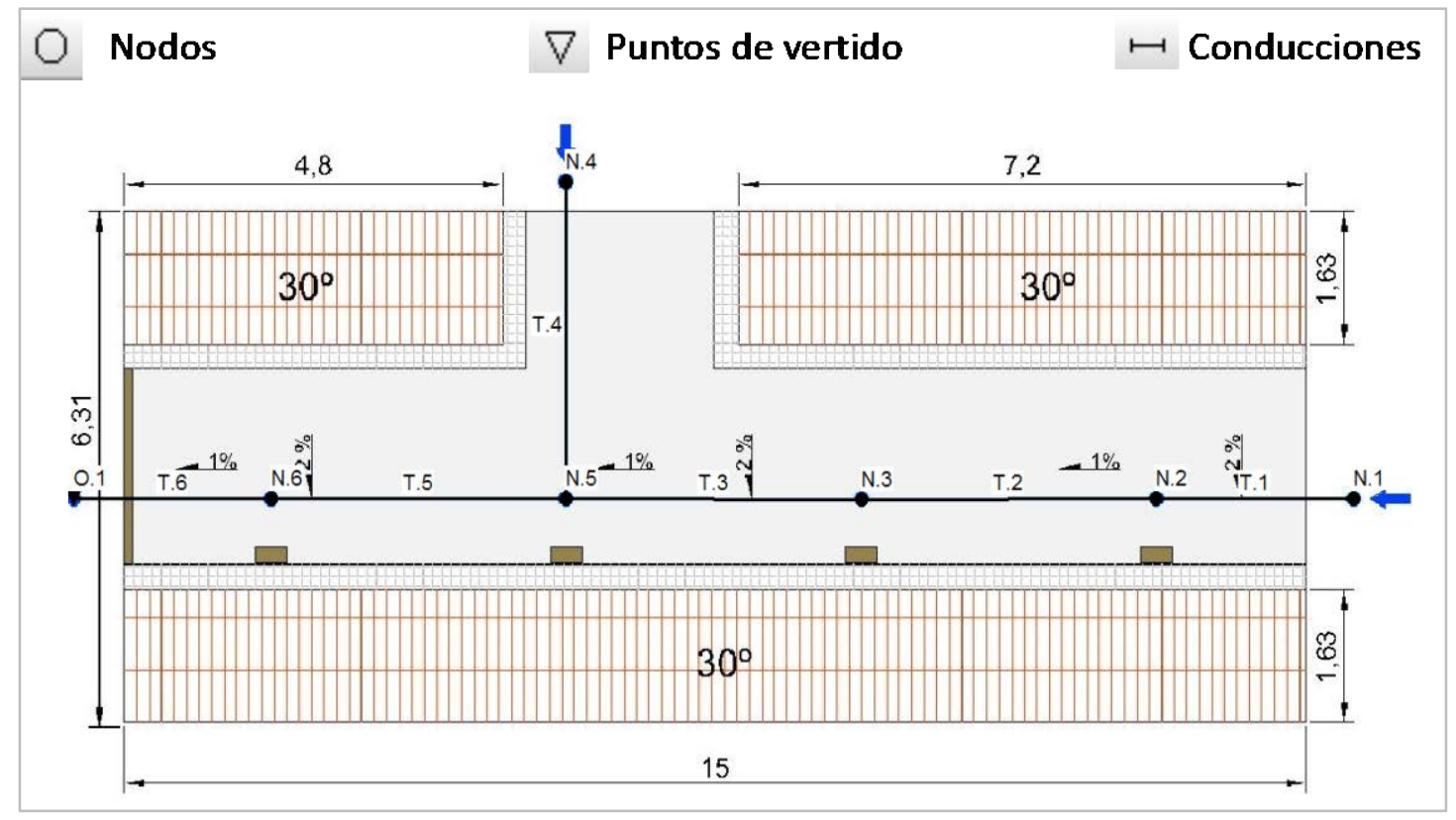

Figura 10. Introducción de nodos y conductos en el modelo de drenaje de la PCEHU.

Para mostrar las etiquetas (ID) de los nodos, conductos y demás elementos visuales del entorno de trabajo se debe ir al menú Tools > Map Display Options e indicar los elementos que queremos visualizar en la opción Annotation. En la ventana de Map Display Options también se pueden ajustar las opciones de visualización de los elementos del entorno de trabajo - como por ejemplo los bordes y sombreado de las 
subcuencas, los grosores de las líneas, el tamaño de los nodos y de las anotaciones- , o incluso indicar con una flecha la dirección del flujo en los conductos.

A continuación, se repite el proceso con la imagen Barrio_Subcuencas.jpg para dibujar las subcuencas. En primer lugar, se debe descargar la imagen anterior en la opción View > Backdrop >> Unload. Una vez descargada, cargamos la nueva imagen con la opción View >> Backdrop >> Load (Image File). Las subcuencas se dibujarán apoyándose en la imagen (Figura 11). Una vez dibujadas todas las subcuencas, se puede descargar la imagen de fondo. Por último, se introduce un pluviómetro en cualquier punto de la zona de trabajo.

Para preparar este tipo de imágenes de fondo se recomienda utilizar alguna herramienta CAD o SIG que nos permita activar y desactivar las capas con la información de nuestra cuenca. Por ejemplo, se puede utilizar una foto área o un callejero para el fondo. A este fondo se le podrá incorporar el esquema de cuencas y un esquema de las conducciones y pozos. En los esquemas incluso se puede incluir alguna información numérica que ayude a identificar los elementos o a definirlos (por ejemplo, el material y el diámetro de las conducciones, o las cotas de los pozos). Es importante que todas las imágenes tengan exactamente las mismas dimensiones, porque así se podrán intercambiar, como sucede en este ejemplo.

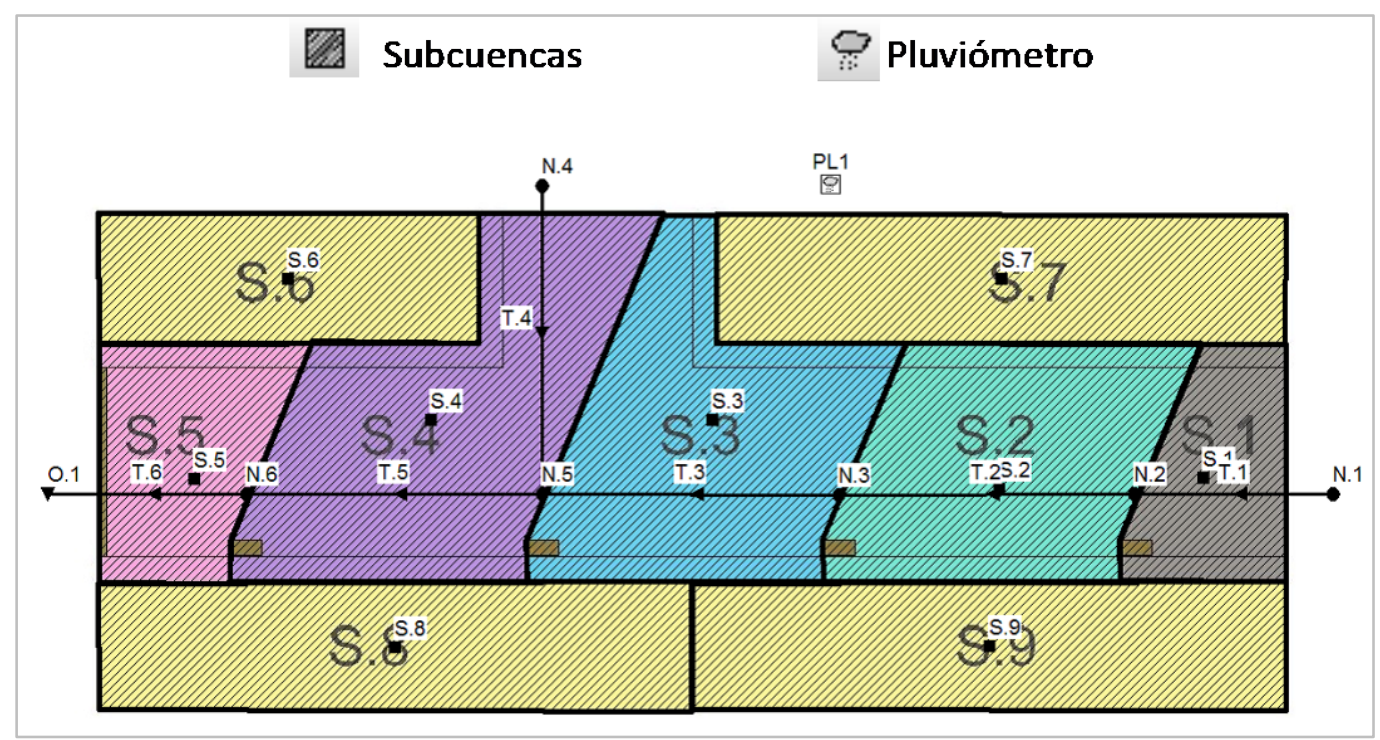

Figura 11. Introducción de subcuencas en el modelo de drenaje de la PCEHU.

\subsubsection{Edición de las propiedades de los objetos}

Una vez dibujados todos los elementos del modelo, el siguiente paso es atribuir a cada objeto sus propiedades. La ventana de propiedades de cada objeto se abre haciendo doble clic sobre él o seleccionando el objeto en el panel de navegación situado a la izquierda de la interfaz de SWMM. A modo de ejemplo se incluyen en la Figura 12 las propiedades de una subcuenca (S.1), un pozo (N.2) y una tubería (T.3). 


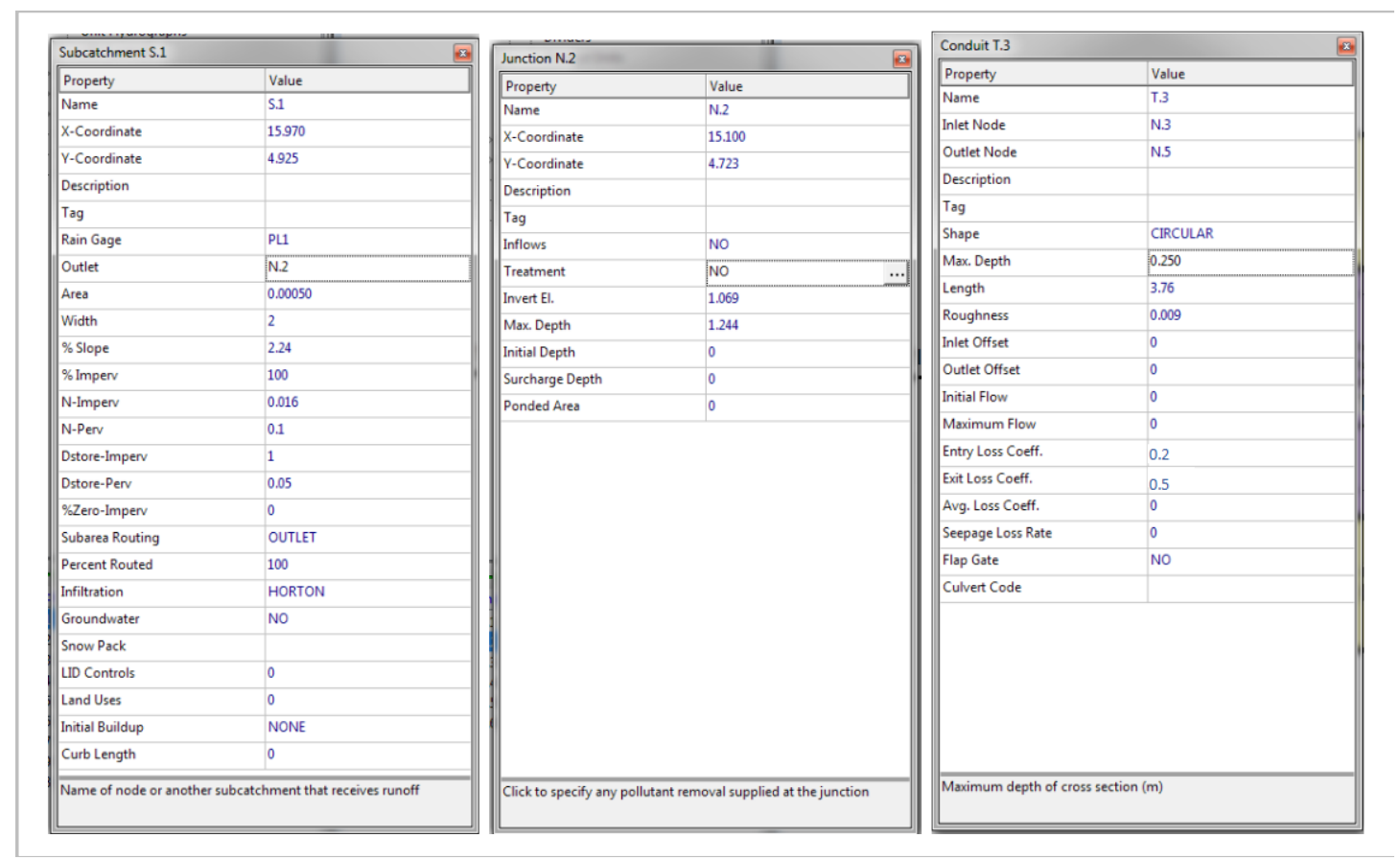

Figura 12. Edición de las propiedades de los objetos del modelo de drenaje de la PCEHU.

En la tubería T.4 es necesario definir, además de sus características principales, un Outlet Offset de $0.3 \mathrm{~m}$, ya que la tubería se inserta en el pozo a ese nivel del fondo. En el resto de las tuberías el Outlet Offset es nulo, ya que se insertan en el fondo del pozo.

Por otro lado, en los nodos N.1 y N.4 se ha de incorporar el caudal de tiempo seco en la opción Inflows, con un valor de 1 y 2 L/s respectivamente (ver Figura 13).

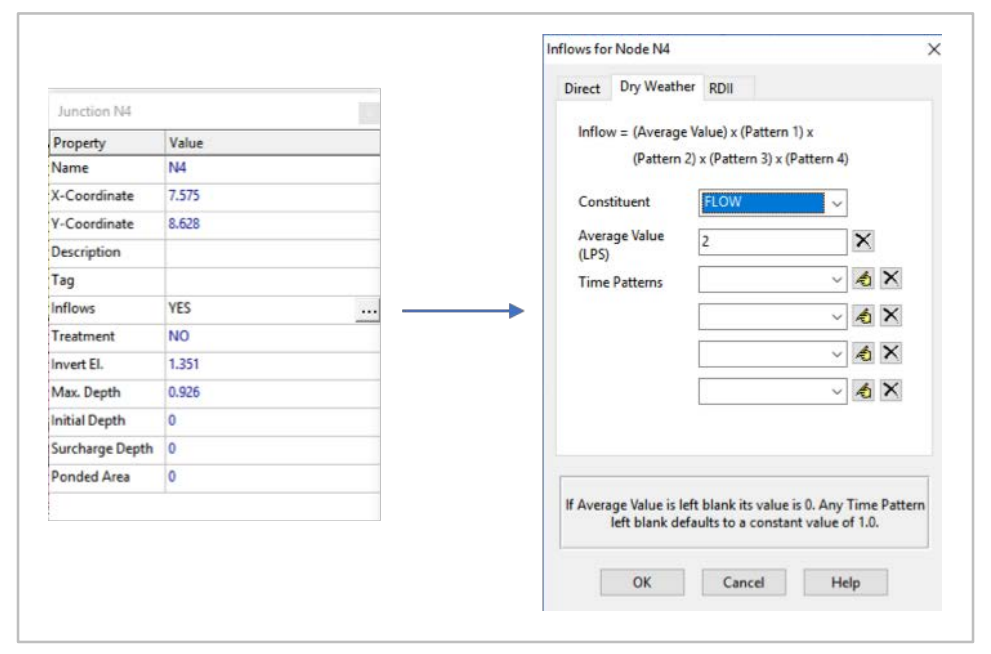

Figura 13. Edición de las opciones de caudal tiempo seco del modelo de drenaje de la PCEHU.

Por último, se ha de definir la precipitación en el pluviómetro. Los datos se pueden importar a partir de un fichero de texto externo de intensidades o volúmenes o a partir de una Time Series definida en el panel de navegación (Figura 14). El primer método es muy recomendable para series de datos largas (capítulo 5). En este caso se utilizará el segundo método, definiendo una serie temporal que es después asignada al pluviómetro indicando el formato de la precipitación (en este caso intensidad en $\mathrm{mm} / \mathrm{h}$ ), 
el intervalo de registro de la lluvia (5 minutos) y el origen de los datos que es una Time Series.

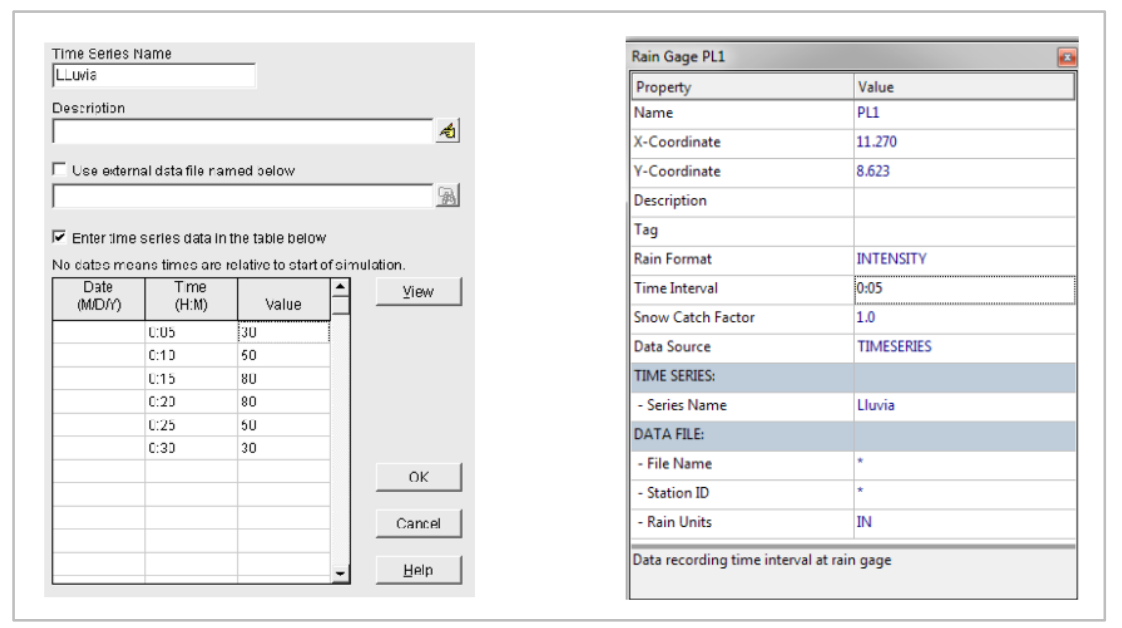

Figura 14. Introducción de los datos de lluvia en el modelo de drenaje de la PCEHU.

\subsubsection{Opciones de análisis y simulación}

Antes de proceder a ejecutar la simulación se deben especificar algunas opciones de análisis. Para ello, se debe seleccionar en el panel de navegación lateral la opción Options > General. Para este ejemplo se emplearán las opciones que se indican en la Figura 15.

Las opciones de la pestaña General permiten indicar los procesos que se quieren simular y los métodos de cálculo. No es necesario cambiar ninguna de las opciones de esta pestaña, ya que han sido definidas previamente en las opciones por defecto.

En la pestaña Dates se indican la fecha de inicio de la simulación, la fecha a partir de la que se deben mostrar de los resultados y la fecha del final de la simulación. Como la serie de precipitaciones introducida no tiene una fecha de inicio en formato MM/DD/AÑO, solo es relevante la hora de inicio y fin de la simulación.

En la pestaña Time Steps se indican el intervalo de tiempo entre resultados (5 minutos es un valor habitual) y los intervalos de tiempos entre cálculos de la simulación en tiempo seco y tiempo de lluvia. En la opción Routing se define el intervalo de tiempo entre dos cálculos del flujo en conducciones. Por último, en la pestaña Dynamic Wave se indican las opciones para la simulación del flujo en onda dinámica. En esta pestaña se deben escoger para este problema las opciones indicadas en la Figura 15. 


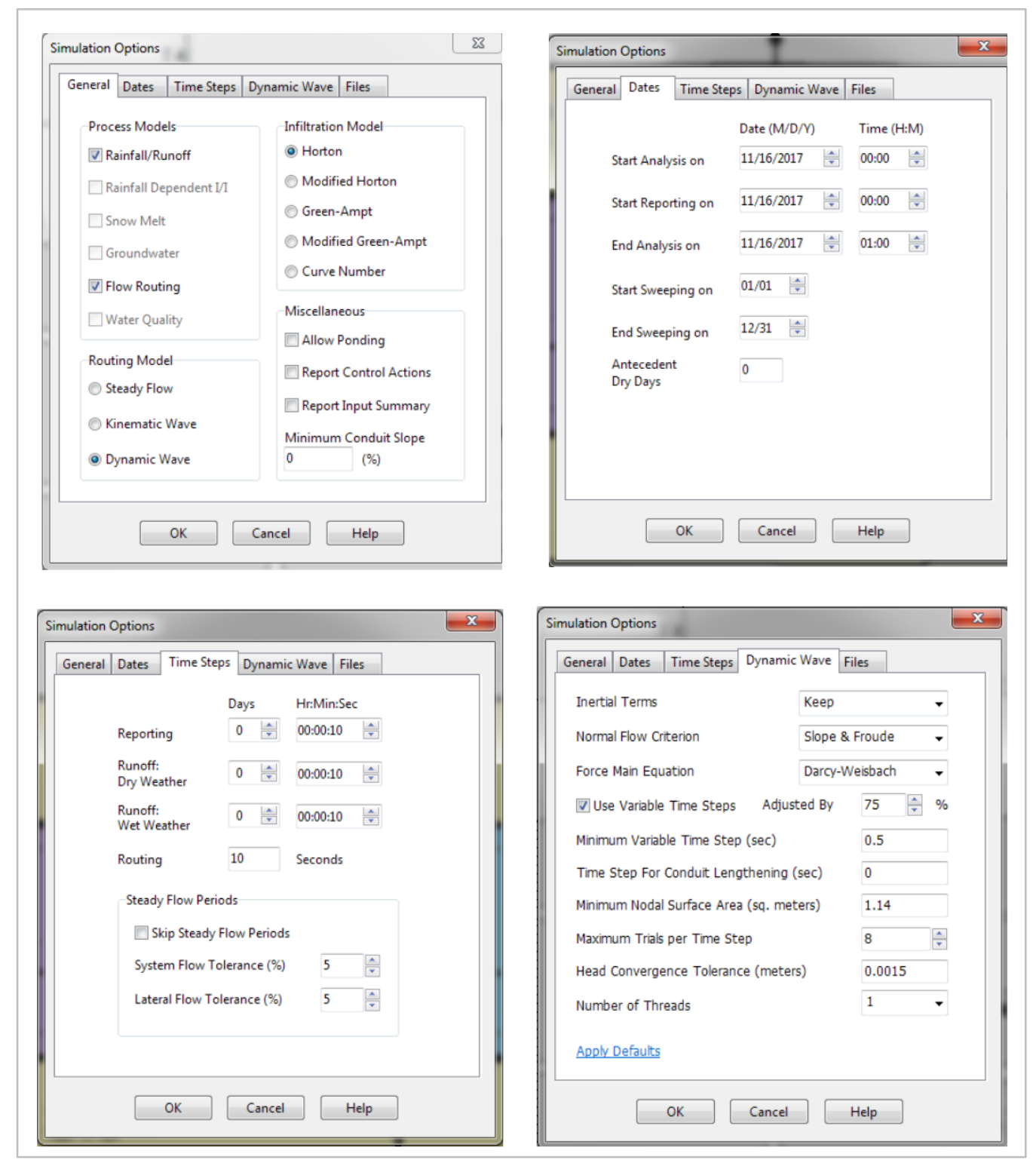

Figura 15. Opciones de simulación en el modelo de drenaje de la PCEHU.

Una vez introducidas todas las opciones, solo queda realizar la simulación. Para ello en el menu principal se selecciona Project $\gg$ Run Simulation, o directamente se hace clic en el icono con un rayo A continuación aparecerá una ventana informando de que los cálculos han ido bien e indicando los errores de continuidad, que son propios de la metodología numérica en la que se basa SWMM. Que cualquiera de los errores de continuidad sea superior al $5 \%$ suele indicar, en general, que se producen inundaciones en el modelo. Esto se puede corregir modificando la geometría de la red.

En ocasiones puede surgir algún problema en la simulación debido a una mala definición del modelo del sistema. Esto ocurre por ejemplo si no se ha definido algún objeto correctamente, si hay errores en el esquema o si hay errores de lectura de archivos de entrada. En este caso, el programa enviaría un mensaje indicando el tipo de problema. Podemos buscar el código del error en la ayuda del programa o incluso en un buscador web para solucionarlo. 


\subsection{Presentación de resultados}

Una primera manera de conocer los resultados de la simulación es a través del Status Report, que proporciona un práctico resumen de los resultados de la simulación realizada. El archivo se abre desde el menú principal Report $\gg$ Status. Este informe permite consultar los nodos o conductos que presentan más problemas numéricos para su posterior resolución.

Además del Status Report, en el menú de informes se puede consultar el Status Summary en Report >> Status Summary, que incluye información detallada de los distintos elementos del modelo. Por ejemplo, se puede revisar si algún nodo entra en carga y se producen inundaciones, los momentos de mayor velocidad de circulación en cada tubería para comprobar si es admisible, o cuantificar el volumen vertido al medio en un punto de la red.

Otra manera de visualizar resultados es a través de gráficos. SWMM permite dibujar tres tipos de gráficos diferentes en el menu Report $\gg$ Graph. Estos gráficos también se pueden dibujar en los iconos de la barra de herramientas.

La opción Profile Plot o el icono permiten dibujar perfiles longitudinales de la lámina de agua dentro de la red de drenaje. Para ver el movimiento del agua, debemos utilizar la barra de herramientas de animación que se encuentra en la opción View/Map del panel de navegación.

Para representar el perfil de la red entre el punto de vertido 0.1 y el nodo N.1 se ha de seleccionar la opción Profile Plot, indicar el nodo de inicio y el nodo final del perfil y seleccionar la opción Find Path para que SWMM añada las tuberías a visualizar. La Figura 16 muestra este resultado del problema.

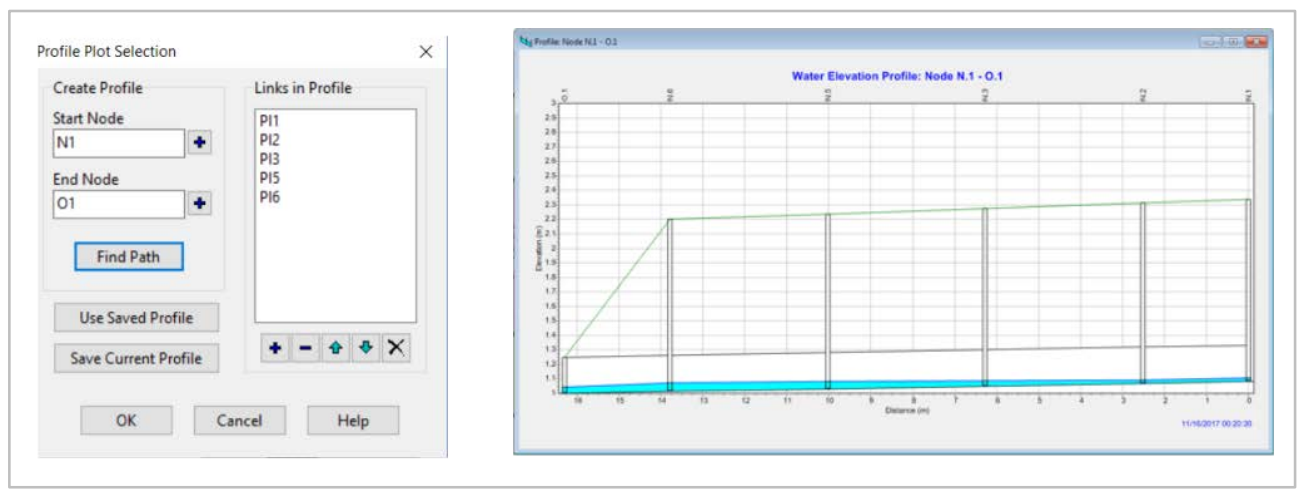

Figura 16. Perfil longitudinal entre los nodos N.1 y 0.1 del modelo de drenaje de la PCEHU.

Para representar series temporales como hidrogramas, debemos emplear la opción Time Series Plot o el icono En la ventana Time Series Plot Selection se añaden las variables y los elementos que se quieren representar utilizando la opción $A d d$ y, una vez terminada la selección, se presiona $O K$. En la Figura 17 se presentan las ventanas de selección de variables y la figura obtenida con los hidrogramas de todas las conducciones del modelo de la PCEHU. 


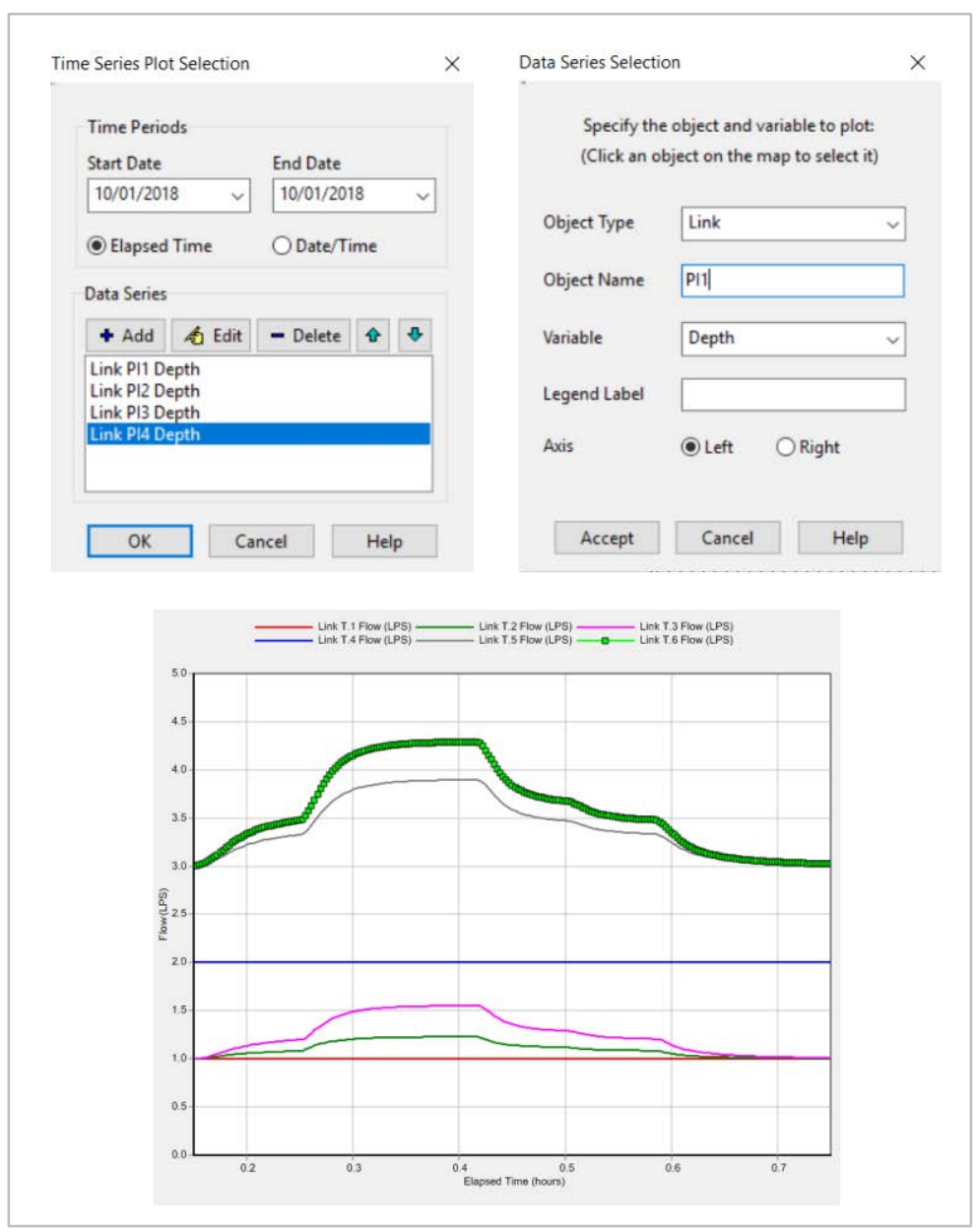

Figura 17. Ventanas para la definición de la visualización de las series temporales e hidrogramas de todos los conductos del modelo de drenaje de la PCEHU.

La tercera opción de visualización gráfica en SWMM nos permite representar gráficos de dispersión de dos variables mediante la opción Scatter Plots o el icono ejemplo de la Figura 18 se presenta la ventana de elección de variables para el gráfico de dispersión y la curva de gasto en el punto de vertido 0.1.

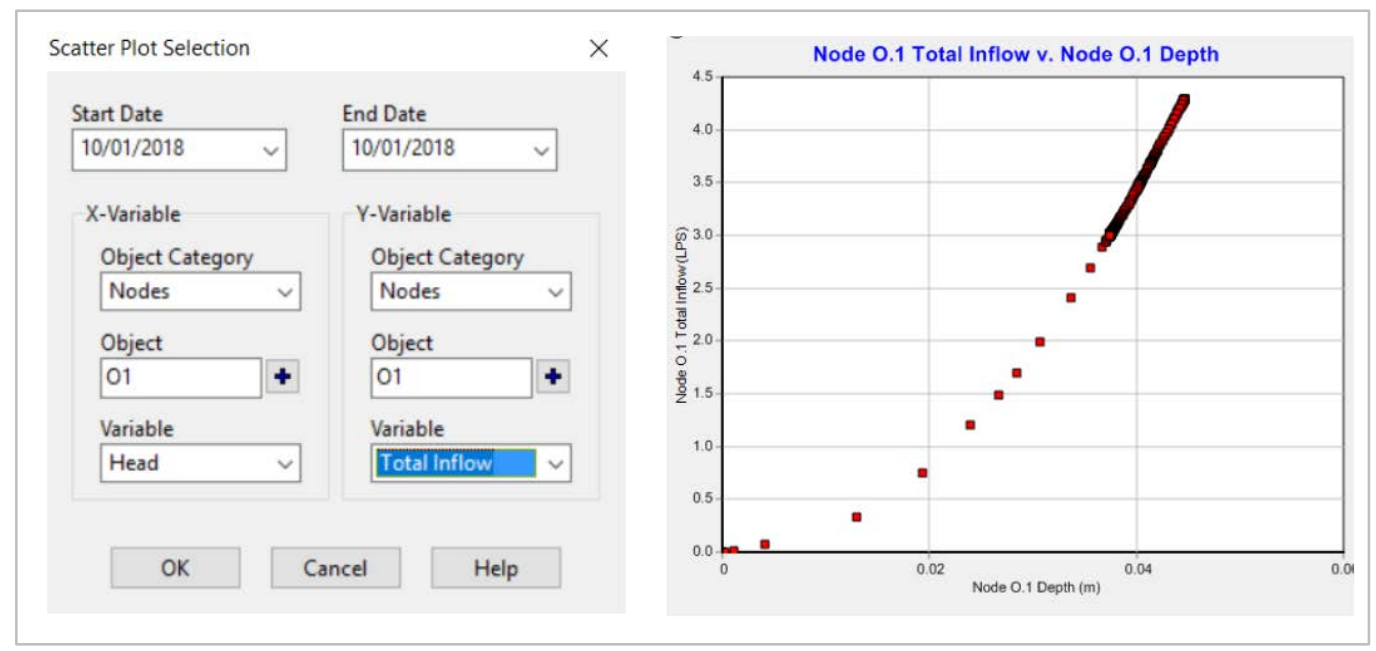

Figura 18. Ventanas para la selección de variables del gráfico de dispersión y curva de gasto obtenida en el nodo de salida del modelo de drenaje de la PCEHU. 
SWMM permite modificar algunas opciones de visualización de las gráficas como por ejemplo añadir una leyenda, ejes secundarios o definir los nombres de las variables. Sin embargo, para obtener una buena visualización de los resultados es conveniente utilizar algún programa externo como una hoja de cálculo. Los resultados se pueden exportar en formato tabla, utilizando la visualización de resultados en tablas (Report >> Table). SWMM prepara dos tipos de tablas: By object y By variable. En una tabla By object se visualizan varias propiedades de un objeto, como por ejemplo velocidades y caudales de una tubería. Una tabla By variable permite conocer las propiedades o registros de una variable en varios elementos. Esta opción es útil, por ejemplo, para conocer el caudal de varios tubos de la red.

La versión del programa SWMM 5 incorpora una nueva forma de visualizar los resultados sobre el área del mapa de estudio, que consiste en mostrar los diferentes rangos de valores que alcanza una determinada variable en un determinado instante de tiempo de la simulación a través de un código de colores. Para activar esta forma de visualización hay que seleccionar la ficha Map del panel de navegación, elegir la variable a ser visualizada para cada tipo de objeto y, por ultimo, elegir el instante de visualización, moviendo el cursor bajo la barra Time. Con este procedimiento se ha obtenido la Figura 19 , en la que se representa la escorrentía generada en cada subcuenca, el calado en cada nodo y la velocidad en cada tubería. Es posible representar parámetros físicos de los elementos, como el área de las subcuencas o el diámetro de los conductos, o variables de la simulación, como calados o velocidades. Las escalas se pueden modificar en la ventana del entorno de tabajo utilizando el botón derecho sobre la leyenda de cada variable.

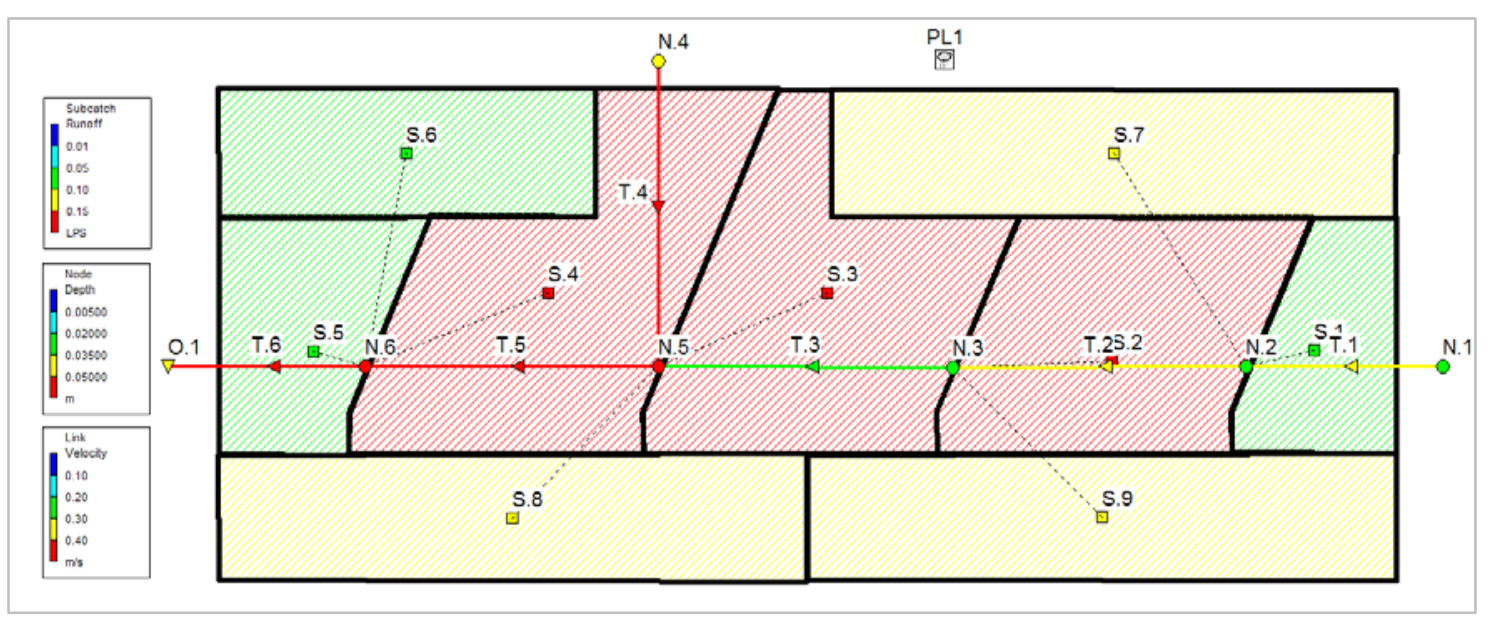

Figura 19. Ejemplo de visualización del mapa del modelo de drenaje de la PCEHU con las variables caudal escorrentía en la subcuenca, calado en los pozos y velocidad del flujo en las conducciones.

Por último, SWMM prepara un informe estadístico de las series de tiempo de los resultados obtenidos en el icono $\Sigma$. Este informe es especialmente útil para simulaciones que involucran largos períodos de simulación, donde se tienen tiempos de simulación del orden de meses o años (véase el capítulo 5). 


\section{CÁlCULO DE UNA RED SIMPLIFICADA DE SANEAMIENTO UNITARIO}

\subsection{Descripción del problema}

Se propone simular el funcionamiento de una red de saneamiento unitaria simplificada. Se trata de una cuenca urbana formada por 6 subcuencas que drenan a los pozos de registro de la red de saneamiento. En la Figura 20 se presenta el esquema de la red. Los datos relativos a las subcuencas, pozos de registro y conducciones del modelo se presentan en las Tablas 4, 5 y 6 .

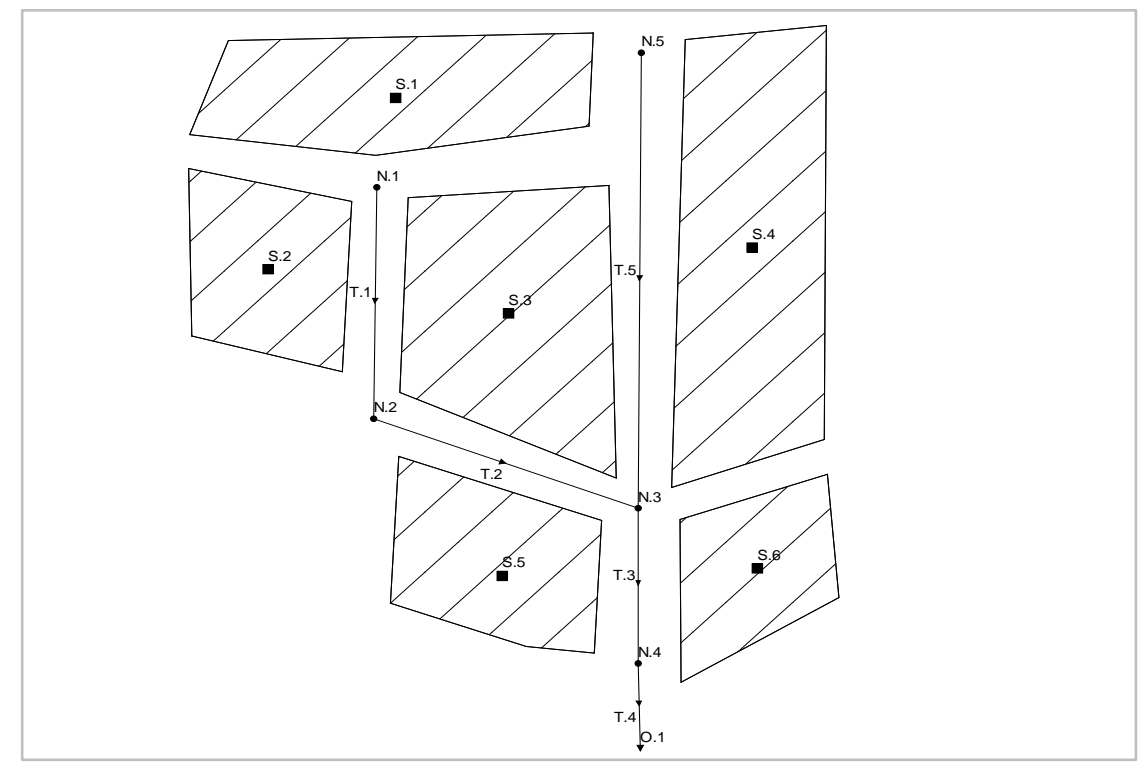

Figura 20. Esquema de la red de saneamiento unitario.

Tabla 4. Definición de las subcuencas en el modelo de la red de saneamiento unitario.

\begin{tabular}{|c|c|c|c|c|c|}
\hline Subcuenca & $\begin{array}{c}\text { Nodo de } \\
\text { salida }\end{array}$ & Área (ha) & Ancho (m) & $\begin{array}{c}\text { Pendiente } \\
\text { (\%) }\end{array}$ & $\begin{array}{c}\text { Impermeab. } \\
\text { (\%) }\end{array}$ \\
\hline S.1 & N.1 & 10 & 500 & 2 & 60 \\
\hline S.2 & N.2 & 8 & 900 & 6 & 75 \\
\hline S.3 & N.3 & 9 & 225 & 4 & 80 \\
\hline S.4 & N.3 & 12 & 240 & 5 & 20 \\
\hline S.5 & N.4 & 6 & 200 & 1 & 75 \\
\hline S.6 & N.4 & 5 & 200 & 3 & 80 \\
\hline
\end{tabular}

Tabla 5. Definición de los nodos (pozos y punto de vertido) en el modelo de la red de saneamiento unitario.

\begin{tabular}{|c|c|c|}
\hline POZO & $\begin{array}{c}\text { Elevación } \\
\text { fondo }(\mathbf{m})\end{array}$ & $\begin{array}{c}\text { Profundidad } \\
\text { máxima }(\mathbf{m})\end{array}$ \\
\hline N.1 & 14.5 & 2.5 \\
\hline N.2 & 13.9 & 2.5 \\
\hline N.3 & 6.9 & 2.5 \\
\hline N.4 & 0.15 & 2.5 \\
\hline N.5 & 7.9 & 2.5 \\
\hline O.1 & 0 & 2.5 \\
\hline
\end{tabular}


Tabla 6. Definición de las conducciones en el modelo de la red de saneamiento unitario.

\begin{tabular}{|c|c|c|c|c|}
\hline Conducto & $\begin{array}{c}\text { Nodo de } \\
\text { entrada }\end{array}$ & Nodo de salida & Longitud & D (m) \\
\hline T.1 & N.1 & N.2 & 500 & 0.8 \\
\hline T.2 & N.2 & N.3 & 900 & 0.8 \\
\hline T.3 & N.3 & N.4 & 225 & 1.5 \\
\hline T.4 & N.4 & 0.1 & 240 & 1.5 \\
\hline T.5 & N.5 & N.3 & 200 & 1 \\
\hline
\end{tabular}

Además de la información proporcionada en la Tabla 4, para definir las subcuencas se necesita conocer los coeficientes de rugosidad de Manning. Se adoptan $n=0.025$ para las áreas impermeables y $\mathrm{n}=0.15$ para las permeables. El valor de la detracción inicial se ha estimado en $1 \mathrm{~mm}$ y $2 \mathrm{~mm}$ para las áreas impermeables y permeables respectivamente. Para modelizar la infiltración se emplea la ecuación de Horton con los siguientes parámetros característicos: máxima capacidad de infiltración de $75 \mathrm{~mm} / \mathrm{h}$, mínima capacidad de infiltración $25 \mathrm{~mm} / \mathrm{h}$, y coeficientes de recuperación e infiltración de 0.001. La influencia de estos parámetros en la simulación será baja, ya que la cuenca es eminentemente impermeable.

Un parámetro importante que condiciona la respuesta hidrológica de las subcuencas es el ancho y la pendiente de las mismas. Así, a mayor pendiente y ancho, los hidrogramas resultado de la transformación lluvia-escorrentía serán más apuntados. Por el contrario, las cuencas con menor pendiente y menor ancho provocarán caudales menores y con mayor tiempo hasta el caudal punta. Los volúmenes de escorrentía quedarán definidos por el porcentaje de impermeabilidad de las cuencas y por su capacidad de almacenar agua en superficie, simulada a través de la detracción inicial. La definición de todos estos parámetros será clave a la hora de representar adecuadamente el comportamiento hidrológico de los sistemas de drenaje urbano. En este sentido, se recomienda intentar definir cuencas homogéneas con anchos y pendientes muy regulares. Por ejemplo, se pueden definir las subcuencas como calles y como las cubiertas vertientes a cada una de las calles de un entorno urbano.

También se puede simplificar la realidad urbana empleando cuencas semidistribuidas como las presentadas en este ejemplo. Para realizar este trabajo de conceptualización de la red se recomienda seguir las indicaciones recogidas en el Manual de Referencia Hidráulico del modelo SWMM (Rossman y Huber, 2016) o en el Libro Monográfico de gestión de aguas pluviales editado por varios miembros del Grupo de Ingeniería del Agua y del Medio Ambiente (GEAMA; Puertas et al., 2005)

En la red propuesta, la forma y geometría de los elementos del modelo vienen ya preestablecidos y no es necesario definir el modelo conceptual de la red, sino introducir los elementos ya definidos en el modelo de SWMM.

Con respecto a la definición de los pozos de registro, únicamente será necesario introducir los datos recogidos en la Tabla 5. Además, en pozo N.5 se debe introducir un caudal constante proveniente de una cuenca aguas arriba de valor $200 \mathrm{~L} / \mathrm{s}$. El punto de 
vertido 0.1 representa la conexión de la cuenca a un colector interceptor situado aguas abajo. Se considerará como condición de contorno un vertido en calado crítico.

La red de drenaje está compuesta por tubos de hormigón circulares con un coeficiente de Manning $n=0.015$. En una primera fase de la resolución del ejemplo no se añadirán pérdidas de carga en los pozos. Las pérdidas de carga se introducirán en el siguiente problema propuesto, donde también se incluirá un tanque anti-DSU previo al punto de vertido de la cuenca (capítulo 5).

La precipitación utilizada en este ejemplo se corresponde con la lluvia del Ejemplo 7 de la ITOHG SAN 1-1 (Aguas de Galicia, 2010). Esta lluvia está calculada con la IDF de la instrucción de carreteras 5.2 y con la precipitación del pluviómetro de la estación meteorológica de A Coruña de la AEMET. El hietograma de diseño de 1 hora de duración ha sido definido utilizando el método de los bloques alternados para un periodo de retorno de 10 años y promediando los dos valores máximos de precipitación. Considerando este periodo de retorno, se está realizando un diseño de la red para limitar el grado de llenado de las conducciones a una ratio calado-diámetro máximo de $y / D=0.75$. El hietograma se presenta en la Figura 21.

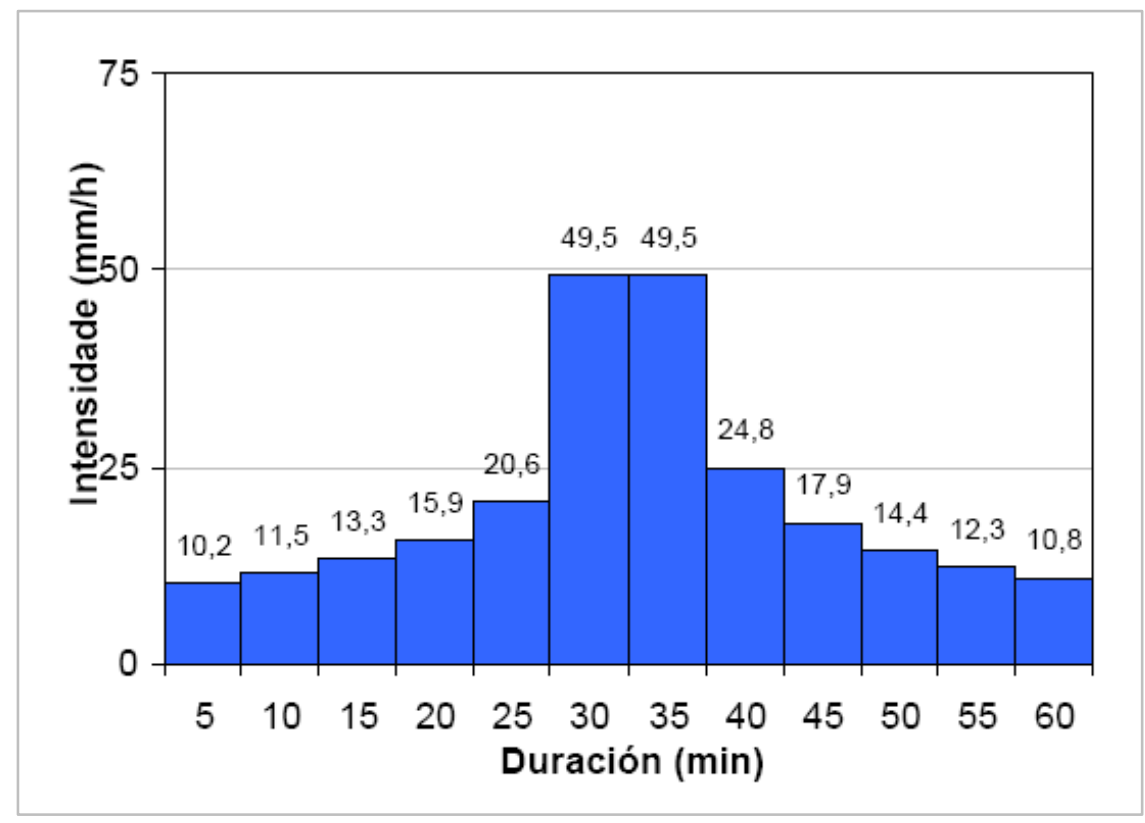

Figura 21. Hietograma de diseño para $T=10$ años y 1 hora de duración empleado en el modelo de la red de saneamiento unitario.

Una vez simulado el comportamiento de la red para este hietograma de diseño con el SWMM, se realizarán las siguientes tareas:

- Comprobar el funcionamiento de la red: existencia de inundaciones y grado de llenado de las conducciones ( $y / D<0.75$ ).

- Ajustar la red para evitar problemas de inundación en la superficie de la cuenca.

- Visualizar el hidrograma de las conducciones T1 a T5. 


\subsection{Metodología de resolución del ejercicio}

La modelización del sistema de drenaje a resolver seguirá los siguientes pasos:

- Determinar las propiedades por defecto de los objetos visuales.

- Esquematizar la red y el área de estudio: dibujo de las subcuencas, nodos y conductos.

- Editar las propiedades de los objetos que componen el sistema.

- Definir las opciones del análisis.

- Realizar la simulación con el modelo.

- Presentar los resultados.

\subsubsection{Propiedades por defecto}

Las propiedades por defecto de los identificadores de los elementos, las subcuencas y los conductos se definen en la pestaña ID Labels de la ventana Project $>>$ Defaults. Los prefijos de los objetos visuales se ajustan como se indica en la Figura 22. A continuación, se ajustan las propiedades por defecto de las subcuencas y de los nodos y tuberías. En este caso, se utilizan como unidades por defecto metros cúbicos por segundo (CMS).

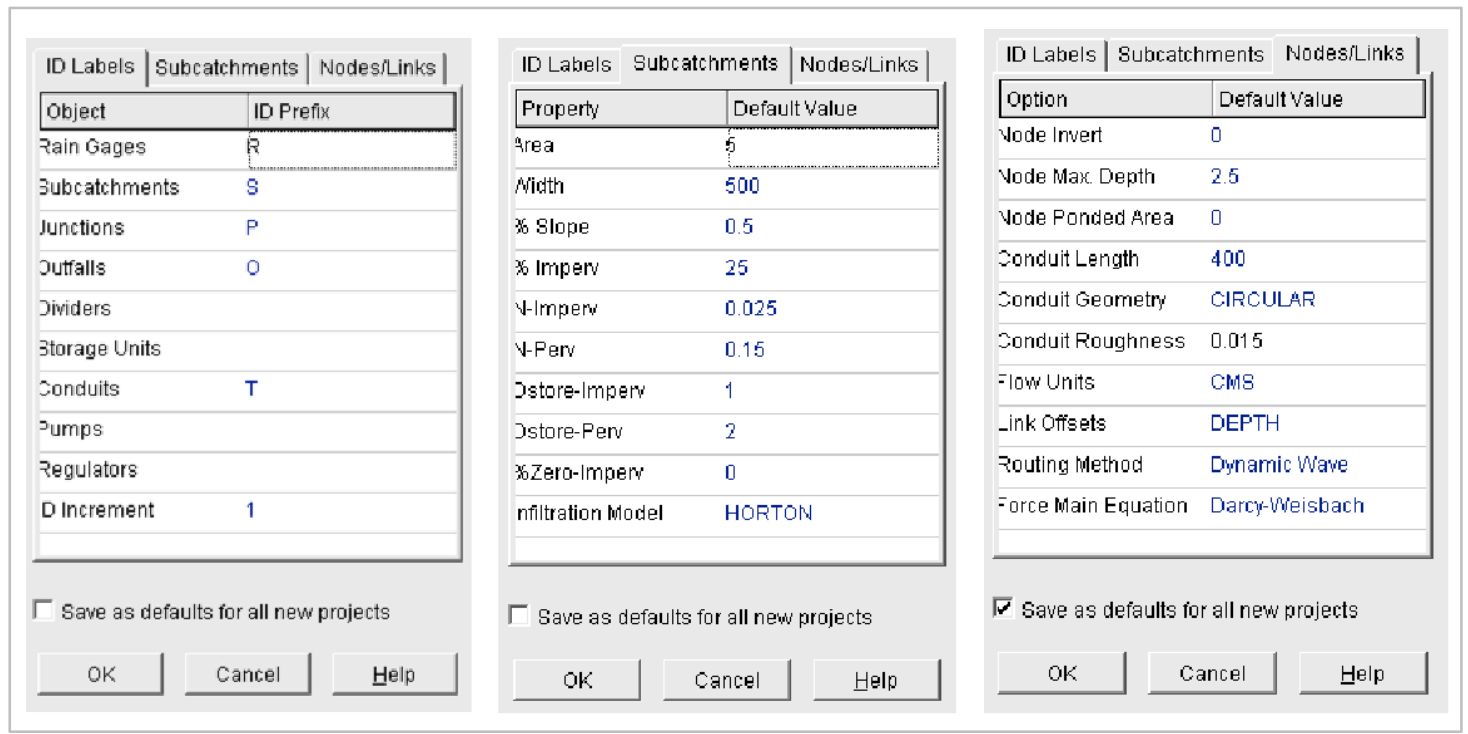

Figura 22. Edición de las propiedades por defecto de los objetos del modelo de la red de saneamiento unitario.

Para que el programa proporcione una solución adecuada en las unidades definidas, se deben revisar las propiedades de precisión numérica. En la pestaña Numerical Precision del menú Tools >> Programs Preferences se deben establecer tres cifras decimales para los datos de caudal como se indica en la Figura 23. 


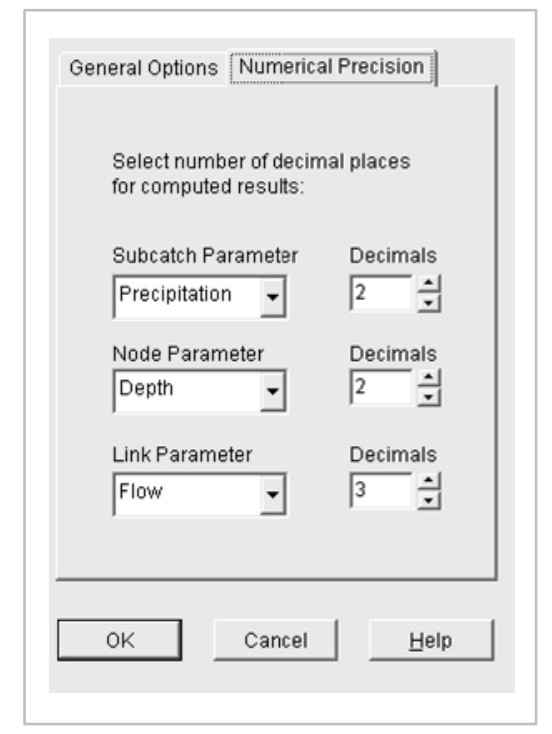

Figura 23. Edición de la precisión numérica de los objetos en el modelo de la red de saneamiento unitario.

\subsubsection{Esquematización del área de estudio}

El siguiente paso es dibujar el esquema del modelo con sus subcuencas, nodos y tuberías, en el área de trabajo del mapa.

Antes de comenzar a dibujar los elementos del modelo, se cargará como fondo la imagen de la zona de estudio y la red. La imagen de fondo se corresponde con el archivo Red_unitaria.jpg. Para cargarla se utilizará la opción View >> Backdrop >> Load (Image File). En este caso, la imagen de fondo no tiene escala gráfica y solo se utilizará para facilitar el dibujo de la red. No se debe activar la opción Auto-Length en la barra de herramientas inferior y los dibujos se copiarán de un modo aproximado, puesto que los datos de área y longitud se introducirán numéricamente.

Para el dibujo de los elementos de la red se utilizan los iconos de la barra de herramientas Objects Toolbar. En primer lugar, se dibujan las subcuencas haciendo clic en el icono $\mathrm{E}$. Se ha de seguir el orden del esquema para que así coincida la numeración. A continuación se dibujan los pozos de registro empleando el icono 0 , y el punto de vertido de la red (outfall) empleando el icono $\nabla$. Por último se dibujan los conductos utilizando el icono $\rightarrow$, y siempre siguiendo la dirección del nodo aguas arriba al nodo aguas abajo. El último elemento que se debe incluir en la red es un pluviómetro, que se inserta con el icono $:$

Una vez dibujados los elementos del modelo de la red de drenaje unitaria, se puede descargar la imagen de fondo con la opción View >> Backdrop >> Unload.

\subsubsection{Edición de las propiedades de los objetos}

A continuación se deben editar las propiedades de los elementos del modelo. Para ello, se debe entrar en la ventana de propiedades de cada objeto, bien haciendo doble clic con el botón izquierdo del ratón o bien seleccionando el objeto en el panel de navegación. En la Figura 24 se presentan a modo de ejemplo las propiedades de la 
subcuenca S.1 y el nodo N.5. En el nodo N.5 se debe introducir un caudal de tiempo seco de 200 L/s empleando el apartado Inflows de las propiedades.

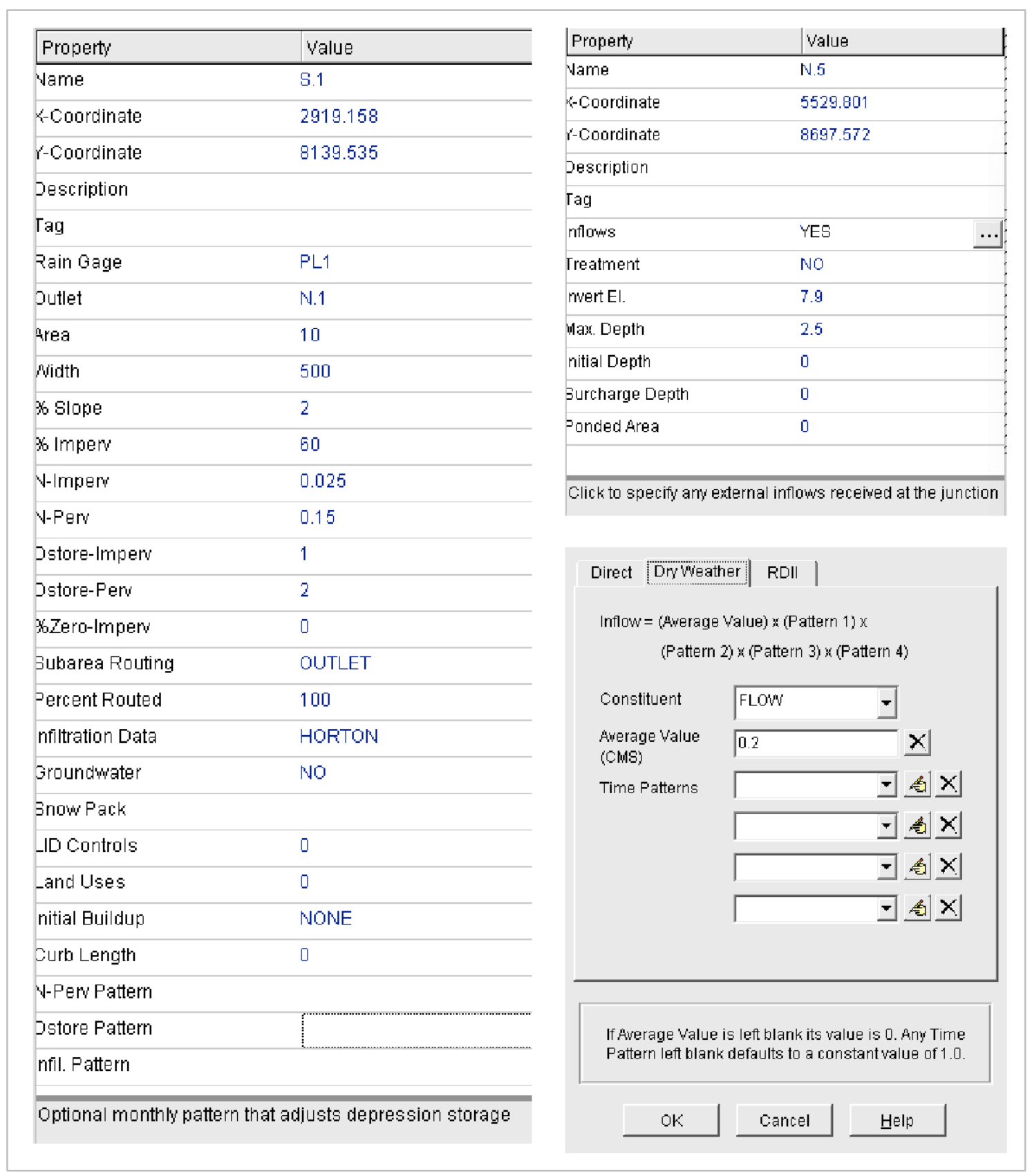

Figura 24. Edición de las propiedades de los objetos en el modelo de la red de saneamiento unitario. Ejemplo para la subcuenca S.1 y el nodo N.5.

Por último, se define la precipitación en el pluviómetro. Para la resolución de este ejemplo se facilita un archivo Iluvia_T10.dat con los datos del hietograma de diseño. Los datos se deben introducir empleando una Time Series definida por el usuario. Se crea una nueva Time Series en el panel Project utilizando el botón "+". Se selecciona la opción Use external data file named below y se importan los datos del archivo Iluvia_T10.dat como se indica en la Figura 25.

Existe también la opción de copiar y pegar los datos de precipitación desde un archivo de texto o una hoja de cálculo. Se ha de seleccionar la opción Enter time series data in 
the table below y, posicionando el ratón en la primera celda Time (H:M), pegar los valores mediante un clic del botón derecho. Esta opción es más conveniente, ya que con el botón View de la venta de edición de las series temporales permite ver si SWMM reconoce la serie.

El último paso consiste en editar las opciones del pluviómetro PL1 indicando la fuente y características de los datos de lluvia, como se indica en la Figura 25.

\begin{tabular}{|c|c|c|c|c|c|}
\hline \multicolumn{4}{|c|}{ Time Series Name } & Property & Value \\
\hline \multicolumn{4}{|c|}{ |luvia_diseñ̃o } & Vame & PL1 \\
\hline \multicolumn{4}{|l|}{ Description } & $\{$-Coordinate & 1461.794 \\
\hline \multicolumn{4}{|c|}{ |lluvia T10 Ejemplo ITOHO. 1 hora } & $r$-Coordinate & 3399.779 \\
\hline \multicolumn{4}{|c|}{ V Use external data file named below } & Description & \\
\hline \multicolumn{4}{|c|}{ 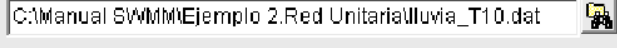 } & Tag & \\
\hline \multirow{2}{*}{\multicolumn{4}{|c|}{$\begin{array}{l}\Gamma \text { Enter time series data in the table below' } \\
\text { No dates means times are relative to start of simulation. }\end{array}$}} & Fain Format & INTENSITY \\
\hline & & & & Time Interwal & $0: 05$ \\
\hline \multirow[t]{10}{*}{$\begin{array}{l}\text { Date } \\
\text { (Miom) }\end{array}$} & $\begin{array}{l}\text { Time } \\
(\mathrm{H}: \mathrm{M})\end{array}$ & value & Yiew & Snow Catch Factor & 1.0 \\
\hline & & & & Data Source & TIMESERIES \\
\hline & & & & TIME SERIES: & \\
\hline & & & & - Series Name & |luvia_diseño \\
\hline & & & & DATAFILE: & \\
\hline & & & & - File Name & * \\
\hline & & & OK & - Station ID & * \\
\hline & & & & - Rain Units & IN \\
\hline & & & Cancel & & \\
\hline & & & Help & $\begin{array}{l}\text { Name of rainfall tim } \\
\text { series) }\end{array}$ & auble-click to edit time \\
\hline
\end{tabular}

Figura 25. Introducción de los datos de lluvia en el modelo de la red de saneamiento unitario.

\subsubsection{Opciones de análisis y ejecución}

Antes de ejecutar la simulación se deben definir las opciones de análisis. Para ello, en el panel de navegación lateral Project se debe seleccionar la opción Options. En la pestaña General no es necesario realizar ningún cambio si se han introducido correctamente las opciones por defecto indicadas en el apartado 4.2.1. En la pestaña Dates se debe indicar que la simulación tenga 4 horas de simulación. Como no hemos definido la fecha (en formato MM/DD/AA) en la serie temporal de precipitación, se puede dejar el día que el programa establezca por defecto. En la pestaña Time Steps se debe definir el intervalo de tiempo para la presentación de los resultados (ver Figura 26). Un valor habitual oscila entre 1 y 5 minutos. A continuación, debemos establecer los incrementos de tiempo de cálculo para el caudal en tiempo seco (dry weather flow), en tiempo de lluvia (wet weatherflow) y para el flujo por los conductos (flow routing). Los valores habituales para estos intervalos oscilan entre 15 y 30 minutos para el tiempo seco, entre 1 y 5 minutos para el tiempo de lluvia, y entre 5 y 30 segundos para el flujo por los conductos. Por último, los valores de la pestaña Dynamic Wave se establecerán como se indica en la Figura 26. 


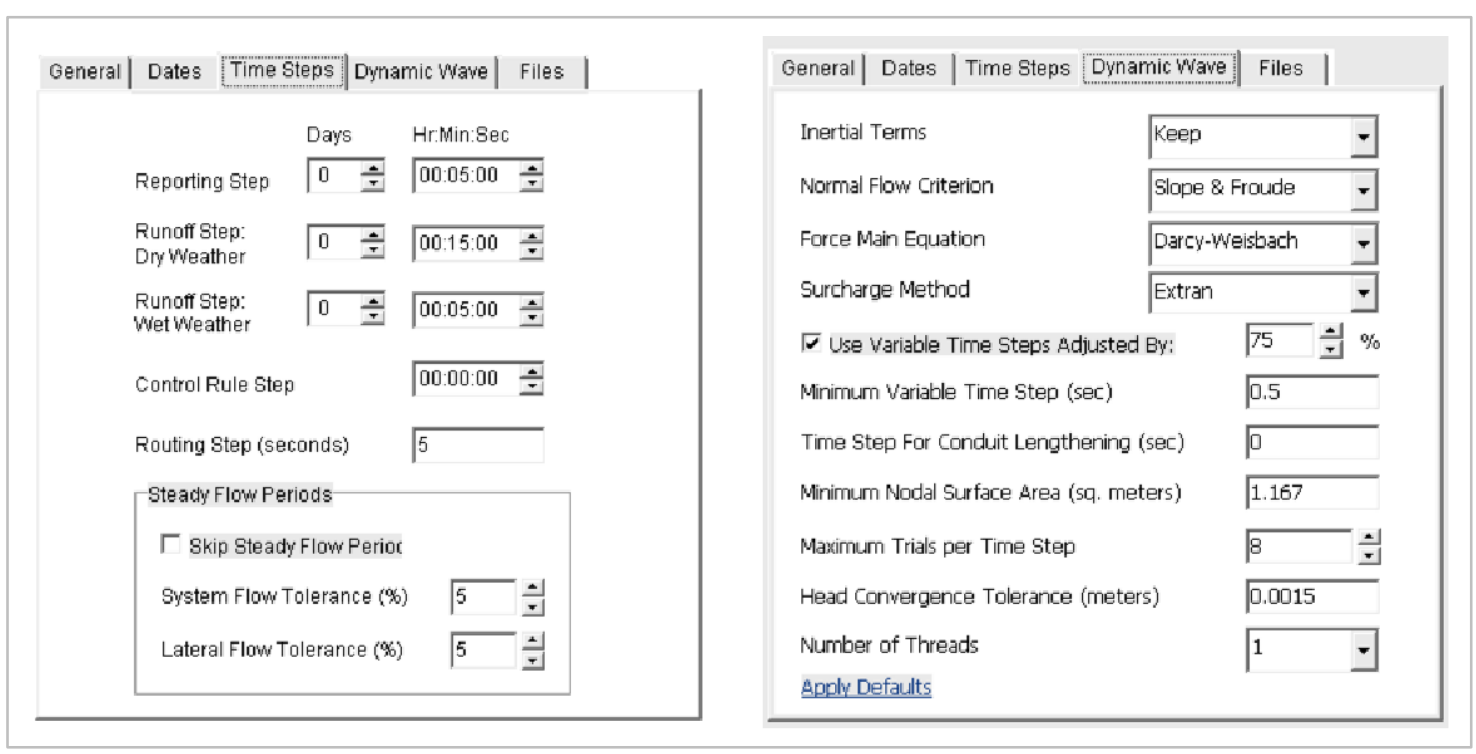

Figura 26. Opciones de simulación en el modelo de la red de saneamiento unitario.

A continuación se realiza la simulación haciendo clic sobre el icono o seleccionando en el menú principal Project $\gg$ Run Simulation. Inmediatamente después de la simulación aparece una ventana donde se indica al usuario que la ejecución se ha realizado sin ningún contratiempo y que los errores de continuidad son reducidos. En el caso de que se produzca un error en la simulación, se deben revisar el modelo y los códigos de error indicados en el informe de estado para solucionarlos.

\subsection{Visualización de resultados y resolución del ejemplo}

Una vez ejecutada la simulación, se revisa el Status Report seleccionando Status en el menú Report y el Summary Report seleccionando Report >> Summary. El Status Report no señala ningún problema puesto que no se producen problemas de continuidad significativos ni entran en carga las tuberías. El Summary Report permite analizar el funcionamiento general del sistema visualizando varios resúmenes de todos los elementos del modelo agrupados por tipos.

En la Figura 27 se presentan los datos de flujo en las conducciones y los nodos de la red en los que se producen inundaciones. El informe proporciona información de los valores pésimos registrados y el momento exacto de ocurrencia. Esto es muy importante porque permite detectar problemas no mostrados en los resultados. Como ejemplo, el instante de máximo caudal en la conducción T.4 se produce en el minuto 43 de simulación y no sería mostrado en los resultados generales al mostrarse estos en intervalos de 5 minutos (como se ha indicado en las opciones de la simulación).

En la Figura 27 se observa también que la conducción T.1 tiene una relación máxima $y / D=1$, lo que supone que la conducción entra en carga y pueden producirse inundaciones. Para comprobar si se producen inundaciones se busca en la lista de ítems del Summary Report el que se denomina Node Flooding. Si este ítem aparece en el listado, es que se producen inundaciones. 
En los nodos N.1 y N.2 se producen inundaciones de 0.08 horas ( 5 minutos) y 0.03 (2 minutos) de duración, respectivamente (Figura 27). En la Figura 28 se ha representado un perfil longitudinal (Graph >> Profile Plot) entre los nodos N.1 y 0.1 en el instante de tiempo 00:45 en el que se puede ver como el agua llega a la superficie en el nodo N.1.

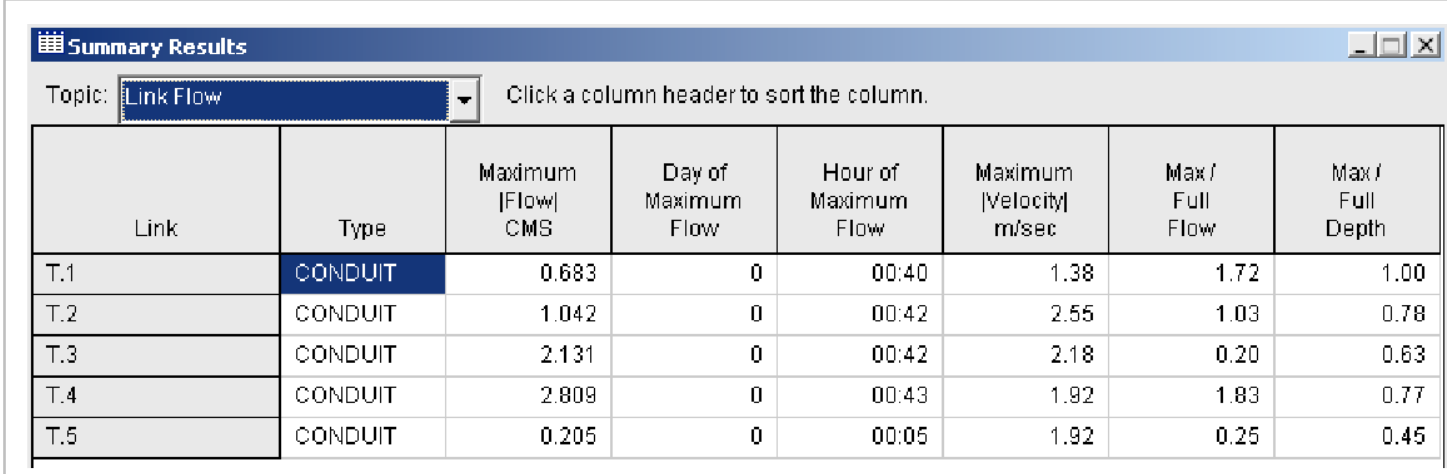

\begin{tabular}{|c|c|c|c|c|c|c|c|c|}
\hline \multicolumn{6}{|c|}{ 麗 Summary Results } & & & \multirow[t]{2}{*}{$-|\nabla| x \mid$} \\
\hline Topic: & Node & & \multicolumn{5}{|c|}{ Click a column header to sort the column. } & \\
\hline & Node & $\begin{array}{l}\text { Hours } \\
\text { Flooded }\end{array}$ & $\begin{array}{l}\text { Maximum } \\
\text { Rate } \\
\text { Clms }\end{array}$ & $\begin{array}{l}\text { Day of } \\
\text { Maximum } \\
\text { Flooding }\end{array}$ & $\begin{array}{l}\text { Hour of } \\
\text { Maximum } \\
\text { Floading }\end{array}$ & $\begin{array}{l}\text { Total } \\
\text { Flood } \\
\text { volume } \\
10^{\Omega} 6 \mathrm{Itr}\end{array}$ & $\begin{array}{l}\text { Maximum } \\
\text { Ponded } \\
\text { Depth } \\
\text { Weters }\end{array}$ & \\
\hline N.1 & & 0.08 & 0.205 & 0 & $00: 42$ & 0.037 & 0.000 & \\
\hline N.2 & & 0.03 & 0.416 & 0 & $00: 40$ & 0.016 & 0.000 & \\
\hline
\end{tabular}

Figura 27. Pestañas de información del flujo en las conducciones y de las inundaciones en los nodos recogidas en el Summary Report del modelo de la red de saneamiento unitario.

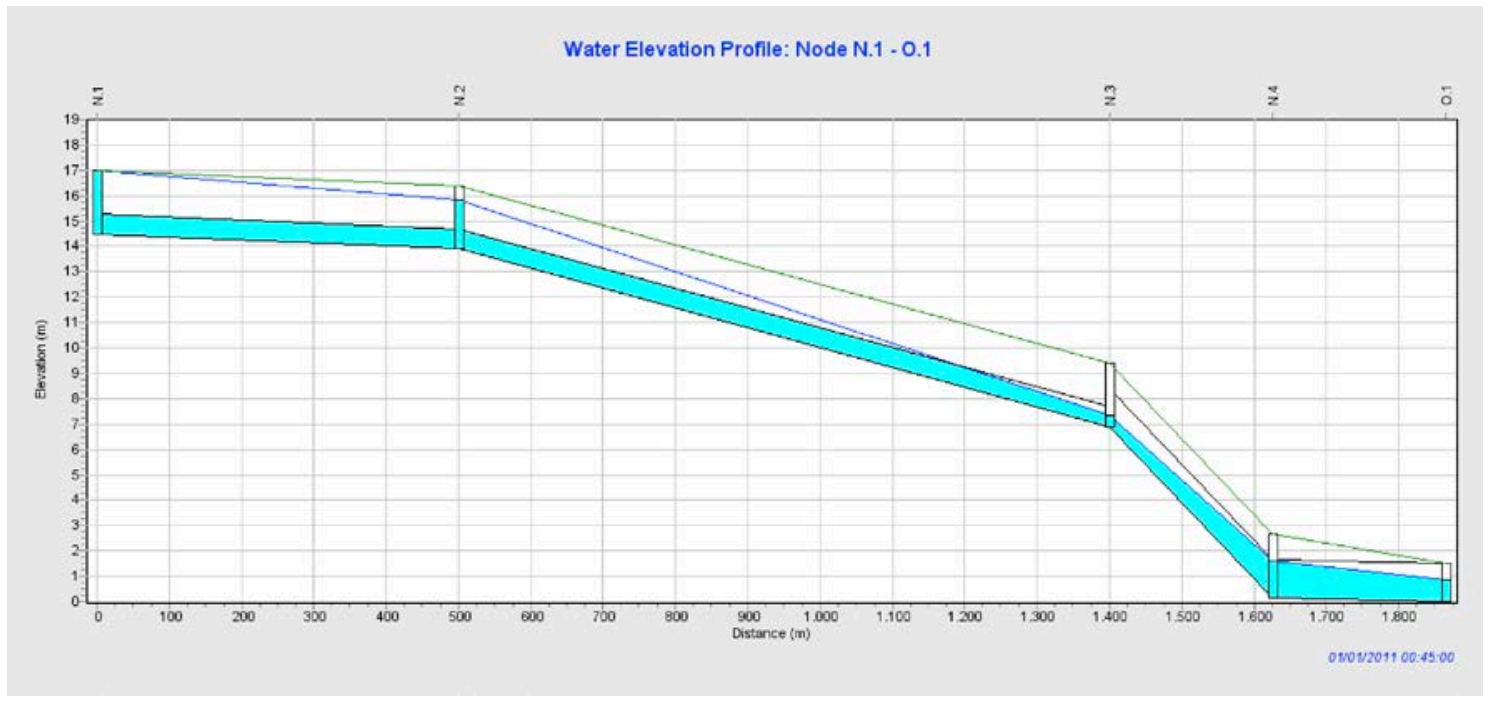

Figura 28. Perfil longitudinal entre los nodos N.1 y 0.1 del modelo de la red de saneamiento unitario en el instante de tiempo 00:45.

La red debe aumentar su capacidad de desagüe para solucionar los problemas de inundación. En la mayoría de las ocasiones, esto se puede conseguir con alguna de las siguientes estrategias: (i) aumentando el área de la sección de la conducción, (ii) incrementando la pendiente, (iii) empleando materiales con menor coeficiente de rugosidad, o (iv) reduciendo las pérdidas de carga puntuales. 
En la red simulada se van a aumentar los diámetros de las conducciones T.1 y T.2. Este tipo de cambios deben realizarse siempre desde aguas abajo hacia aguas arriba, porque en algunos casos se podría resolver un problema de una conducción situada aguas arriba cambiando únicamente la capacidad de desagüe de una o varias conducciones situadas aguas abajo.

Se editan las propiedades de las conducciones T.1 y T.2 y se cambia su diámetro de 800 $\mathrm{mm}$ a $1000 \mathrm{~mm}$. Ejecutando el modelo de nuevo y revisando el Status Report y el Summary Report, se comprueba que ya no se producen inundaciones en superficie. También se puede revisar el nuevo perfil de la red (Graph >> Profile Plot) mostrado en la Figura 29.

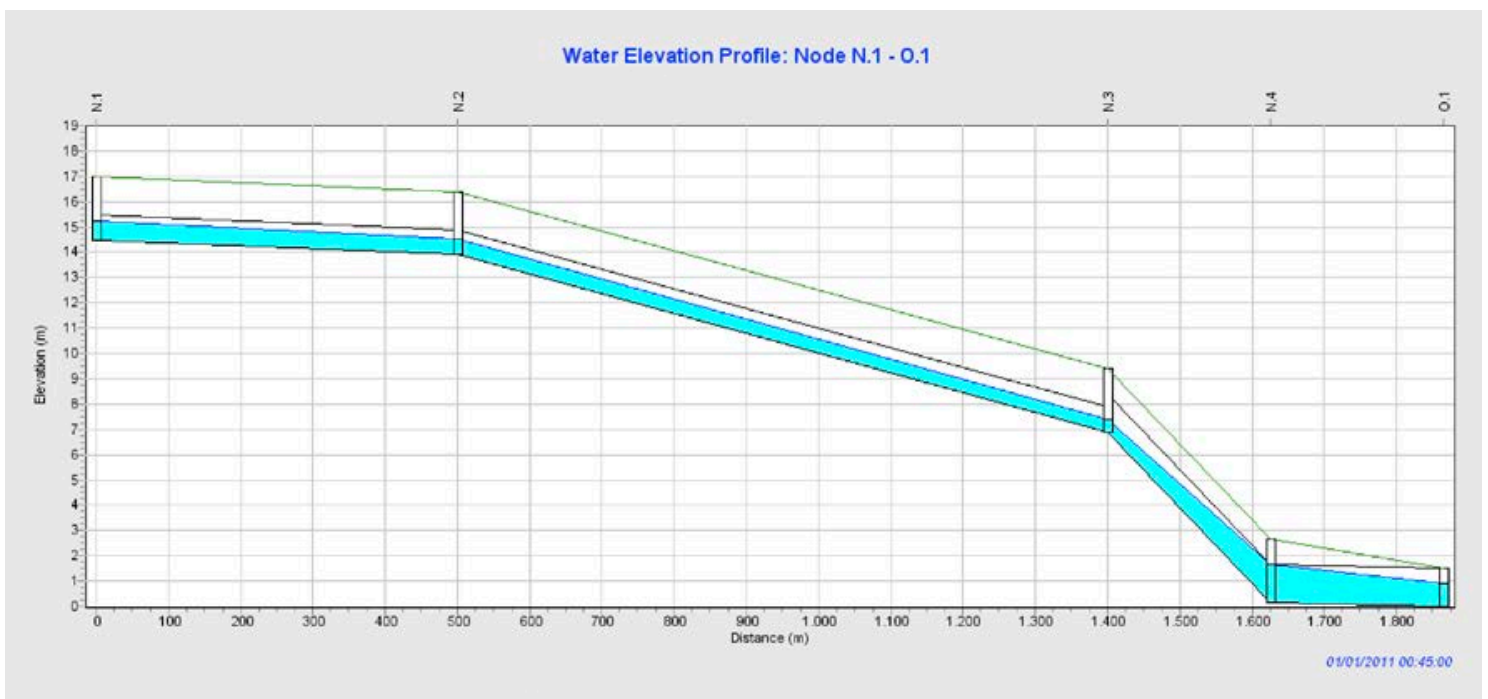

Figura 29. Perfil longitudinal entre los nodos N.1 y 0.1 del modelo de la red de saneamiento unitario una vez incrementado el diámetro de las conducciones T.1 y T.2.

Además de asegurar que no existan inundaciones, se debe comprobar que la ratio de llenado de los conductos, $y / D$, es menor que 0.75 . Esta condición está vinculada a la elección del periodo de retorno de cálculo, como establece la norma de saneamiento UNE-EN-752 y se indica en la ITOHG SAN 1/0. Sistemas de Saneamento (Aguas de Galicia, 2010). En el Summary Report se puede comprobar que únicamente se supera ligeramente el ratio máximo en la conducción T.4, alcanzando un valor de 0.79 (ver Figura 30). Dado el carácter didáctico del ejemplo, se considera este valor como asumible y no se realizan más cambios en la red.

También se comprueba que las velocidades de circulación máximas no superan los 3 $\mathrm{m} / \mathrm{s}$, que es el valor de referencia para conducciones de hormigón. 


\begin{tabular}{|c|c|c|c|c|c|c|c|}
\hline \multicolumn{5}{|c|}{ 唒 Summary Results } & & & \multirow[t]{2}{*}{$-|\nabla| x \mid$} \\
\hline Topic: LinkF & & Click a co & $\mathrm{nn}$ header to $\mathrm{s}$ & the column. & & & \\
\hline Link & Type & $\begin{array}{l}\text { Maximum } \\
\text { |Flow| } \\
\text { CMS }\end{array}$ & $\begin{array}{c}\text { Day of } \\
\text { Maximum } \\
\text { Flow }\end{array}$ & $\begin{array}{c}\text { Hour of } \\
\text { Maximum } \\
\text { Flow }\end{array}$ & $\begin{array}{l}\text { Maximum } \\
\text { |Velocity| } \\
\text { misec }\end{array}$ & $\begin{array}{l}\text { Maxi } \\
\text { Full } \\
\text { Flow }\end{array}$ & $\begin{array}{l}\text { Maxi } \\
\text { Full } \\
\text { Depth }\end{array}$ \\
\hline T.1 & CONDUIT & 0.612 & 0 & $00: 42$ & 1.09 & 0.85 & 0.67 \\
\hline T.2 & CONDUIT & 1.181 & 0 & $00: 43$ & 2.72 & 0.64 & 0.54 \\
\hline T.3 & CONDUIT & 2.227 & 0 & $00: 43$ & 2.15 & 0.21 & 0.65 \\
\hline T.4 & CONDUIT & 2.908 & 0 & $00: 44$ & 1.94 & 1.90 & 0.79 \\
\hline T.5 & CONDUIT & 0.205 & 0 & 00:05 & 1.93 & 0.25 & 0.46 \\
\hline
\end{tabular}

Figura 30. Resumen de variables de las conducciones en el modelo de la red de saneamiento unitario una vez incrementado el diámetro de las conducciones T.1 y T.2.

En la Figura 31 se presenta el hidrograma de todas las conducciones del modelo, una vez efectuados los cambios de diámetro en las conducciones T.1 y T.2. Se aprecia cómo en la tubería T.5 el caudal es constante e igual a $0.2 \mathrm{~m}^{3} / \mathrm{s}$, que se corresponde con el caudal de tiempo seco introducido en el nodo N.5. El caudal máximo de salida de la red asciende a unos $2.9 \mathrm{~m}^{3} / \mathrm{s}$.

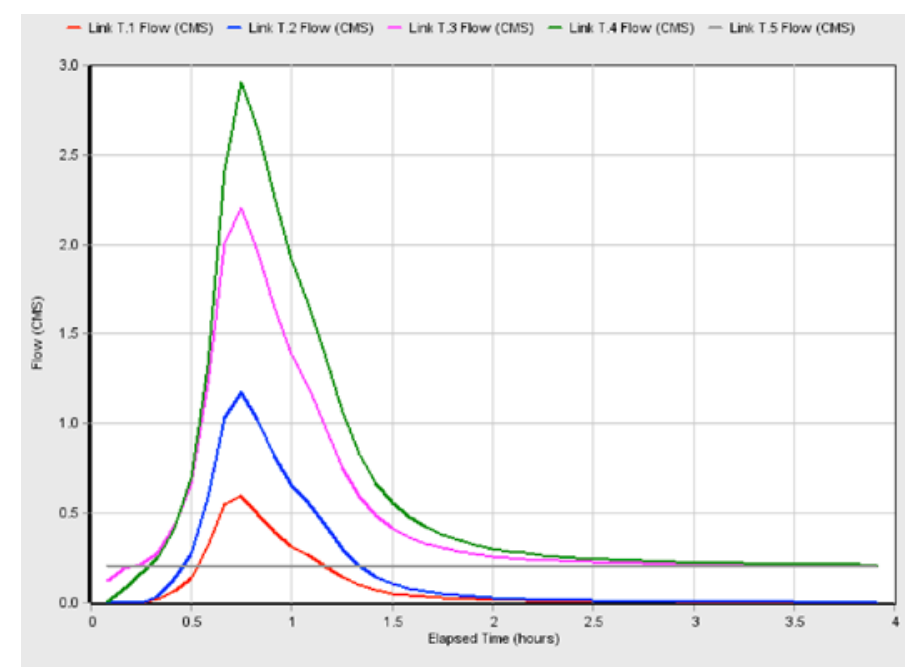

Figura 31. Hidrogramas de todas las conducciones del modelo de la red de saneamiento unitario, una vez incrementado el diámetro de las conducciones T.1 y T.2. 


\section{CÁLCULO DE UN DEPÓSITO ANTI-DSU}

\subsection{Descripción del problema}

En este capítulo se parte de la red unitaria modelizada en el capítulo 4 y se introduce en el punto de vertido de la red un depósito de tormentas predimensionado con el método simplificado propuesto en las ITOHG (Aguas de Galicia, 2010) para una zona urbana con vertido a zona no sensible. Inicialmente se dimensiona el depósito para la lluvia de proyecto de T igual a 10 años. Se comprueba el correcto funcionamiento de la red y sus órganos de desagüe frente a las inundaciones para esta lluvia de diseño.

Partiendo del modelo del capítulo 4, se han de realizar los siguientes cambios:

- Introducir pérdidas de carga a la entrada y salida de las conducciones con valores de 0.2 y 0.5 respectivamente.

- Cambiar el caudal en tiempo seco introducido en nodo N.4 (200 L/s) por el caudal de diseño para este tipo red en tiempo seco de acuerdo a las recomendaciones para Galicia (Augas de Galicia, 2010). Este caudal se corresponde con el caudal

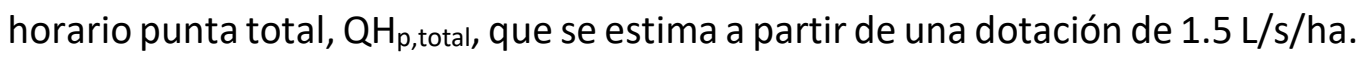

- El caudal de salida del tanque hacia aguas abajo se limita en el depósito empleando un regulador de caudal ideal que permite un flujo máximo de tres veces el caudal diario punta total, $3 \cdot Q D_{p, t o t a l}$. Este caudal se calcula empleando una dotación de $0.6 \mathrm{~L} / \mathrm{s} / \mathrm{ha}$.

- El calado del labio de vertido será de $2 \mathrm{~m}$ y el aliviadero se dimensiona como un vertedero de pared delgada $\left(C_{D}=1.7\right)$ para la lluvia de $T$ igual a 10 años. El calado máximo del depósito se establece en $3 \mathrm{~m}$.

- Los puntos de vertido del depósito, hacia la EDAR y hacia el medio natural a través de DSU, se modelizan con un vertido en calado crítico.

Una vez comprobado el funcionamiento de la red para la lluvia de diseño, se analiza el funcionamiento del depósito en términos de control de los DSU siguiendo las indicaciones de la ITOHG SAN 1/5 (Aguas de Galicia, 2010). Para ello, se emplea la serie anual de precipitaciones correspondiente al año medio pluviométrico.

\subsection{Cálculo del depósito anti-DSU para la lluvia de diseño}

Para introducir las pérdidas de carga a la entrada y salida de las conducciones del modelo, se han de introducir los coeficientes de pérdidas de carga 0.2 y 0.5 , respectivamente. Estos valores se pueden ir modificando uno a uno en todos los conductos del modelo, o utilizando la herramienta Select Region $\mathbb{Z}$ para hacer el cambio de todos los objetos a la vez. Se seleccionará toda la cuenca con dicha herramienta y se utiliza la opción Group Editor del menú View para modificar todas las pérdidas de carga a la entrada y salida de los conductos como se indica en la Figura 32. 


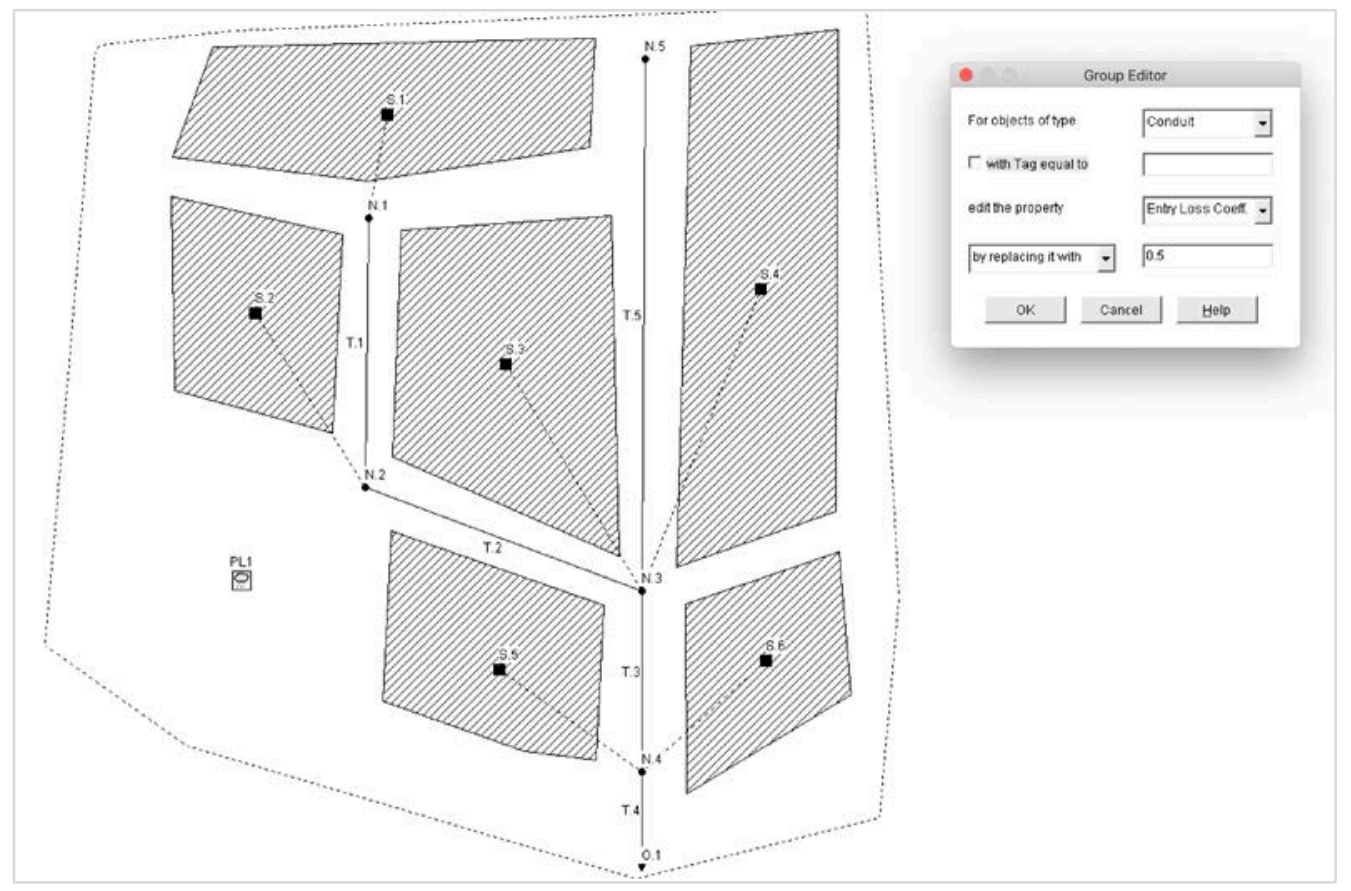

Figura 32. Edición de las propiedades de los objetos de un modelo empleando la opción Group Editor.

El caudal de diseño en tiempo seco se considera igual al caudal horario punta total,

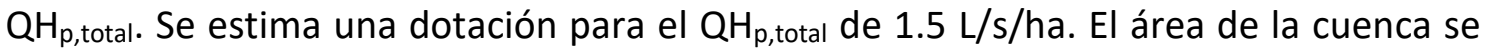
puede calcular a partir de los datos incluidos en el archivo de entrada inp, que puede leerse con un editor de texto, o en el menú Project $\gg$ Details. En la pestaña [SUBCATHMENTS] de este menú se presenta el área total de cada subcuenca y su coeficiente de impermeabilidad (Figura 33). El área total del modelo es de 50 ha y el área impermeable, calculada a partir del producto del área de cada subcuenca y su

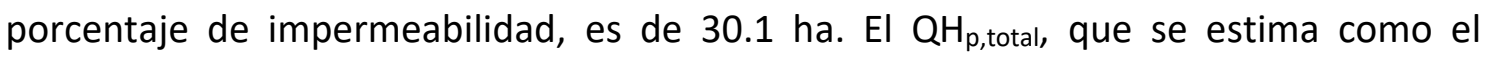
producto de la dotación de $1.5 \mathrm{~L} / \mathrm{s} /$ ha por la superficie, es igual a $75 \mathrm{~L} / \mathrm{s}$. Este caudal se introduce como caudal de tiempo seco en el nodo N.4 del modelo.

\begin{tabular}{|c|c|c|c|c|c|c|c|c|}
\hline Data Category & Name & Rain Gage & Outlet & Area & * Imperv & Width & *Slope & CurbLen SnowPack \\
\hline [TITLE] & 5.1 & PL1 & N. 1 & 10 & 60 & 500 & 2 & 0 \\
\hline [OPTIONS] & 5.2 & PL1 & N. 2 & 8 & 75 & 900 & 6 & 0 \\
\hline [EVAPORATION] & 5. 3 & PL1 & n. 3 & 9 & 80 & 225 & 4 & 0 \\
\hline [RAINGAGES] & 5.4 & PL1 & n. 3 & 12 & 20 & 240 & 5 & 0 \\
\hline [ SUBCATCHIENTS] & s. 5 & PL1 & n. 4 & 6 & 75 & 200 & 1 & 0 \\
\hline [SUBAREAS] & S. 6 & PL1 & n. 4 & 5 & 80 & 200 & 3 & 0 \\
\hline
\end{tabular}

Figura 33. Características de las subcuencas del modelo del depósito anti-DSU.

El volumen del tanque anti-DSU se calcula empleando la Tabla 1 del método simplificado de la ITOHG SAN 1/5 (Augas de Galicia), que propone un almacenamiento específico de $80 \mathrm{~m}^{3} /$ ha neta o impermeable. Por tanto, el volumen total de depósito hasta la cota de vertido será de $2408 \mathrm{~m}^{3}$. Para un calado de $2 \mathrm{~m}$ hasta el labio de vertido, la superficie en planta del depósito asciende a $1204 \mathrm{~m}^{2}$.

El caudal máximo de salida del depósito hacia la EDAR es igual a $3 \cdot Q D_{p, t o t a l}$. El caudal diario punta total, estimado empleando una dotación de $0.6 \mathrm{~L} / \mathrm{s} / \mathrm{ha}$, es igual a $Q D_{p, t o t a l}=30 \mathrm{~L} / \mathrm{s}$. El caudal máximo de salida del depósito hacia la EDAR es, por tanto, igual a $90 \mathrm{~L} / \mathrm{s}$. 
El caudal de vertido por DSU en el tiempo depende de la geometría del depósito (debido al efecto laminador) y de las dimensiones del propio aliviadero. Para predimensionar la longitud del aliviadero, se utiliza el caudal máximo que puede ser determinado con el modelo. Se ejecuta el modelo de la red después de cambiar el caudal de tiempo seco y ajustar las pérdidas de carga locales de las conducciones (sin depósito). El caudal máximo en la conducción de salida asciende a $2.8 \mathrm{~m}^{3} / \mathrm{s}$, que se toma como caudal de diseño del aliviadero. La longitud del aliviadero se calcula empleando la siguiente ecuación de vertido para aliviaderos frontales:

$$
Q=C_{D} \cdot L \cdot H^{1.5}
$$

donde $C_{D}$ es coeficiente de vertido igual a $C_{D}=1.7, H$ es la altura de lámina de agua sobre el labio de vertido igual a $0.20 \mathrm{~m}$, y $Q$ es el caudal igual a $2.8 \mathrm{~m}^{3} / \mathrm{s}$. Se obtiene una longitud del vertido $\mathrm{L}$ igual a $18.41 \mathrm{~m}$. Se adoptará un valor de prediseño para la longitud del vertedero de $L=20 \mathrm{~m}$.

A continuación, se incluyen el depósito y los puntos de vertido en el modelo de la red. Para ello, se puede convertir el punto de vertido en un depósito haciendo clic en el botón derecho sobre el punto O.1. A continuación, se puede renombrar este elemento como DEP en las propiedades del objeto. Se añaden dos nuevos puntos de vertido mediante elementos tipo Outfall $\nabla$, para la conexión con la EDAR y para definir el punto de DSU. Estos nodos los renombraremos como EDAR y DSU. Por último, se conecta el elemento DEP con el elemento DSU usando un elemento tipo weir $₫$, que renombraremos como Aliviadero, y con el elemento EDAR con un elemento outlet $\nabla$, que regulará los caudales hacia la EDAR. La Figura 34 muestra la disposición final de los elementos en el modelo.

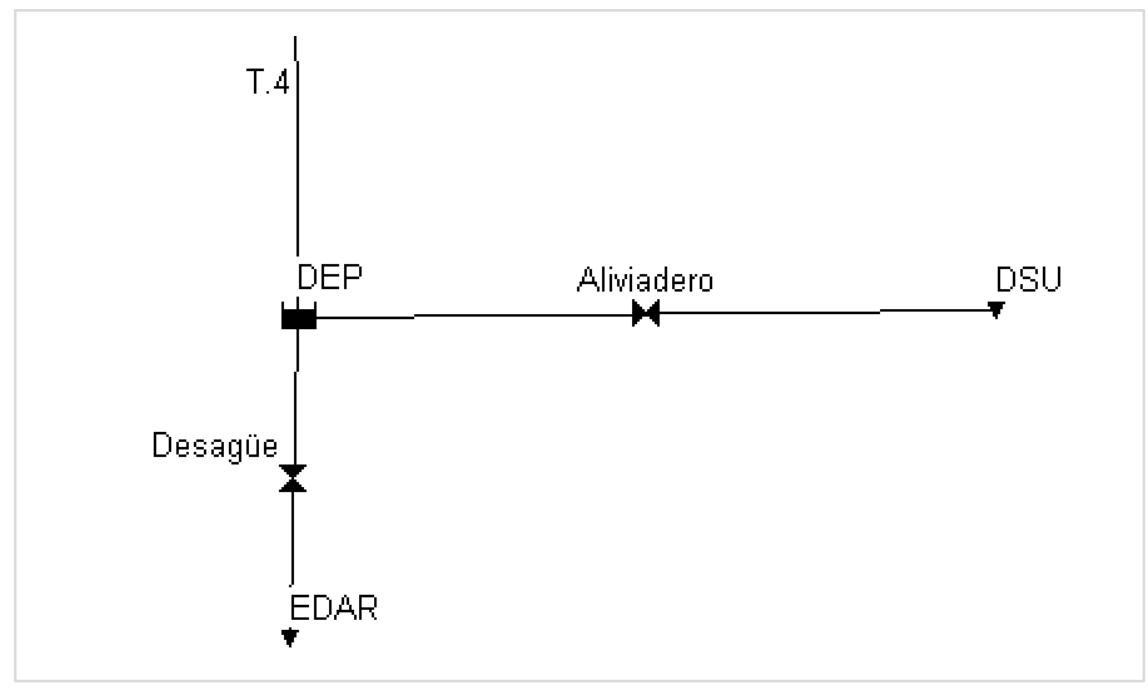

Figura 34. Esquema del depósito con el aliviadero y el regulador de caudal hacia la EDAR.

Es necesario editar las propiedades del depósito anti-DSU en el modelo. El depósito se ubicará a cota $+0 \mathrm{~m}$, que se introducirá en la propiedad Invert El. La altura total del depósito debe superar la cota del labio del aliviadero con cierto resguardo para evitar 
problemas de inestabilidad numérica. En este ejemplo, la altura total del depósito se ha definido igual a $3 \mathrm{~m}$. Este valor se introduce en la propiedad Max. Depth.

Para introducir la geometría del depósito definiremos un nuevo elemento tipo Curve >> Rating curve en la pestaña del panel de navegación situado a la izquierda. La curva de llenado se define a través de pares calado-superficie en planta del depósito. Se considera un depósito prismático con un área transversal constante de $1204 \mathrm{~m}^{2}$. Para definir la curva de llenado es suficiente con dos puntos: $(0,1204)$ y $(3,1204)$. Las abscisas se corresponden con la cota mínima y máxima del depósito (no la cota del labio de vertido) y las ordenadas corresponden a la superficie del depósito. En la Figura 35 se muestran los datos que se introducen para definir la curva de llenado y la visualización proporcionada por SWMM de la curva. Una vez definida, se ha de asignar al depósito la curva de llenado en la opción Storage Curve de las propiedades del elemento DEP escogiendo el tipo Tabular (ver Figura 36).
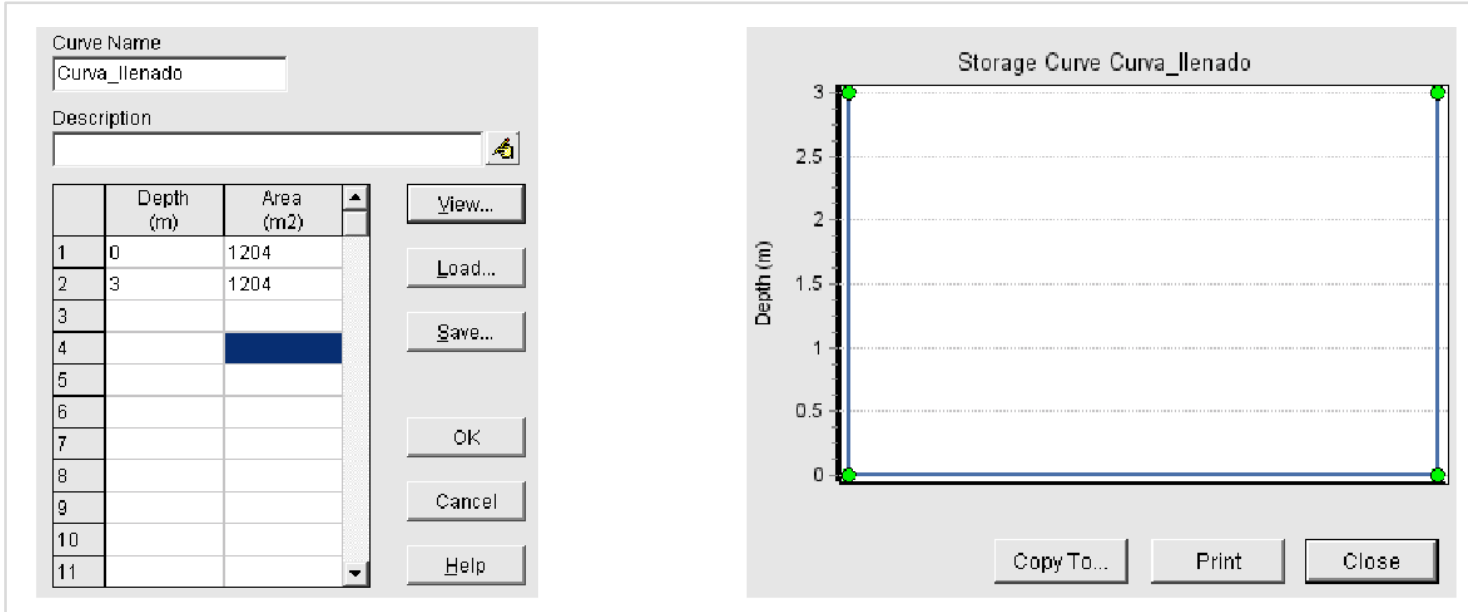

Figura 35. Definición de la curva de llenado del depósito en el modelo del depósito anti-DSU.

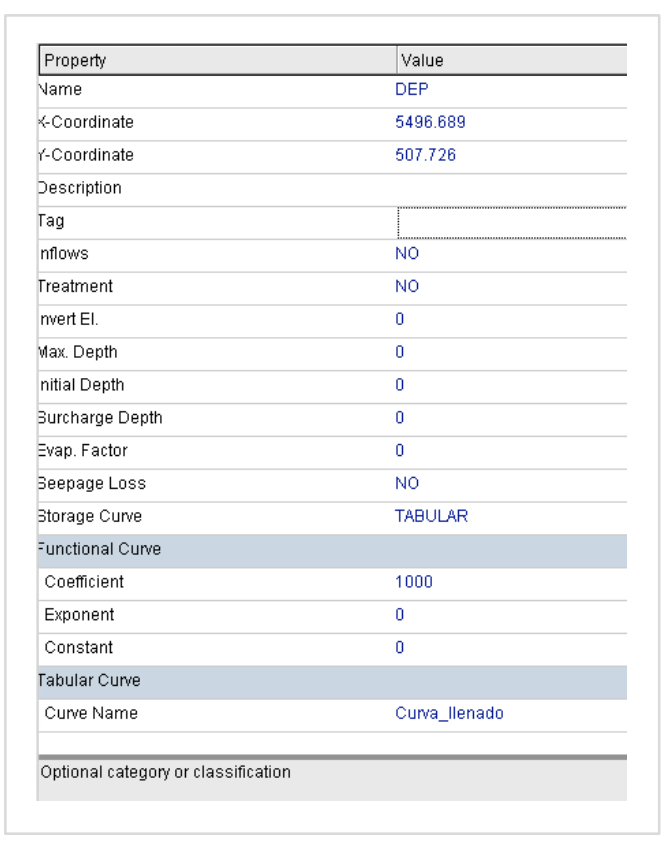

Figura 36. Propiedades del depósito. 
Para definir el regulador de caudal del depósito hacia la EDAR (desagüe) se usa un sistema de regulación ideal que proporcione un caudal máximo de salida de $90 \mathrm{~L} / \mathrm{s}$. Se define una curva de gasto con la opción Curve >> Rating Curve del panel de navegación. La curva de regulación constará de 3 pares de puntos como se indica en la Figura 37. El primero es $(0,0)$ para indicarle al modelo que, si el depósito está vacío, el caudal de salida es nulo. El segundo punto $(0.3,0.090)$ sirve como zona de transición entre el caudal nulo y el caudal máximo. De este modo evitaremos vaciados bruscos del depósito que generarían inestabilidades numéricas y errores de continuidad. Por último se fija el punto $(3,0.090)$, que asegura que el caudal máximo es igual a $3 \cdot Q D_{p, t o t a l}$ para el resto de niveles del depósito. Esta curva de gasto del depósito se ha de asignar al elemento Desagüe editando sus propiedades: definiendo Rating Curve igual a Tabular/Depth y seleccionando el nombre de la curva en Tabular Curve, como se indica en la Figura 38.

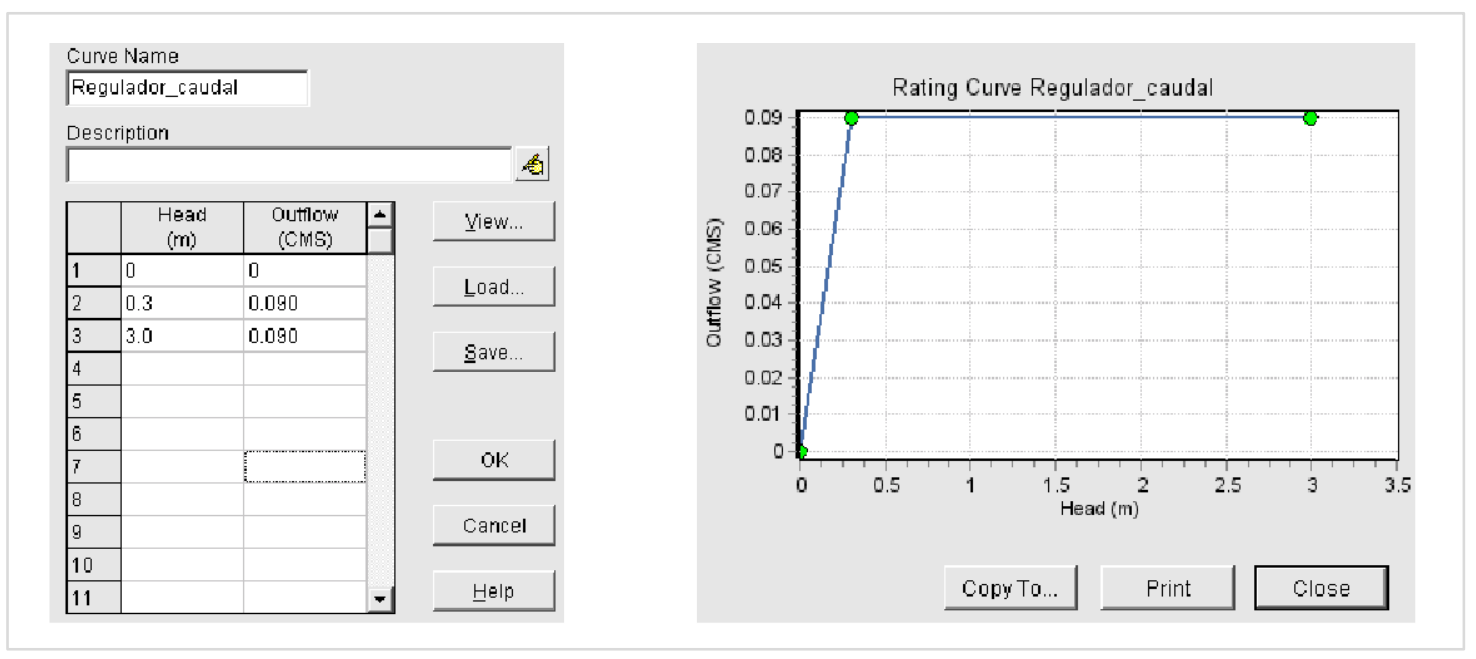

Figura 37. Definición de la curva de regulación de caudal del depósito.

\begin{tabular}{|ll|}
\hline Property & Value \\
\hline Vame & Desagüe \\
\hline nlet Node & DEP \\
\hline Jutlet Node & EDAR \\
\hline Jescription & \\
\hline Tag & 0 \\
\hline nlet Offset & NO \\
=lap Gate & TABULARIDEPTH \\
\hline Rating Curve & 10.0 \\
\hline unctional Curve & 0.5 \\
\hline Coefficient & \\
\hline Exponent & Desagüe \\
\hline Tabular Curve & \\
\hline Curve Name & \\
\hline Name of rating curve that relates outflow to either depth or head (after \\
specifing a curve, you can double-click to edit it)
\end{tabular}

Figura 38. Propiedades del elemento outfall EDAR.

Se editan también las propiedades del elemento Aliviadero: la longitud del labio de vertido (Length), la abertura (Height) y la cota del mismo (Weir Offset). La longitud del aliviadero son $20 \mathrm{~m}$, su altura es de $1 \mathrm{~m}$ (que coincide con la distancia entre el labio y el 
forjado superior del tanque) y la cota del labio de vertido es igual a $2 \mathrm{~m}$. Se establece como tipo de vertedero (Type) el Tranverse con un coeficiente de desagüe (Discharge Coeff) igual a 1.7. Las propiedades del aliviadero se presentan en la Figura 39.

\begin{tabular}{|c|c|c|}
\hline Property & Value & \\
\hline Vame & Alviadero & $\Delta$ \\
\hline nlet Node & DEP & - \\
\hline Dutlet Node & DSU & \\
\hline \multicolumn{3}{|l|}{ Jescription } \\
\hline \multicolumn{3}{|l|}{$\mathrm{Tag}$} \\
\hline Type & TRANSVERSE & \\
\hline Height & 1 & \\
\hline _ength & 20 & \\
\hline Side Slope & 0 & \\
\hline nlet Offset & 2 & \\
\hline Discharge Coeff. & 1.7 & \\
\hline =lap Gate & No & \\
\hline End Contractions & 0 & \\
\hline End Coeff. & 0 & \\
\hline Can Surcharge & YES & \\
\hline Coeff. Curve & & -1 \\
\hline
\end{tabular}

Figura 39. Propiedades del elemento weir Aliviadero.

Después de las modificaciones del modelo de la red, se ejecuta la simulación haciendo clic sobre el icono o seleccionando en el menú principal Project $\gg$ Run Simulation. Inmediatamente después de la simulación aparecerá una ventana donde se indica al usuario que la ejecución se ha realizado correctamente y que los errores de continuidad son reducidos. Si se produjese algún error en la simulación, se deben revisar los códigos de error indicados en el Status Report para solucionarlos.

A continuación, se sigue el procedimiento de los problemas anteriores para revisar la simulación. Se comprueba si hay mensajes de error o problemas de continuidad en el informe de estado (Report >> Status) y si hay inundaciones en el informe resumen (Report > Summary). No debería aparecer ninguna incidencia; si surgiese se debería revisar la definición del modelo.

El funcionamiento de la red y del depósito se comprueba en el Summary Report en la pestaña Link Flow, que mostrará los caudales máximos, las velocidades máximas y las ratios de llenado de las tuberías. Las velocidades de circulación son admisibles en todas las tuberías. La conducción T.4 - de entrada al depósito- entra en carga debido a la condición de contorno impuesta por el propio depósito cuando está lleno (ver Figura 40). Esta situación es habitual en las zonas situadas aguas arriba de los depósitos antiDSU, y no hay que preocuparse siempre que no se produzcan inundaciones. 


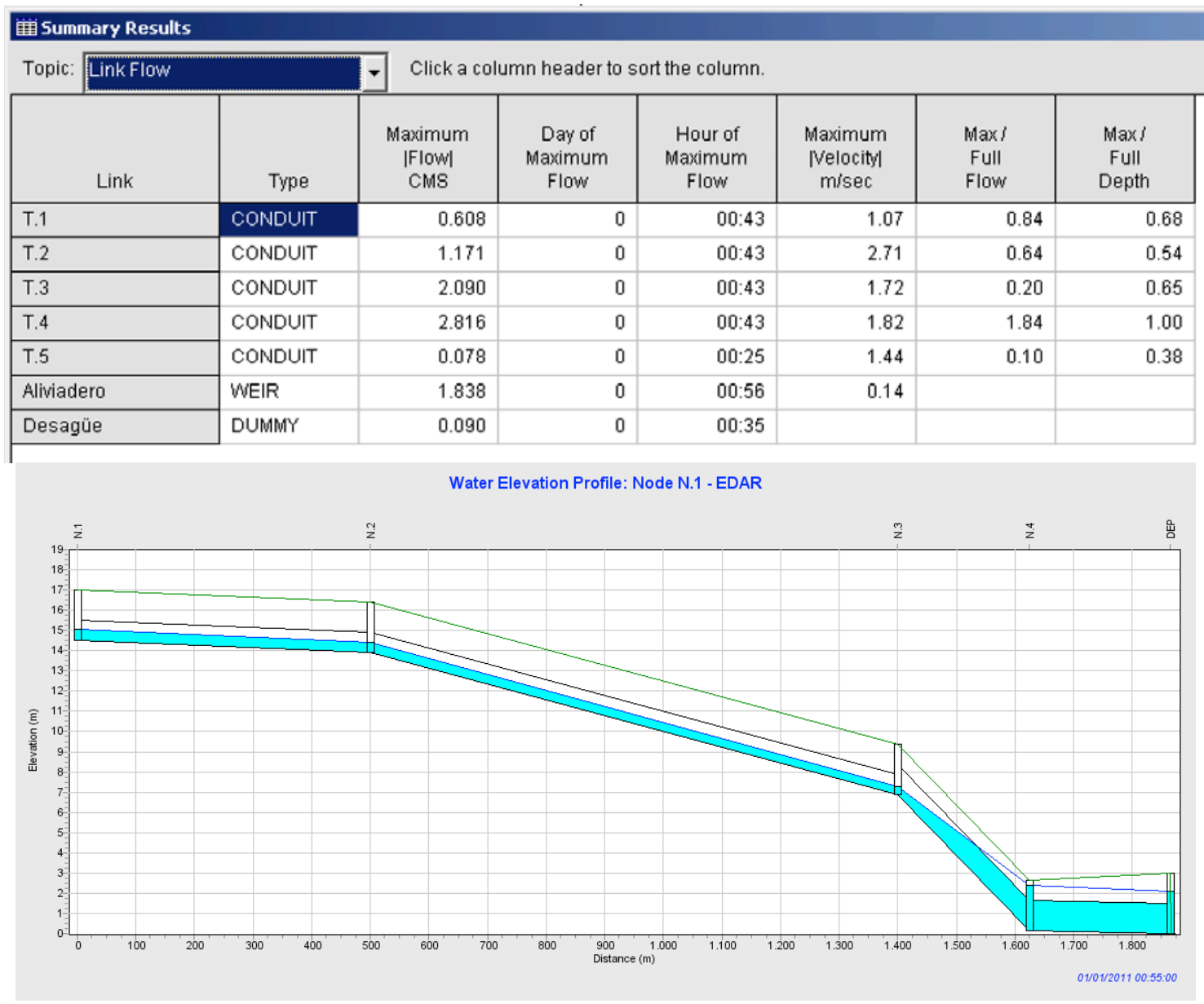

Figura 40. Resultados de la simulación del depósito anti-DSU para la lluvia de proyecto: resumen del flujo en las conducciones y perfil longitudinal entre el pozo N.1 y el punto de vertido EDAR.

Para analizar posibles problemas de inundación se puede comprobar el resguardo que tienen los pozos de registro y otros elementos como el depósito anti-DSU en la pestaña Node Depth del Summary Report (Figura 41). El nodo con menor resguardo es el N.4, que tiene un resguardo de $21 \mathrm{~cm}$ (el nivel máximo es de $2.29 \mathrm{~m}$ y la altura total es de $2.50 \mathrm{~m}$ ). La lámina de agua en el depósito alcanza la cota $2.14 \mathrm{~m}$, por lo que el nivel máximo sobre el labio de vertido es de $14 \mathrm{~cm}$.

\begin{tabular}{|c|c|c|c|c|c|c|c|}
\hline \multicolumn{8}{|c|}{ 笛Summary Results } \\
\hline \multirow[t]{2}{*}{ Topic: } & Node Depth & \multicolumn{6}{|c|}{ Click a column header to sort the column. } \\
\hline & Type & $\begin{array}{l}\text { Average } \\
\text { Depth } \\
\text { Meters }\end{array}$ & $\begin{array}{l}\text { Maximum } \\
\text { Depth } \\
\text { Meters }\end{array}$ & $\begin{array}{c}\text { Maximum } \\
\text { HGL } \\
\text { Meters }\end{array}$ & $\begin{array}{l}\text { Day of } \\
\text { Maximum } \\
\text { Depth }\end{array}$ & $\begin{array}{l}\text { Hour of } \\
\text { Maximum } \\
\text { Depth }\end{array}$ & $\begin{array}{l}\text { Maximum } \\
\text { Reported } \\
\text { Depth } \\
\text { Meters }\end{array}$ \\
\hline N.1 & JUNCTION & 0.18 & 0.74 & 15.24 & 0 & $00: 42$ & 0.72 \\
\hline N.2 & JUNCTION & 0.15 & 0.63 & 14.53 & 0 & $00: 43$ & 0.62 \\
\hline N.3 & JUNCTION & 0.16 & 0.45 & 7.35 & 0 & $00: 43$ & 0.45 \\
\hline N.4 & JUNCTION & 1.65 & 2.29 & 2.44 & 0 & $00: 54$ & 2.27 \\
\hline N.5 & JUNCTION & 0.18 & 0.20 & 8.10 & 0 & 00:05 & 0.19 \\
\hline EDAR & OUTFALL & 0.00 & 0.00 & 0.00 & 0 & 00:00 & 0.00 \\
\hline $\mathrm{DSU}$ & OUTFALL & 0.00 & 0.00 & 0.00 & 0 & 00:00 & 0.00 \\
\hline DEP & STORAGE & 1.67 & 2.14 & 2.14 & 0 & $00: 56$ & 2.14 \\
\hline
\end{tabular}

Figura 41. Resultados de la simulación del depósito anti-DSU para la lluvia de proyecto: resumen del calado máximo en los nodos del sistema. 
Por último, se evalúa el comportamiento del tanque de tormentas para la lluvia de proyecto de $\mathrm{T}=10$ años. La Figura 42 presenta los hidrogramas de entrada, de salida hacia la EDAR y de DSU del depósito, e ilustra el funcionamiento del depósito y su efecto sobre la red de saneamiento. Para crear el gráfico se ha empleado la opción Report >> Graph $\gg$ Time Series. El hidrograma de entrada al tanque (línea roja) tiene un caudal máximo de $2.82 \mathrm{~m}^{3} / \mathrm{s}$ que se produce en el minuto 43 de la simulación (véase también la Figura 40). El caudal de vertido por DSU (línea magenta) alcanza un máximo de 1.84 $\mathrm{m}^{3} / \mathrm{s}$ y se produce en el minuto 56 de la simulación. Las diferencias entre los caudales máximos y el tiempo del caudal punta se deben al efecto laminador del tanque. El caudal enviado hacia EDAR (línea azul) está limitado por un valor máximo de $90 \mathrm{~L} / \mathrm{s}\left(3 \cdot \mathrm{QDD}_{\mathrm{p}, \text { total }}\right.$ ). En la figura se aprecia además como el proceso de vaciado del tanque se extiende más allá del tiempo de simulación.

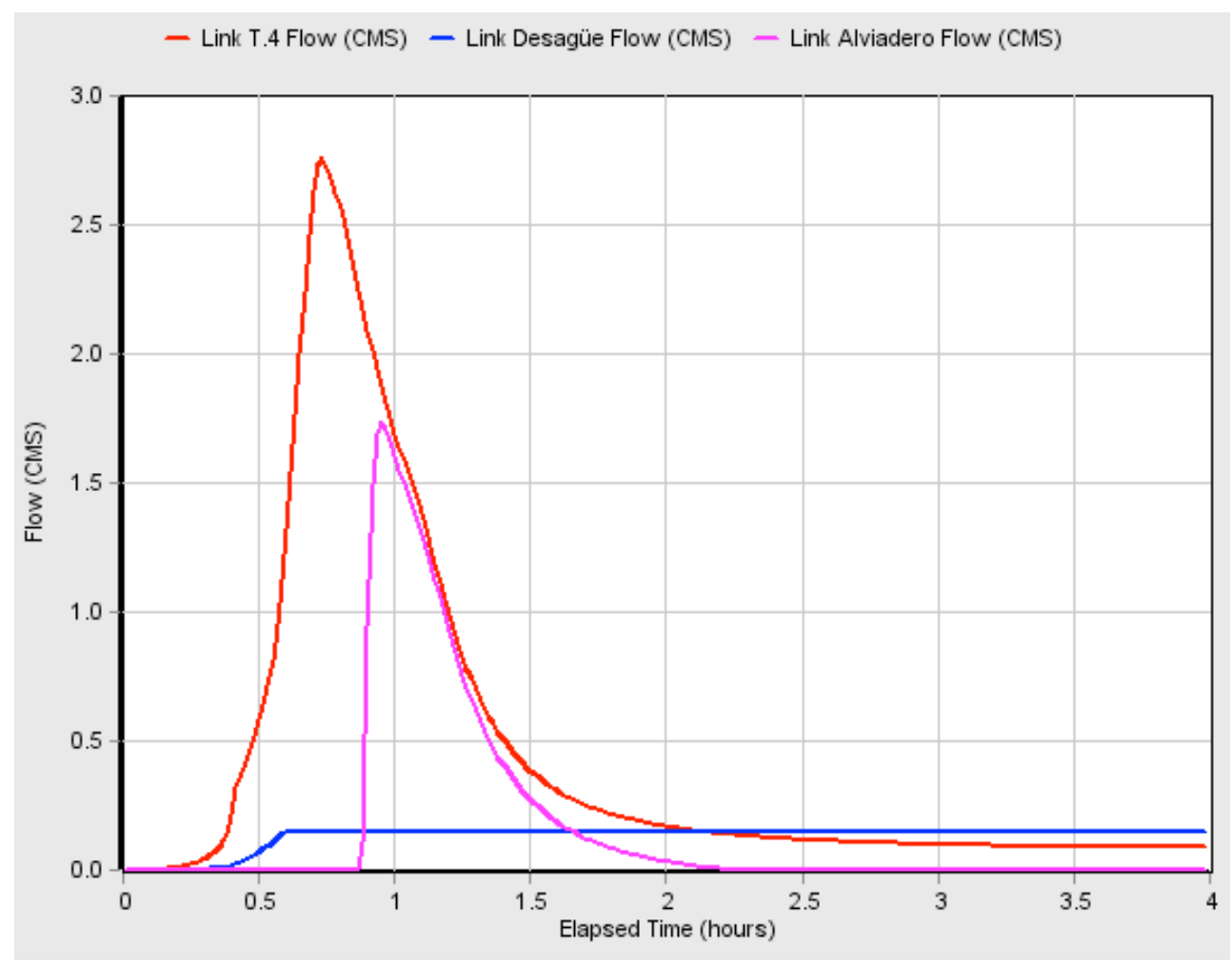

Figura 42. Resultados de la simulación del depósito anti-DSU para la lluvia de proyecto: hidrogramas de entrada, salida y DSU del depósito.

\subsection{Cálculo del depósito anti-DSU para el año medio}

La evaluación del funcionamiento de la red y el depósito para la lluvia de proyecto tiene por objetivo evitar las inundaciones En este apartado se va a evaluar el funcionamiento del sistema para un año medio de precipitaciones.

Se parte del modelo del apartado anterior y se guarda el archivo con un nuevo nombre. Para realizar el análisis del año medio se deben modificar en el modelo las dotaciones del caudal de tiempo seco y el registro de lluvia, e introducir un valor para la evapotranspiración. 
El caudal de tiempo seco, que se introduce en el nodo N.5, no debe ser el caudal horario punta total $\left(Q H_{p, t o t a l}\right)$ sino el caudal diario punta total $\left(Q D_{p, t o t a l}\right)$ para estos nuevos cálculos. Debemos editar la propiedad Inflows de la ventana de propiedades del pozo N.5 e incluir en la pestaña Dry Weather un caudal medio de $30 \mathrm{~L} / \mathrm{s}$ (Figura 43).

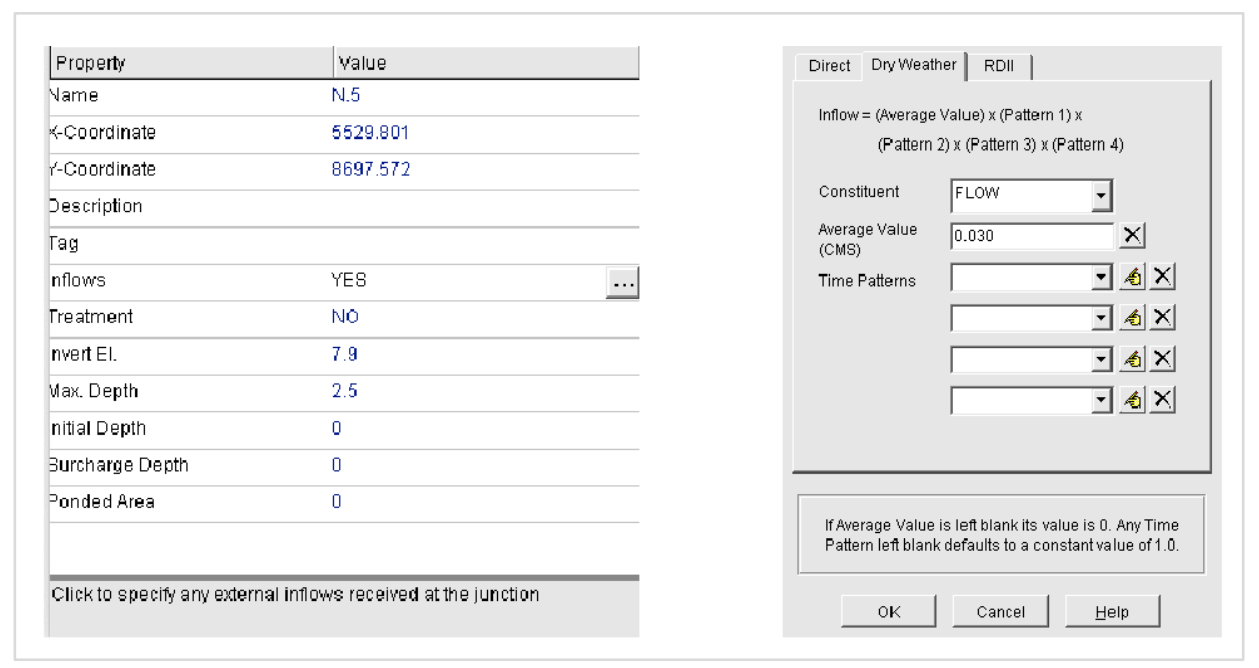

Figura 43. Introducción del $Q D_{p, \text { total }}$ para la simulación continua en el nodo N.5.

A continuación, debemos preparar un archivo de lluvia con el año medio de precipitaciones a modelizar. Las características del año medio se indican en la Instrucción ITOHG SAN 1/5. Cálculo de depósitos en sistemas unitarios (Augas de Galicia, 2010). Entre los archivos digitales correspondiente a este problema se entregan, además de los archivos del modelo resueltos, dos archivos que contienen la lluvia media para simulación en formato .xls y en formato .dat (ver capítulo 6). El archivo .xls contiene los datos del pluviómetro representativo del año medio, que en este caso es el año 2008. El archivo .dat es el archivo de entrada que debe seleccionarse para ejecutar el modelo.

Para crear el archivo de entrada del modelo se deben eliminar los instantes de lluvia nula de la serie temporal y crear un archivo de texto plano con la estructura que se indica a continuación:

$\begin{array}{lllllll}\text { Station ID } & \text { Año } & \text { Mes } & \text { Dia } & \text { HH } & \text { MM } & \text { P } \\ \text { STA01 } & 2008 & 1 & 1 & 9 & 30 & 1.2\end{array}$

El parámetro Station ID es el nombre del pluviómetro. A la derecha se incluye la información temporal de cada instante de lluvia, introduciendo en cada columna el valor del año, mes, día, hora y minuto. El intervalo de registro debe ser de valor constante y la lluvia debe tener una resolución temporal máxima diez-minutal. En la última columna se añade el valor de la precipitación que puede ir en formato milímetros de lluvia acumulados para cada intervalo de tiempo $(\mathrm{mm})$ o en formato de intensidad de lluvia $(\mathrm{mm} / \mathrm{h})$. En general, la información pluviométrica de series largas de precipitación se expresa en volumen de lluvia $\left(\mathrm{mm} \circ \mathrm{L} / \mathrm{m}^{2}\right)$. En el archivo de entrada del modelo (año_medio_18.dat), las lluvias están en formato volumen $(\mathrm{mm})$, tienen una resolución temporal de 10 minutos y el pluviómetro se denomina R01. 
La precipitación se configura en las propiedades del pluviómetro PL1 en el que se deben modificar las siguientes opciones (Figura 44):

- Formato de lluvia (Rain Format): Seleccionar VOLUME.

- Paso de tiempo para lluvia (Time Interval): 10 minutos.

- Fichero de entrada (Data Source): Seleccionar FILE.

- Archivo de entrada (DATA FILE/File Name): ruta del archivo.

- Nombre del pluviómetro (DATA FILE/Station ID): R01.

- Unidades de la lluvia (DATA FILE/Rain Units): $\mathrm{mm}$.

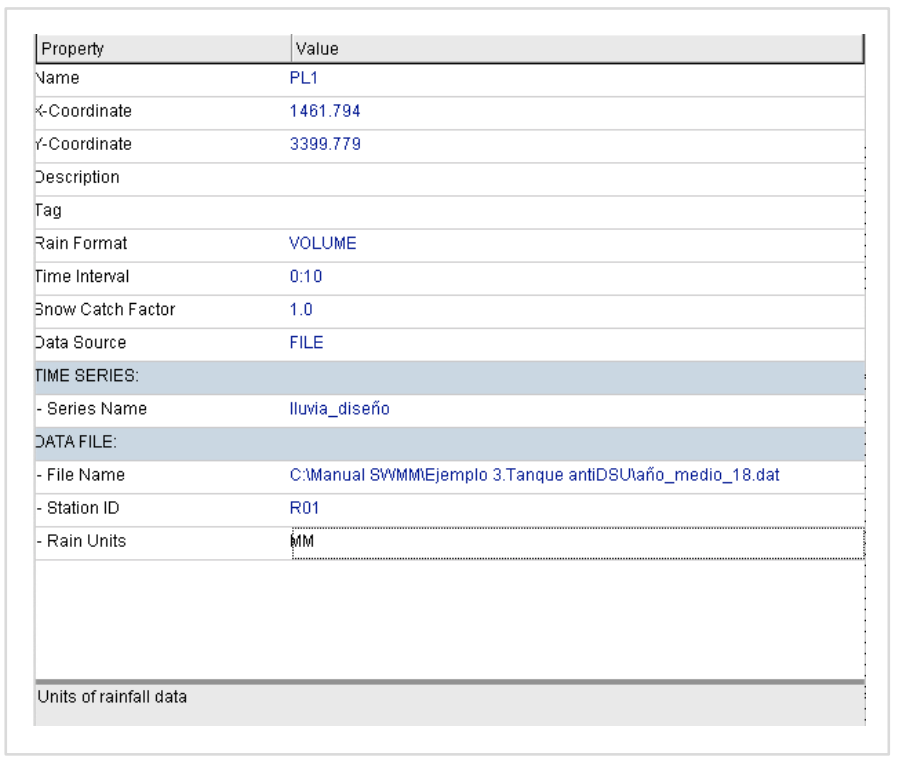

Figura 44. Edición de las propiedades del pluviómetro para la simulación continua.

También es necesario modificar el inicio y el fin de la simulación, al incluir fechas en la definición del hietograma. Las fechas de la simulación son del 01/01/2008 - 00:00 al 01/01/2009 - 00:00, y se han de introducir en Options >> Dates (Figura 45).

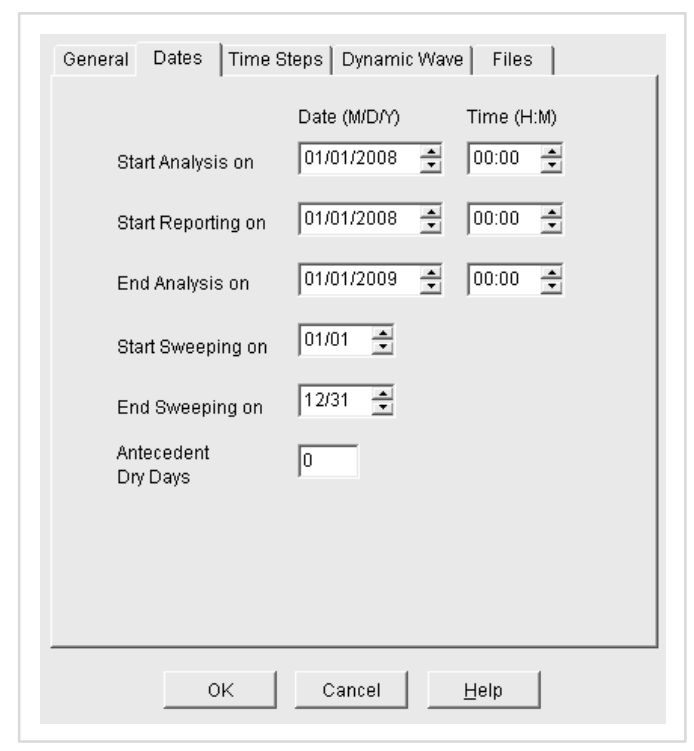

Figura 45. Edición de la fecha de inicio y fin para la simulación continua. 
Para terminar con los cambios del modelo, se debe introducir un valor medio de evapotranspiración para favorecer el "secado" de las depresiones superficiales y charcos tras los sucesos de lluvia. Para ello, en el panel de navegación introduciremos en la pestaña Evaporation de la opción Climatology un valor de evaporación de $1.5 \mathrm{~mm} / \mathrm{d}$ áa (Figura 46).

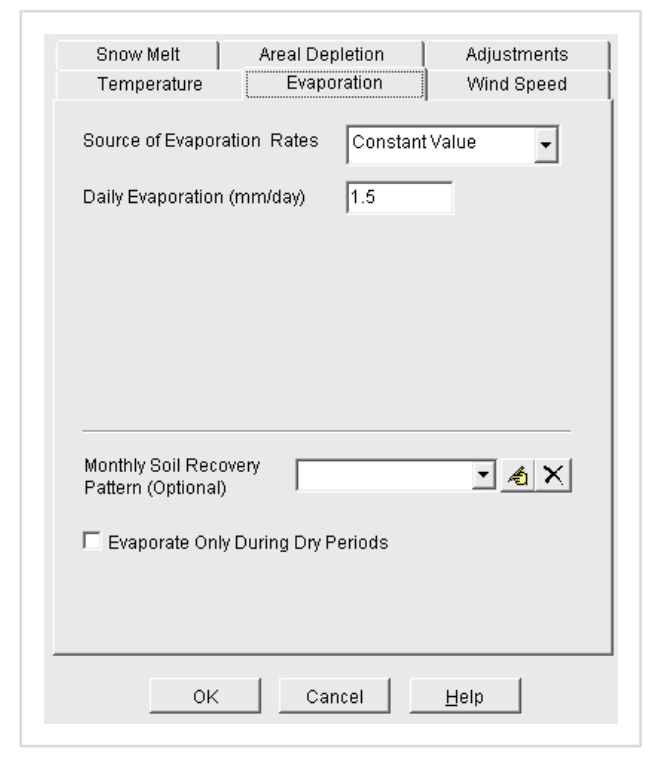

Figura 46. Edición de la opción Evaporation para la simulación continua.

Se ejecuta de nuevo el modelo haciendo clic sobre el icono En esta ocasión, el modelo puede tardar un par de minutos en terminar la simulación. Inmediatamente después, aparece una ventana donde se indica al usuario que la ejecución se ha realizado con éxito y con errores de continuidad reducidos. Si surgiese algún error en la simulación, se deben revisar los códigos de error indicados en el informe de estado para solucionarlos.

Se comprueba, en primer lugar, si hay mensajes de error o problemas de continuidad en el informe de estado (Report >> Status) y si hay inundaciones en el informe resumen (Report >> Summary). Si apareciese alguna incidencia, se debe revisar la definición del modelo.

El análisis de los resultados del año medio de simulación se va a centrar en determinar tanto los volúmenes como el número de eventos de vertido o DSU del sistema. Las ITOHG (Aguas de Galicia, 2010) proponen los siguientes estándares de emisión a través del aliviadero de un depósito:

- Limitar el número de vertidos en el año medio a un valor de 15-20.

- Limitar el porcentaje de agua pluvial vertida a un 15\%-10\% del agua pluvial generada en la cuenca. Esto es equivalente a enviar hacia la EDAR entre el $85 \%$ y el $90 \%$ de la escorrentía pluvial.

Para comprobar el cumplimiento de estos estándares con SWMM vamos a emplear dos herramientas distintas. La evaluación de los volúmenes de vertido frente a los volúmenes de escorrentía se realiza utilizando la pestaña Outfall Loadings del Report 
Summary (Figura 47). La tabla de resultados muestra el volumen total de agua vertido en la simulación durante el año medio a través del outfall de vertido hacia EDAR y a través del outfall de vertido por DSU.

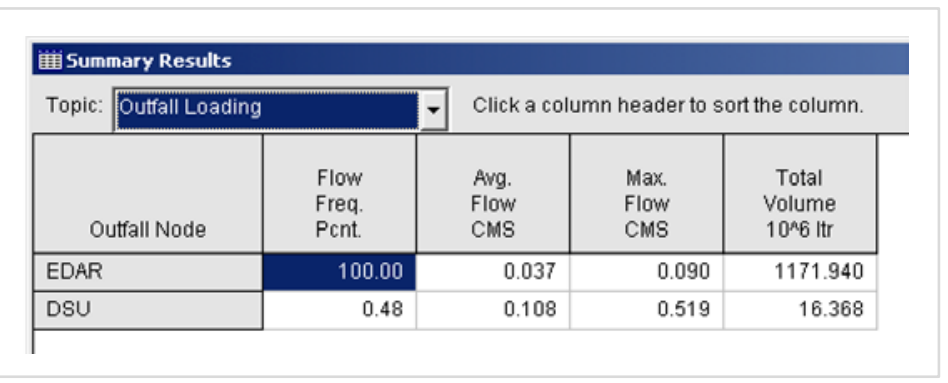

Figura 47. Resultados de la simulación del depósito anti-DSU para la simulación continua: resumen de volúmenes vertidos por el modelo.

Para calcular el porcentaje de agua pluvial vertida por DSU o el rendimiento hidráulico del tanque en términos de volumen de agua de escorrentía enviada hacia la EDAR, se puede emplear la siguiente metodología:

1. El volumen total de agua residual en tiempo seco y pluvial durante el año medio para la cuenca será la suma del volumen de agua enviado hacia la EDAR y el volumen de agua vertido por DSU. La suma de estos dos valores da 1,188,308 $\mathrm{m}^{3} /$ año.

2. El volumen de agua residual en tiempo seco es igual a $30 \mathrm{~L} / \mathrm{s}$, que son 946,080 $\mathrm{m}^{3} /$ año.

3. El volumen de escorrentía pluvial durante el año de diseño se obtiene restando los dos volúmenes anteriores. Por tanto, el volumen de escorrentía anual es $242,228 \mathrm{~m}^{3}$ /año.

4. El cálculo del rendimiento del tanque en términos de volumen de agua pluvial vertido se obtiene como el cociente entre el volumen de DSU $\left(16,368 \mathrm{~m}^{3} / \mathrm{año}\right)$ y el volumen total de escorrentía pluvial $\left(242,228 \mathrm{~m}^{3} / a n ̃ o\right)$. El rendimiento del tanque en términos de agua pluvial vertida a través de DSU es del $6.75 \%$, inferior al límite establecido en las ITOHG.

La evaluación del número de DSU que se efectúan desde el depósito en el año medio se realiza utilizando la herramienta de análisis estadístico, a la que podemos acceder pulsado el botón $\Sigma$ de la barra de herramientas. Esta herramienta permite realizar cálculos sobre todos los elementos de la red y del sistema en su conjunto. Se presentan a continuación un par de ejemplos de las capacidades de esta herramienta antes de realizar la estimación del número de DSU.

La Figura 48 muestra los datos de entrada para obtener un informe estadístico, así como el resumen de parámetros obtenidos cuando se analizan los eventos de precipitación registrados en el año medio simulado. La ventana del informe estadístico permite seleccionar el tipo de objeto a analizar y la variable a analizar. En este caso, como la Iluvia es global a todo el modelo se escoge la opción System como Object Category. La variable a analizar en este caso es la precipitación (Variable Analyzed >> Precipitation), aunque se podrían seleccionar otras variables como escorrentía directa, infiltración, etc. Otra opción de los informes estadísticos es definir el periodo de tiempo a analizar. En la 
variable Event Time Period se puede escoger analizar eventos aislados (EventDependent) o realizar análisis estadísticos diarios, mensuales o anuales. La última variable de los informes es el tipo de estadístico a analizar. Por ejemplo, se puede calcular el valor de la intensidad media o máxima de cada evento de lluvia o escoger el valor del volumen total de precipitación de cada suceso de lluvia. Esta última es la opción seleccionada en la Figura 48 (Statistic $>>$ Total).

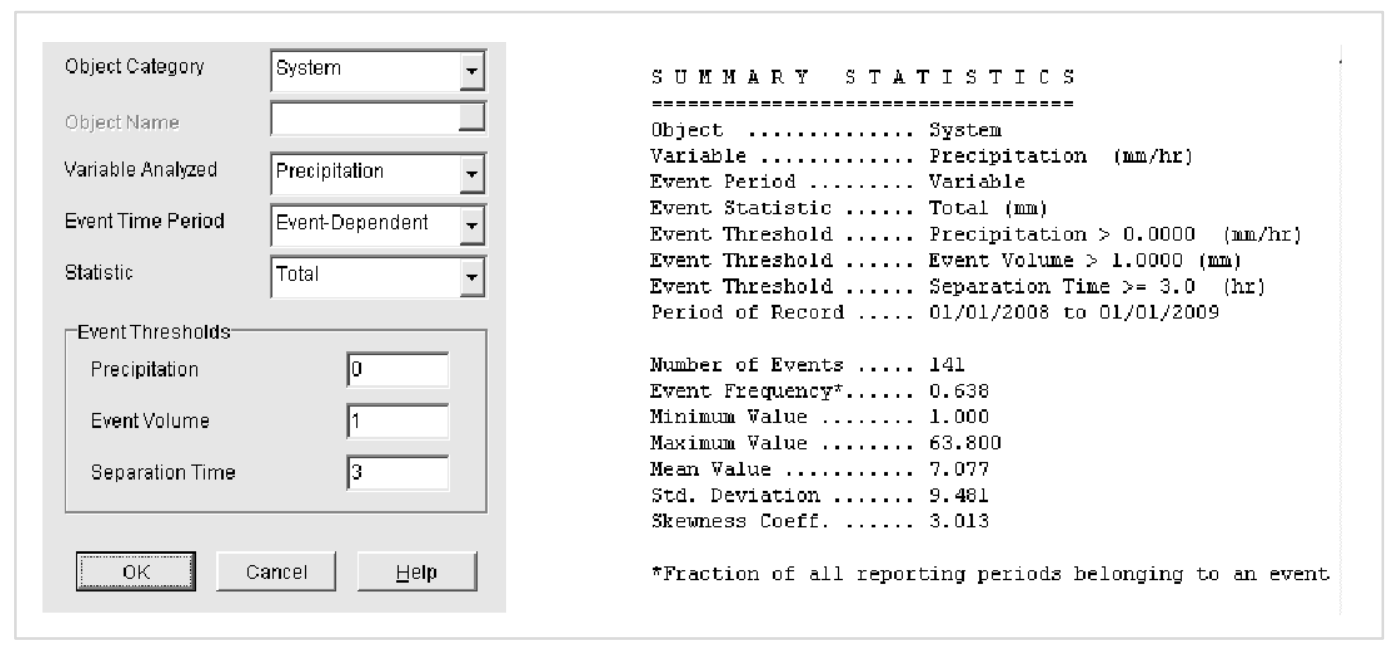

Figura 48. Resultados de la simulación del depósito anti-DSU para la simulación continua: análisis de los eventos de precipitación en el año medio.

Si se escoge analizar eventos aislados, es necesario indicarle al modelo una serie de umbrales que establezcan qué se puede considerar un evento aislado y qué no. Por ejemplo, si comienza a llover durante 2 horas, luego deja de llover 15 minutos, y luego vuelve a llover durante 3 horas, ¿cómo consideramos esta sucesión de lluvias? ¿Estamos hablando de dos eventos de lluvia seguidos o uno con un pequeño descanso en el medio? Responder a esta pregunta no es trivial. Existen varias formas, más o menos sofisticadas, para decidir si en el ejemplo anterior estamos hablando de uno o de dos eventos de lluvia. Si se desea profundizar en la problemática de la definición adecuada del tiempo de separación entre sucesos, también denominado tiempo interevento, se recomienda consultar el capítulo 4 de Adams y Pappa (2000). A nivel práctico, en España se recomienda utilizar un tiempo interevento para el análisis de las variables de precipitación o caudal en cuencas urbanas del orden de 3 horas. Por este motivo, la propiedad Separation Time, en Event Tresholds, se define en este caso igual a 3 horas (Figura 48).

Las opciones Precipitation y Event Volume permiten definir otros umbrales para descartar, por ejemplo, las lluvias con muy poca intensidad o volumen. Por ejemplo, es habitual descartar de este tipo de análisis las lluvias de volumen inferior a $1 \mathrm{~mm}$, porque debido a las pérdidas por detracción, evaporación y eventual infiltración, no generarán escorrentía superficial. En este caso, se definirá Event Volume igual a 1 mm (Figura 48).

SWMM nos proporciona como resultado un informe de los estadísticos objeto de estudio (Figura 48). En este caso, se producen 141 episodios de lluvia durante el año medio. La precipitación media de cada evento es de $7 \mathrm{~mm}$, aunque el registro máximo asciende a un volumen de $63.8 \mathrm{~mm}$. 
Una vez presentada la herramienta de análisis estadístico, se indica cómo utilizarla para determinar el número de DSU. Antes de abrir la ventana para la definición y generación del informe estadístico, se recomienda seleccionar el objeto que se va estudiar. En este caso, se hace clic sobre el outfall Aliviadero. De este modo, al abrir la herramienta con el botón $\Sigma$ ya aparece seleccionado este elemento para su análisis. Se escoge como variable a analizar el caudal (Variable Analyzed $\gg$ Flow), con análisis de sucesos aislados y con el estadístico caudal total, que se corresponde con el volumen de vertido (ver Figura 49). Para definir los umbrales que definirán los sucesos de DSU se empleará un volumen mínimo de vertido de $50 \mathrm{~m}^{3}$ (Event Volume >> 50) y un tiempo de separación de eventos de 3 horas (Separation Time >> 3).

El resultado del informe estadístico relativo al número de DSU se presenta en la parte derecha de la Figura 49. Se puede observar que el número total de vertidos es de 11 durante el año medio. Este valor también es inferior al límite establecido por las ITOHG en $15-20$ vertidos.

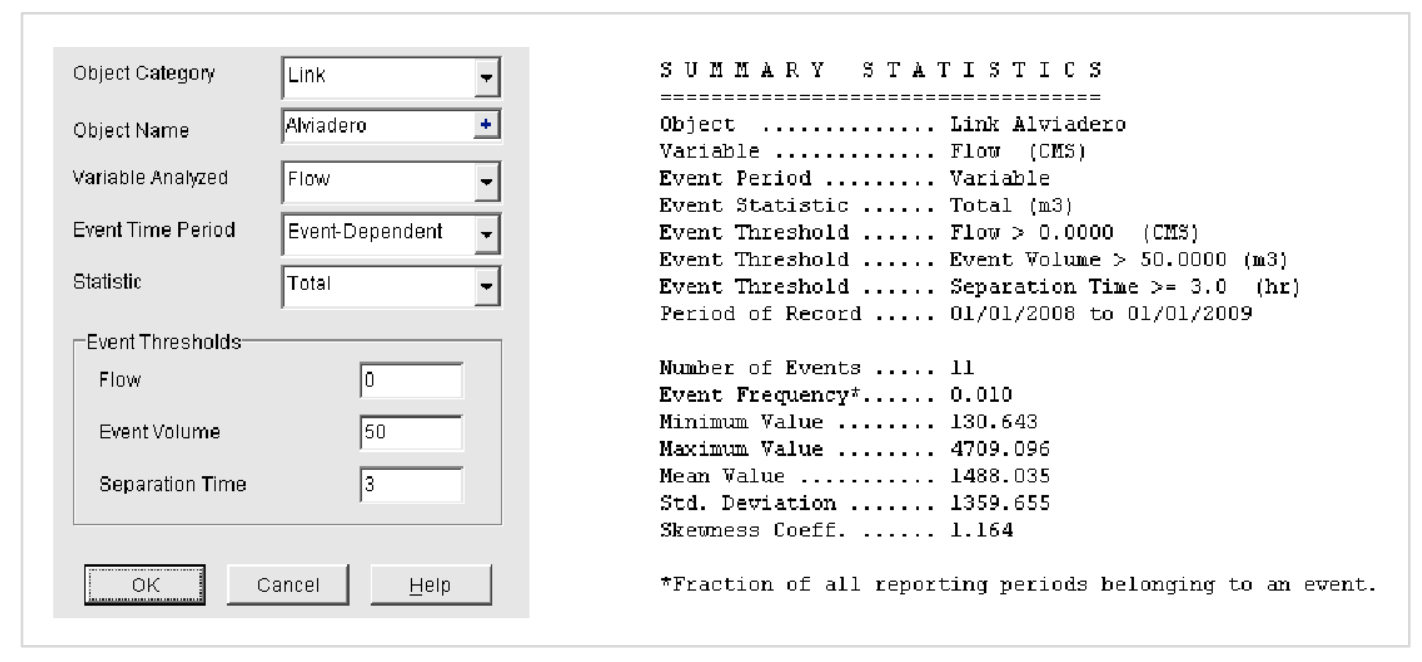

Figura 49. Resultados de la simulación del depósito anti-DSU para la simulación continua: análisis del número de DSU producidos desde el outfall Aliviadero.

Por tanto, el tanque añadido a la red en el modelo de SWMM cumple con holgura los estándares de las ITOHG en cuanto a número y volumen de DSU. Por este motivo, su diseño podría ser optimizado reduciendo ligeramente su volumen de almacenamiento, ya sea reduciendo la superficie en planta del tanque o la altura del mismo. Lo más habitual es modificar la superficie del tanque, porque las cotas del mismo suelen estar condicionadas por la geometría de la red y de los puntos de vertido. La optimización del volumen del tanque, variando la superficie en la curva de llenado del depósito, queda como propuesta de trabajo para los estudiantes de este manual. 


\section{DATOS PARA LA REALIZACIÓN DE LOS MODELOS}

En el archivo zip con la URL permanente http://hdl.handle.net/2183/23619 se encuentran los ejemplos y ficheros necesarios para el desarrollo de los modelos.

La Tabla 7 muestra una guía en la que se indica el capítulo del documento al que se vincula cada fichero, la carpeta en la cual se encuentran los archivos del modelo, así como los archivos auxiliares (como fondos y series de precipitaciones) y el nombre de cada fichero. En los archivos .inp se incluye una breve descripción de los mismos.

Para el empleo de los datos de este Manual se recomienda copiar la carpeta Manual SWMM (que se halla en el zip) al directorio raíz del disco duro (C:\Manual SWMM).

Tabla 7. Tabla guía con los ejemplos resueltos presentados en este Manual.

\begin{tabular}{|c|c|c|c|}
\hline EJEMPLO & Capítulo & Carpeta & Nombre del archivo \\
\hline \multirow{3}{*}{ Modelo de la PCEHU } & \multirow{3}{*}{3} & \multirow{3}{*}{$\begin{array}{l}\text { Ejemplo } 1 . \\
\text { PCEHU }\end{array}$} & PCEHU_resuelto.inp \\
\hline & & & Barrio_red.jpg \\
\hline & & & Barrio_Subcuencas.jpg \\
\hline \multirow{4}{*}{$\begin{array}{l}\text { Modelo de una red } \\
\text { de drenaje unitaria }\end{array}$} & \multirow{4}{*}{4} & \multirow{4}{*}{$\begin{array}{l}\text { Ejemplo } 2 . \\
\text { Red Unitaria }\end{array}$} & Sistema_unitario_original.inp \\
\hline & & & Sistema_unitario_resuelto.inp \\
\hline & & & Red_unitaria.jpg \\
\hline & & & Iluvia_T10.dat \\
\hline \multirow{6}{*}{$\begin{array}{l}\text { Prediseño de un } \\
\text { tanque anti-DSU }\end{array}$} & \multirow{6}{*}{5} & \multirow{6}{*}{$\begin{array}{c}\text { Ejemplo } 3 . \\
\text { Tanque anti-DSU }\end{array}$} & antiDSU_original.inp \\
\hline & & & antiDSU_T10.inp \\
\hline & & & antiDSU_simulac_continua.inp \\
\hline & & & Iluvia_T10.dat \\
\hline & & & año_medio_18.xlsx \\
\hline & & & año_medio_18.dat \\
\hline
\end{tabular}




\section{BIBLIOGRAFÍA}

Adams, B.J. y Pappa, F. (2000). Urban Stormwater Management Planning with Analytical Probabilistic Models. New York: John Wiley \& Sons.

Augas de Galicia (2010). Instrucciones técnicas para obras hidráulicas en Galicia. Serie Saneamiento. Disponible en: https://augasdegalicia.xunta.gal/c/document_library /get_file?folderld=216484\&name=DLFE-17836.pdf

Puertas, J., Suárez, J. y Anta, J. (2008). Gestión de las aguas pluviales. Implicaciones en el diseño de los sistemas de saneamiento y drenaje urbano. Monografías CEDEX M98. Madrid: Centro de Publicaciones, Ministerio de Fomento.

Rossman, L. (2015). Storm Water Management Model User's Manual Version 5.1 (revised version). U.S. Environmental Protection Agency, Office of Research and Development, Washington, DC, EPA/600/R-14/413 (NTIS EPA/600/R-14/413b). Disponible en: https://nepis.epa.gov/Exe/ZyPDF.cgi?Dockey=P100N3J6.TXT

Rossman, L. y Huber, W. (2016). Storm Water Management Model Reference Manual Volume I, Hydrology (revised version). U.S. Environmental Protection Agency, Office of Research and Development, Washington, DC, EPA/600/R-15/162A. Disponible en: https://nepis.epa.gov/Exe/ZyPDF.cgi?Dockey=P100NYRA.txt [Storm Water Management Model Reference Manual Errata: https://www.epa.gov/sites/production/files /2018-08/documents/swmm_reference_manual_errata.pdf].

Rossman, L. (2017). Storm Water Management Model Reference Manual Volume II, Hydraulics. U.S. Environmental Protection Agency, Office of Research and Development, Washington, DC, EPA/600/R-17/111. Disponible en: https://nepis.epa.gov /Exe/ZyPDF.cgi?Dockey=P100S9AS.pdf [Storm Water Management Model Reference Manual Errata: https://www.epa.gov/sites/production/files/2018-08/documents /swmm_reference_manual_errata.pdf]. 